\title{
Natural Product-Like Combinatorial Libraries
}

\author{
Pedro M. Abreu* and Paula S. Branco \\ Departamento de Química, Centro de Química Fina e Biotecnologia, FCT-UNL, 2829-516 Caparica, Portugal
}

\begin{abstract}
A química combinatorial emergiu ao longo dos últimos anos como uma importante ferramenta na pesquisa de moléculas pioneiras para a modelagem de novos fármacos. Nesta perspectiva, a diversidade estrutural e a vasta gama de propriedades biológicas exibidas pelos metabolitos secundários, constituem um desafio à implementação de estratégias combinatórias na síntese e derivatização de produtos naturais. Este artigo ilustra a aplicação das técnicas combinatórias no desenho e formação de bibliotecas baseadas em produtos naturais de diversa origem biossintética, e seus análogos estruturais.
\end{abstract}

Combinatorial chemistry has emerged over the last few years as an important tool for drug discovery and lead optimisation. In this approach, the molecular diversity and range of biological properties displayed by secondary metabolites constitutes a challenge to combinatorial strategies for natural products synthesis and derivatization. This article surveys the application of combinatorial techniques to the design of "natural product-looking" libraries covering a wide range of structural diversities.

Keywords: natural products, combinatorial chemistry, drug discovery, lead compounds

\section{Introduction}

Natural products represent a rich source of biologically active compounds and are an example of molecular diversity, with recognized potential in drug discovery and development. ${ }^{1-5}$ Despite changing strategies in natural product research, in which concern sample selection and collection, isolation techniques, structure elucidation, biological evaluation, semisynthesis, dereplication, biosynthesis, as well as optimisation of downstream processing, ${ }^{6,7}$ the rate of discovery of truly novel natural product drugs has actually decreased. ${ }^{8}$ Reasons for this fact are related to high costs and time consuming of conventional programs in natural products, ${ }^{9,10}$ which led to the exploitation of modern high-throughput screening and combinatorial strategies by the pharmaceutical industry, to generate new lead structures. ${ }^{3,8,10-12}$ However, far from being competitive, combinatorial and natural product chemistry should complement on a synergistic perspective, since nature continues to be the most diverse and active compound library known. ${ }^{11,13,14}$ An amazing example of a natural combinatorial library is illustrated by the pupal defensive secretion of the coccinellid beetle Epilachna borealis, which is composed principally by

*e-mail: pma@dq.fct.unl.pt several hundred macrocyclic polyamines (polyazamacrolides) generated by a nonselective oligomerization of three building blocks (Figure 1). ${ }^{15,16}$
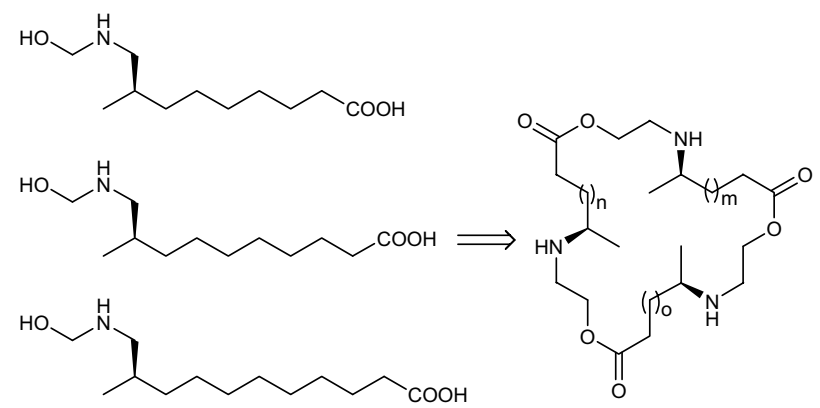

Figure 1. Representative polyazamacrolide from a natural combinatorial library in Epilachna borealis.

Two main strategies have been applied for the integration of natural products into combinatorial chemistry: the total synthesis of natural compounds and analogues; and their use as templates for the construction of libraries. Advantages and limits of these two approaches have been discussed in previous reviews on the basis of selected examples. ${ }^{13,14,17,18}$ Polymer-supported liquid-phase methods for the preparation of libraries of natural product derivatives, were reviewed by Wilson ${ }^{19}$ and Thompson, ${ }^{20}$ respectively, and a comprehensive survey on solution- and 
solid-phase strategies for the design, synthesis, and screening of libraries based on natural product templates was recently reported. ${ }^{21}$

The present article illustrates the importance of combinatorial techniques to generate natural productbased libraries, which were grouped according to type structures of secondary metabolites.

\section{Carbohydrates}

Carbohydrates are the most abundant group of natural compounds, and, as well as their glycoconjugates, are involved in such important functions as cell-to-cell recognition and communication, inflammation, immunological response, bacterial and viral infection, tumorigenesis and metastasis. ${ }^{22-30}$ Also, the saccharide portions of various classes of natural products function as key molecular recognition elements important to the biological properties of the natural compound..$^{24,29,31,32}$ In addition, the conformationally rigid and functionally rich carbohydrate system is unparallel in its value as a molecular scaffold for generating molecular-diversity through combinatorial strategies. ${ }^{24}$ So far, combinatorial chemistry of carbohydrates has been mainly focused on the solid and solution-phase synthesis of oligosaccharide libraries, as well as glycomimetics, and several articles have reviewed this area. ${ }^{31,33-52} \mathrm{~A}$ few examples are highlighted in the section.

The largest oligosaccharide to be constructed on solid phase was achieved by Nicolaou et al. ${ }^{53}$ Starting from a stereochemically homogenous conjugate consisting of the first monosaccharide unit, a benzoate spacer and a photolabile $o$-nitrobenzene linked to a Merrifield resin, a dodecasaccharide was assembled in a building block-type fashion and finally cleaved from the solid support by photolysis (Figure 2). The advantage of this method, highly enabling for the construction of large and diverse libraries of oligosaccharides, include convergence for block-type constructions, high yielding glycosidation steps, maintenance of stereochemical integrity during loading and unloading, and flexibility.

A solution-phase approach to di-, tri-, tetra- and pentasaccharides library assembly was presented by Wong et al. ${ }^{54}$ who designed a building block containing four

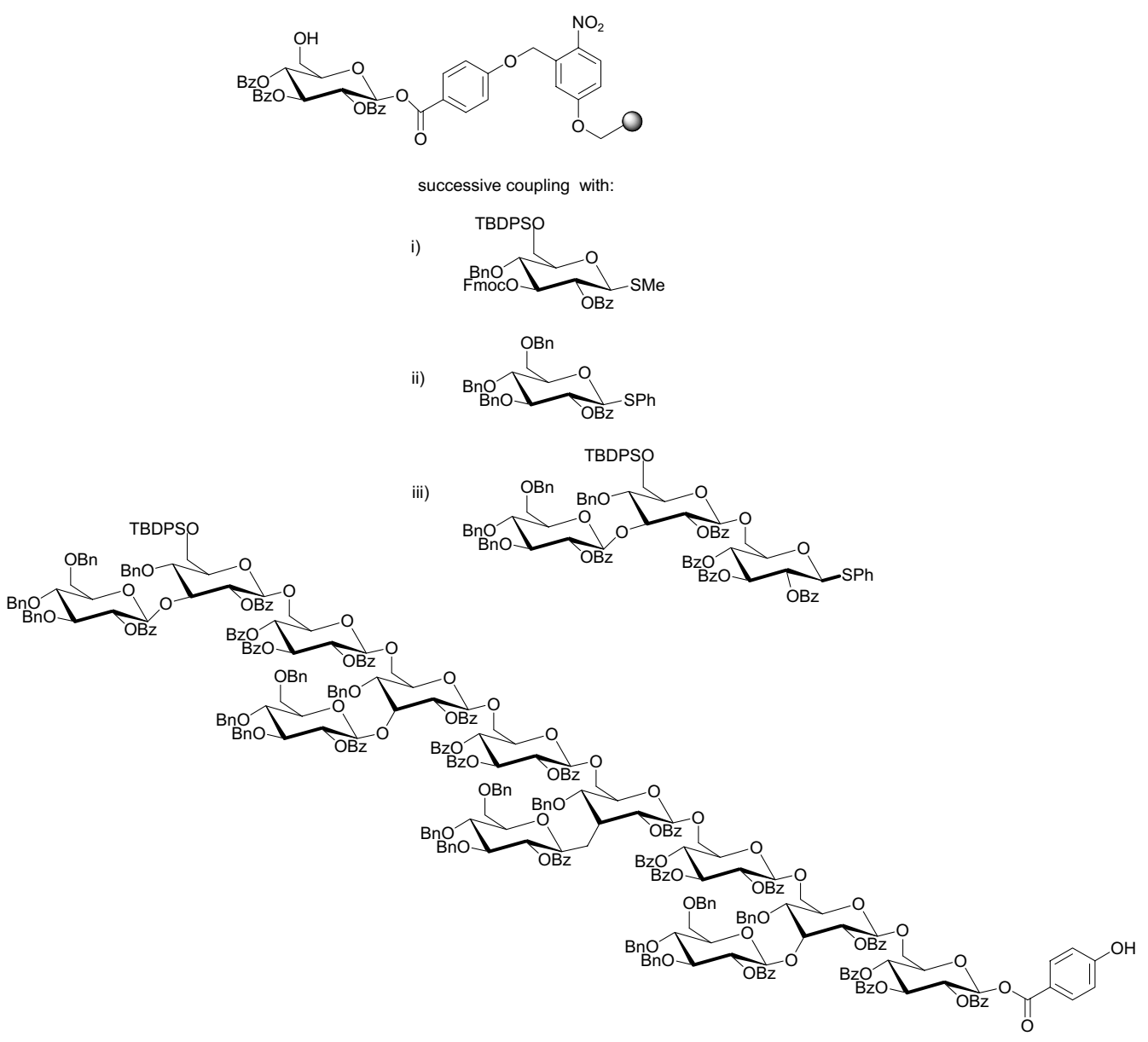

Figure 2. Solid-phase synthesis of a dodesaccharide. 
selectively removable protecting groups as acceptors for glycosylation (Figure 3). This method allows to overcome a major problem of carbohydrate synthesis, that is the lack of an efficient orthogonal protection-deprotection strategy.

The search for antibacterial agents led to the synthesis of disaccharides structurally related to lipid A, the bioactive principle of lipopolysaccharide (LPS) in the cell surface of Gram-X negative bacteria. ${ }^{55-59} \mathrm{~A}$ combinatorial approach to study cell surface carbohydrate binding to their protein targets consisted in the preparation of a library of approximately 1300 di- and trisaccharides, including both the $\alpha$ - and $\beta$-thiophenyl derivatives of Bauhinia purpurea ligand Gal- $\beta$-1,3-GalNAc (Figure 4 ).${ }^{60}$ The library was synthesized with the use of a split and mix strategy

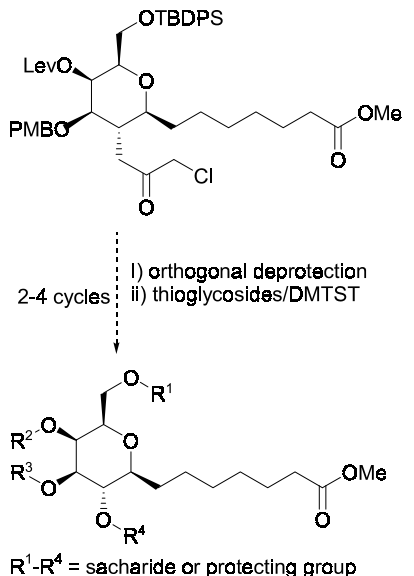

Figure 3. Wong assembly of oligosaccharide libraries.
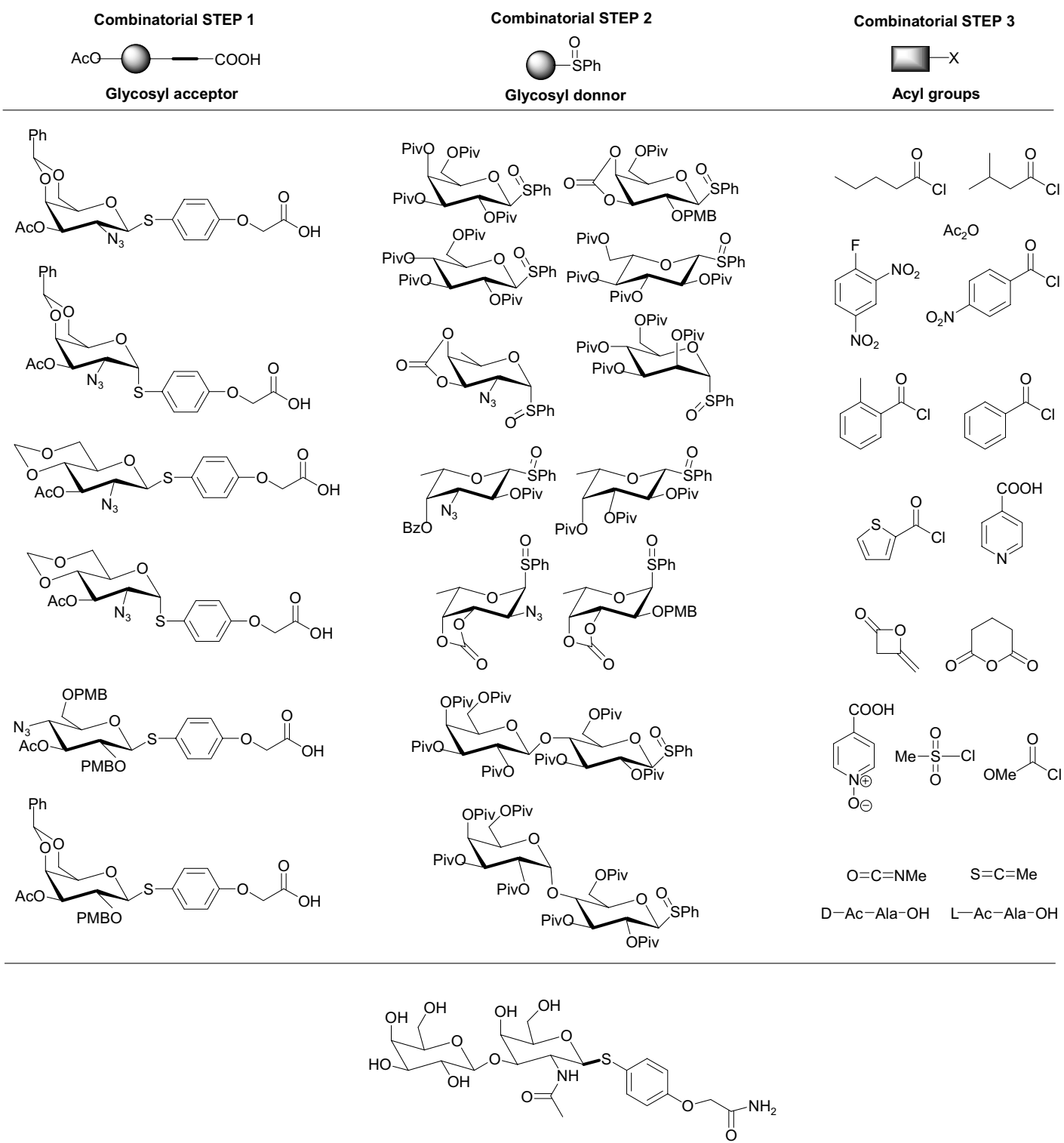

$\alpha$ - and $\beta$-thiophenyl derivative of Bauhinia purpurea ligand Gal- $\beta-1,3-G a I N A c$

Figure 4. Carbohydrate library based on Bauhinia purpurea ligands. 
from six glycosyl acceptors attached separately to TentaGel resin (step 1). Twelve different glycoside sulfoxide donors were coupled separately to mixtures of beads containing all the six monomers, which were recombined and split again, after reduction of sugar azides to amines (step 2). The separate pools of beads were then $N$-acylated (step 3 ), recombined and finally deprotected. Chemical tags were introduced after every reaction for identification purposes. The outlined strategy, which was complemented with the library screening against $B$. purpurea lectin, can be used to identify carbohydrate-based ligands for any receptor and for discovering new compounds that bind to proteins participating in cell adhesion.

The moenomycins are a family of natural product antibiotics which are known to inhibit the synthesis of bacterial cell wall peptidoglycan through inhibition of transglycosylase.$^{61}$ Degradation studies of moenomycin A, a pentasaccharide containing a long lipid attached to the reducing sugar through a phosphoglycerate unit, showed that cell wall inhibitory activity was retained in a disaccharide core structure and that certain structural elements were important for retaining transglycosylase inhibitory activity. These facts led Sofia and co-workers ${ }^{61}$ to use moenomycin A disaccharide analogues (1a,b,c) as templates to build a combinatorial library of 1300 disaccharides (Figure 5), employing the IRORI radiofrequency tagging method for directed-sorting mix-andsplit. ${ }^{62}$ Some of the library compounds, as (2), showed potent antibiotic activity against a panel of Gram-positive and Gram-negative bacteria, with $\mathrm{IC}_{50}$ below $15 \mu \mathrm{g} \mathrm{mL}^{-1}$.

The role of natural carbohydrates in cell adhesion processes, specifically, between the selectins and the Lewis sugars and their derivatives, ${ }^{63}$ led to the design and synthesis of mimics of sialyl Lewis $\mathrm{X}\left(\mathrm{sL}^{\mathrm{x}}\right)$ and related oligosaccharides via combinatorial strategies. ${ }^{40,41}$ Armstrong et al. ${ }^{64}$ and Wong et al. ${ }^{65}$ used the Ugi fourcomponent condensation ${ }^{66}$ with a variety of functionalised C-glycosides to construct librairies of sLx mimetics whose constituents were further tested as inhibitors of E- and Pselectin (Figure 6). A solution-phase library approach to mimics aminoglycosidic antibiotics such as neomycin B, was introduced by Wong et al. ${ }^{67,68}$ and was discussed in previous reviews. ${ }^{40,50,69}$

An example of combinatorial synthesis of deoxy sugars, a class of carbohydrates also involved in human physiology and that are constituents of numerous secondary metabolites, ${ }^{70}$ is illustrated by the construction of libraries composed of linear trisaccharides of 2,6-dideoxy-L-sugars synthesized by an iodonium ion-catalysed "stereoselective-yet-nonregioselective" glycosylation reaction (Figure 7). ${ }^{71}$ In this approach, a glycal (base building block) was
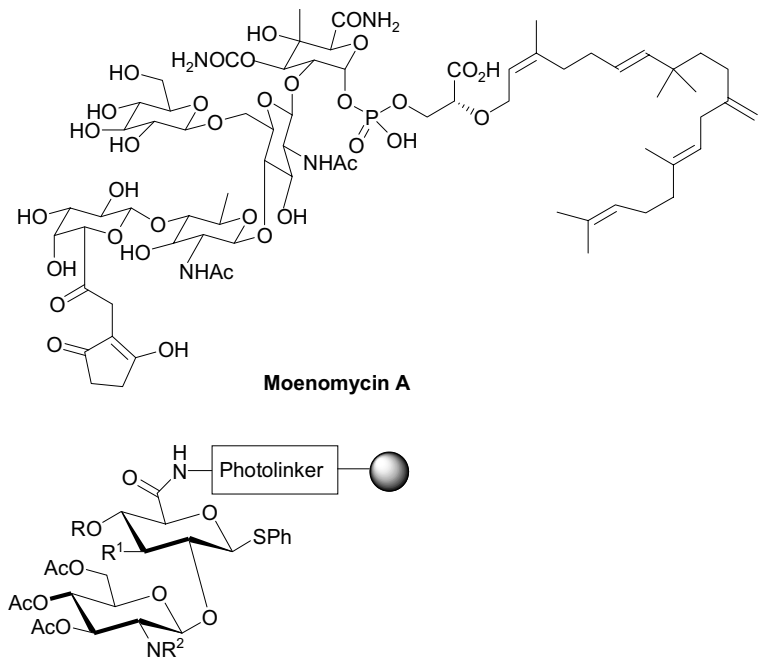

Moenomycin analogs

1a $\mathrm{R}=\mathrm{H}, \mathrm{CH}_{3}, \mathrm{Bz}$

1b $\mathrm{R}^{1}=\mathrm{OLev}, \mathrm{N}_{3}$

1c $\mathrm{R}^{2}=\mathrm{Pht}, \mathrm{HCOCF}_{3}$

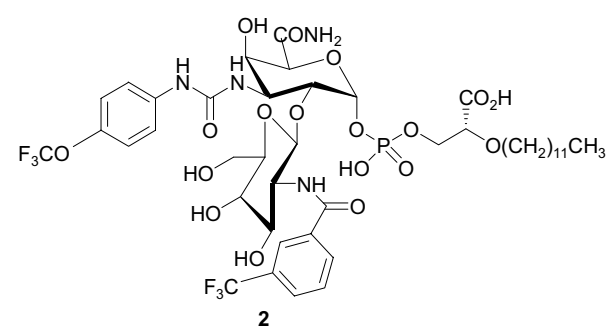

Figure 5. Moenomycin A disaccharide analogues.

non-regioselectively coupled with a glycosyl acceptor to produce two regioisomers, which were sequentially $O$ acetylated and $O$-desilylated to become an acceptor for the next glycosylation reaction. This procedure was repeated until the desired oligosaccharide length was achieved. Through these sequencial glycosylation reactions, a 2-iodo group was introduced into every monosaccharide residue. For further modification, the 2iodo groups were reduced or substituted by an X-group.

Combinatorial synthesis can also be used in the search for new bioactive monosaccharide derivatives. For example, using D-galactose as scaffold, Kunz et al. ${ }^{72}$ achieved the selective coupling of the five hydroxyl groups of the carbohydrate with different side chains $\mathrm{R}^{1} \ldots \mathrm{R}^{6}$, in a combinatorial methodology by application of a set of orthogonally stable protecting groups with a thioglycoside anchor.

\section{Steroids}

Steroids are of particular interest for design and synthesis of scaffolds for combinatorial chemistry, mainly 


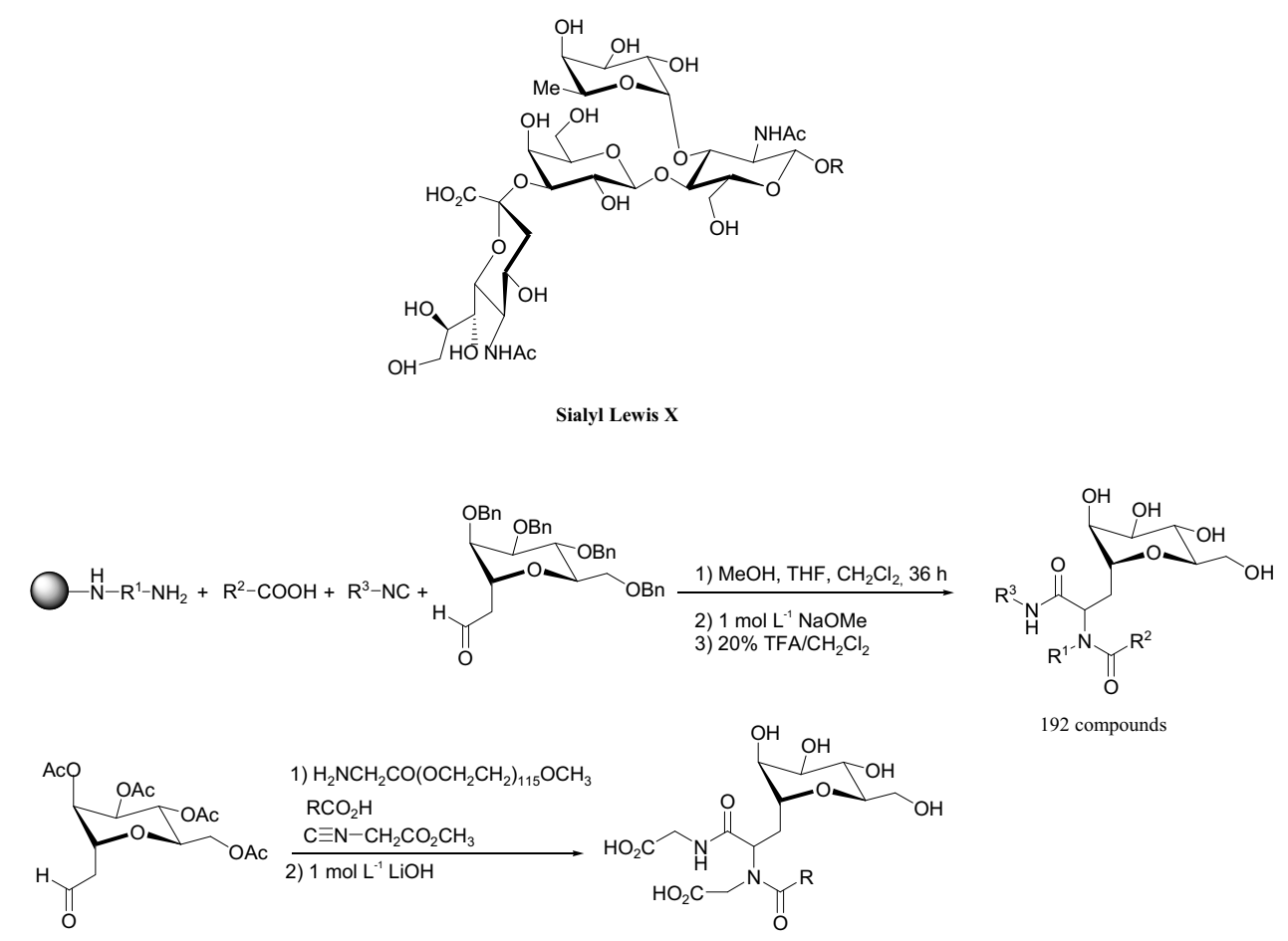

Figure 6. Construction of librairies of sLx mimetics using Ugi four-component condensation.

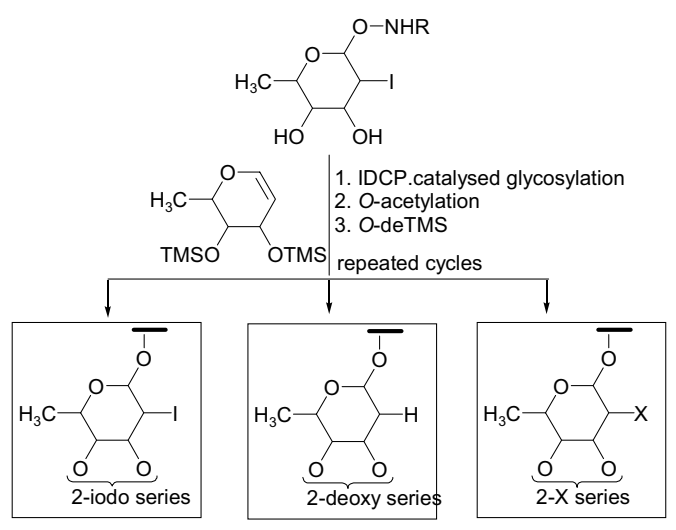

Figure 7. Combinatorial synthesis of oligosaccharide library of 2,6dideoxy sugars.

due to their rigid nucleus which is versatile in terms of functionality and side-chain substitution. ${ }^{73}$ This is the case for bile acids, whose potential as templates for combinatorial derivatization has been exploited by Analyticon and Jerini BioTools, that have applied the kombiNATURik concept to improve the pharmacology of cholic acid through the introduction of peptide and sugar moieties (Figure 8). ${ }^{13,74}$

In the course of studies on therapeutic agents for the treatment of breast cancer, Poirier and co-workers ${ }^{75,76}$ have prepared hydroxysteroid libraries with two levels of molecular diversity that were designed as potential

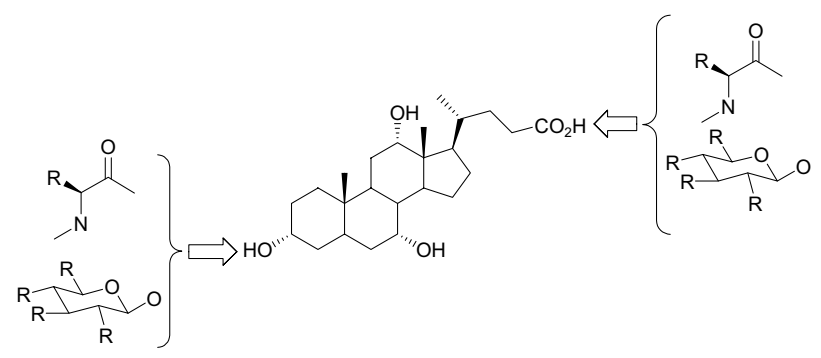

Figure 8. Cholic acid derivatization through the kombiNATURik concept.

inhibitors of steroid sulfatase and $17 \beta$-hydroxysteroid dehydrogenase, two key enzymes involved in the biosynthesis of estradiol. Estradiol libraries bearing functionalised side chains at C-16 (compounds 3 and 4), C-17 (compound 5) and C-7 (compound 7) were synthesized from estrone and 6-dehydro-19-nor-testosterone acetate, previously attached to a polystyrene resin through the phenolic function at C-3 (Figure 9). The functionality at $16 \beta$ and $7 \alpha$ was introduced from precursors bearing an azidoalkyl side chain in those two positions, whereas an oxirane group was chosen as the key precursor function to provide the $17 \alpha$ amide side chain of compound $\mathbf{5}$. This latter methodology was also employed in the construction of libraries from non-phenolic steroids bearing $3 \beta$ and $17 \alpha$ side chains (compounds 8 and $\mathbf{9}$ ). Details of these synthesis have been highlighted in a recent review. ${ }^{21}$ 

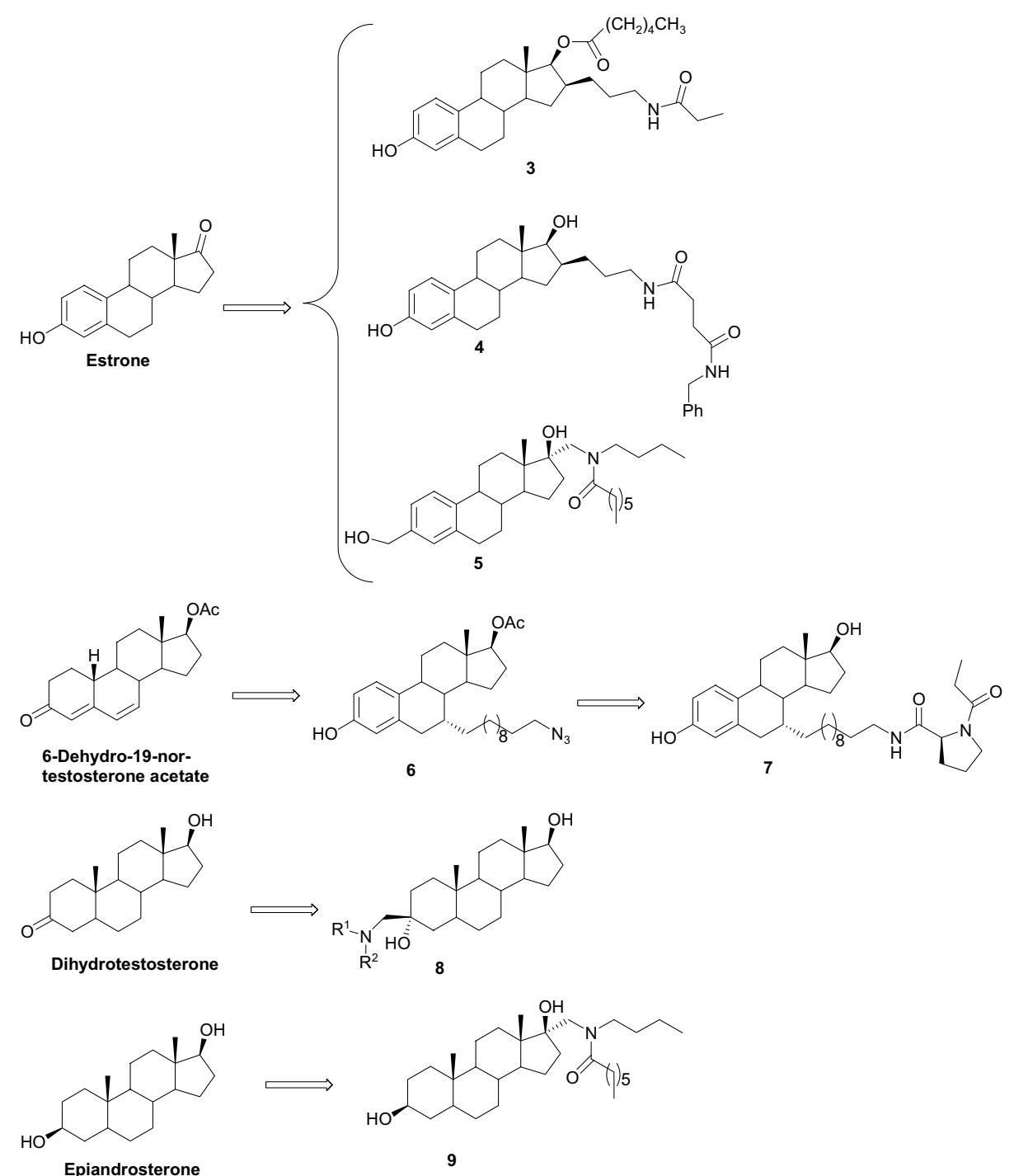

Figure 9. Hydroxysteroid derivatives with two levels of molecular diversity.

The cholesterol derivative $1 \alpha, 25$-dihydroxyvitamin $\mathrm{D}_{3}$ (Vitamine $\mathrm{D}_{3}$ ) is a natural hormone that exhibits a variety of physiological activities, such as regulation of calcium and phosphorous metabolism, cell differentiation and proliferation, and the immune system. In recent years, a number of analogues of vitamine $\mathrm{D}_{3}$ have been synthesized by many laboratories in order to investigate their structureactivity relationships (SAR) and enhance specific activities. On the basis of the scheme depicted in Figure 10, Takahashi and co-workers constructed a vitamin $\mathrm{D}_{3}$ combinatorial library by means of a split and pool methodology utilizing Radiofrequency Encoded Combinatorial (REC) chemistry, and a manual parallel synthesizer for side chain diversification and deprotection. ${ }^{77}$ The Horner-Wadsworth-Emmons reaction of the solid supported CD-ring building block $\mathbf{1 0}$ with the lithiated
A-ring phosphine oxide 11, followed by simultaneous introduction of the side chain and cleavage from resin with a $\mathrm{Cu}^{1}$-catalysed Grignard reagent, afforded the vitamine $\mathrm{D}_{3}$ analogue 13. Three and four $\mathrm{CD}$ - and A-ring building blocks, respectively, and six different side-chains, were used in a parallel synthesis to generate a 72-member vitamin $\mathrm{D}_{3}$ combinatorial library.

\section{Fatty Acids Derivatives}

The prostaglandin family (PGs) constitutes one of the most pharmacologically active low-MW natural products. Combinatorial access to PGs is based on two main strategies of synthesis of its E- and F-series developed by Janda \& Chen $^{78,79}$ and Ellman et al., ${ }^{80}$ whose details have been discussed in previous reviews. ${ }^{13,14,19,21,81}$ In the approach of 


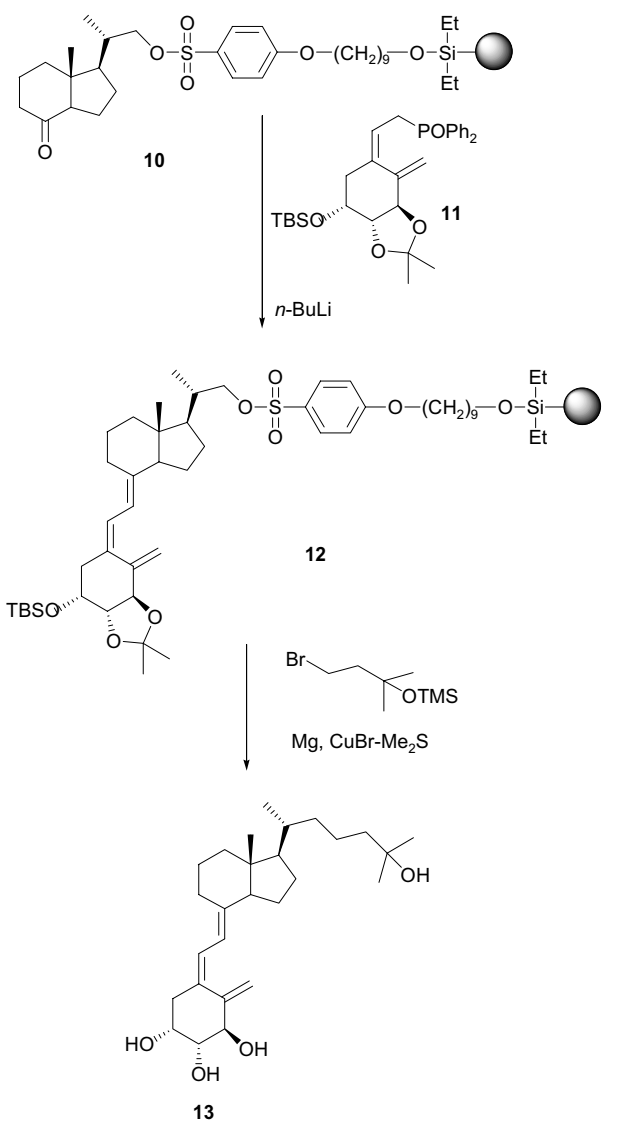

Figure 10. Solid-phase synthesis of a vitamine $\mathrm{D}_{3}$ system.
Janda and co-workers, here illustrated for prostaglandin $\mathrm{E}_{2}$ methyl ester and prostaglandin $\mathrm{F}_{2}$ (Figure 11), a Noyori's convergent three-component coupling ${ }^{82}$ was carried out with a cycopentene core linked to a functionalised polystyrene resin (14), the long-chain cuprate 15 ( $\omega$-side-chain), and the triflate 16 ( $\alpha$-side-chain). Using a parallel-pool library strategy, the same research team prepared a library of 16 prostaglandin derivatives distributed in four pools, each containing a constant $\alpha$-side-chain with four different $\omega$ side-chains resulting from the Noyori's reaction. ${ }^{83}$ Some of these prostaglandin analogues, as compounds 17a-d, have proved to inhibit the growth of the herpes-family virus CMV on infected murines.

Small prostanoid libraries were prepared by Ellman et al. ${ }^{80}$ using the bromo-cyclopentene core $\mathbf{1 8}$ linked to a chlorodibutylsilyl polystyrene resin (Figure 11). The introduction of $\alpha$ - and $\omega$-side-chains were successively inserted by a Suzuki cross-coupling with alkylboranes 19ad and conjugated addition with two types of high order cuprates $\left(\mathrm{R}_{\mathrm{w}}=\mathbf{A}\right.$ and $\left.\mathbf{B}\right)$. A library of 20 prostanoids with an amide $\alpha$-side-chain (22) was generated from the mixture 21a, which was activated for displacement by $N$ cyanomethylation and then treated independently with 10 diverse amines. Cleavage of the mixture $\mathbf{2 1 b} \mathbf{b}$ - from the triethylsilane linker afforded six $\alpha$-alkylated side-chain compounds (23a-c).
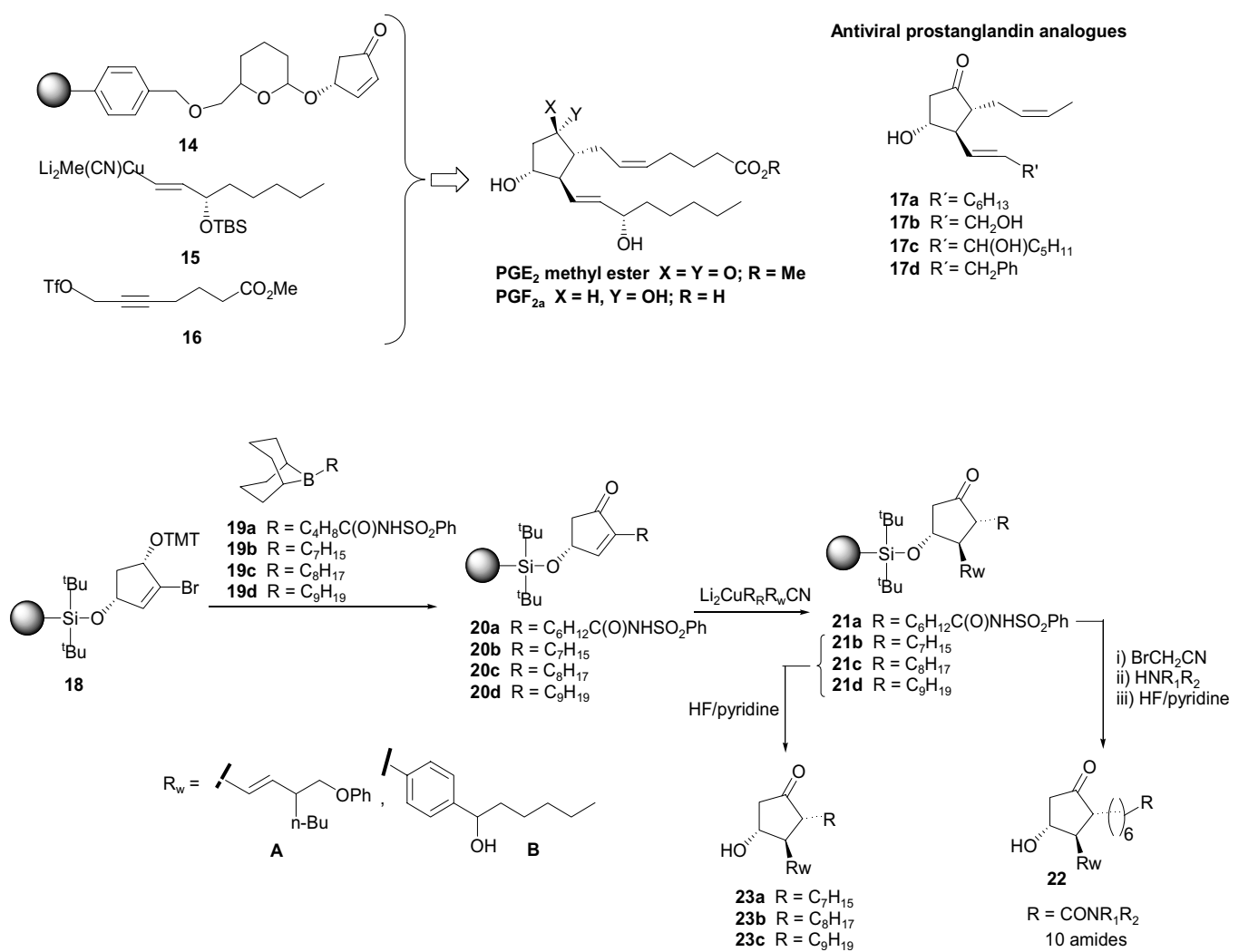

Figure 11. Combinatorial libraries prostaglandins. 


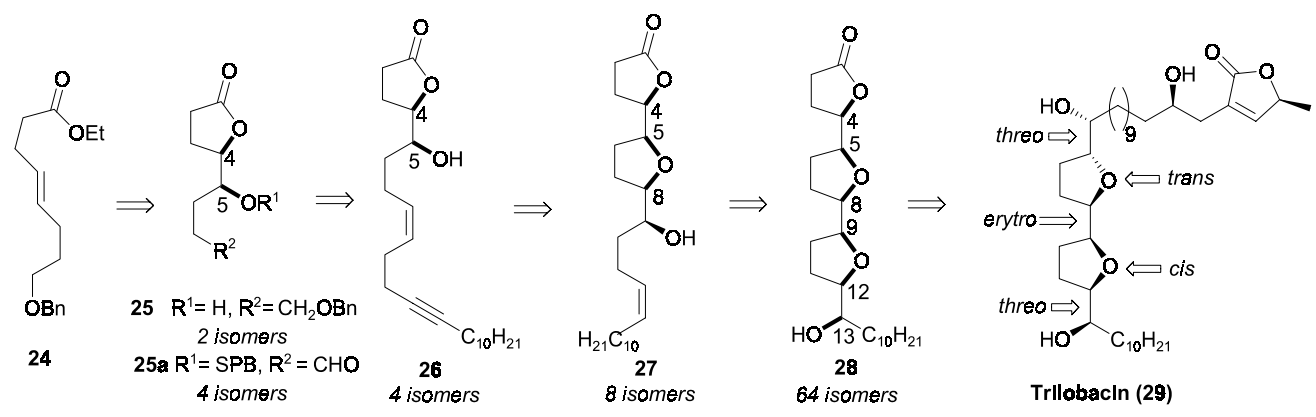

Figure 12. Chemical library of acetogenins.

Acetogenins are one of the most rapidly growing classes of new natural products, which exhibit remarkable cytotoxic, antitumor, antimalarial, immunosuppressive, pesticidal and antifeedant activities ${ }^{84} \mathrm{~A}$ solution-phase synthesis with potential application in library generation of acetogenins, particularly those belong to the bis-THF subgroup, has been developed by Keinan et al. (Figure 12) ${ }^{85}$ Based on retrosynthetic analysis of trilobacin (29), the alcene $\mathbf{2 4}$ was selected as "naked carbon skeleton" for the successive introduction of stereogenic carbinol centers of the target molecules. The lactonisation of $\mathbf{2 4}$ via the Sharpless asymmetric dihydroxylation reaction yielded the $(4 R, 5 R)$ and $(4 S, 5 S)$ stereoisomers of $\mathbf{2 5}$, which were respectively converted into the pair of isomers $(4 R, 5 R) /(4 R, 5 S)$ and $(4 S$, $5 S) /(4 S, 5 S)(\mathbf{2 5 a})$ by Mitsunobu inversion of the free alcohol's configuration. The cis alkenes $\mathbf{2 6}$, obtained by Wittig reaction of the aldehydes 25a with pentadec-4ynyltriphenylphosphorane, were treated separately with vanadium and rhenium organometalics $\mathrm{VO}(\mathrm{acac})_{2}$ and $\mathrm{Re}_{2} \mathrm{O}_{7}$, to yield four $(8 S)$ and four $(8 R)$ isomers (27), respectively. Each one of these compounds was then converted to four bis-THF stereoisomers by using four different reaction conditions: Mitsunobu reaction followed by $\mathrm{Re}_{2} \mathrm{O}_{7}$; oxidative cyclization with $\mathrm{Re}_{2} \mathrm{O}_{7}$; oxidative cyclization with $\mathrm{VO}(\mathrm{acac})_{2} / \mathrm{TBHP}$; and Mitsunobu reaction followed by reaction with $\mathrm{VO}(\mathrm{acac})_{2} / \mathrm{TBHP}$. Overall, this approach led to the generation of a 64-member library of bis-THF acetogenin analogues (28). Trilobacin (29) was further synthesized from the $(4 R, 5 R, 8 R, 9 S, 12 R)$ isomer of $\mathbf{2 8}$.

In the search for fatty acids derivatives of biologically importance, a 528-member library of ceramides (32) was generated using 33 acyl groups (30) and 16 sphingosinelike core structures (31), and tested for induction of apoptosis and NF- $\kappa \mathrm{B}$ signaling (Figure 13) ${ }^{86}$ The most active ceramide analogues showed apoptotic activity in U937 leukemia cells with $\mathrm{IC}_{50}$ values ranging from 4 to $50 \mu \mathrm{M}$, whereas NF- $\kappa \mathrm{B}$ activation was just induced by compounds $(10 \mu \mathrm{M})$ having a $\beta$-galactose head group ( $>8$-fold increase of NF- $\kappa$ B activity).

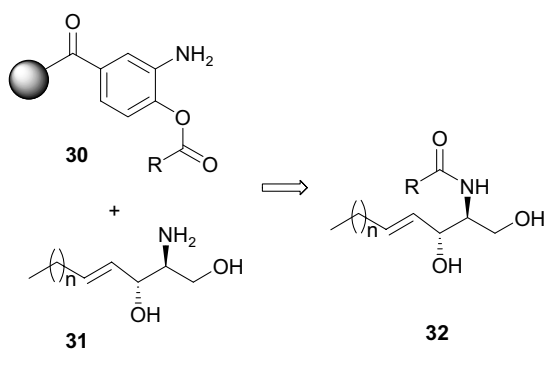

Figure 13. Ceramide library.

Muscone is a sex pheromone of the musk deer and a chemical component of cosmetics. A 12-member library of racemic muscone analogues was synthesized by Nicolaou et al.,${ }^{87}$ who employed a cyclorelease method on solid support to form the macrocycle scaffold (Figure 14). A phosphonate-functionalized resin loaded on encoded SMART microreactors (34) was coupled to olefinic esters 33, to form the $\beta$-ketophosphonates 35. Sorting and cross olefin metathesis of $\mathbf{3 5}$ with two alkenols followed by oxidation with Dess-Martin reagent gave aldehydes 36. An intramolecular ketophosphonate-aldheyde condensation (Horner-Emmons-Wadsworth reaction) of $\mathbf{3 6}$ caused smooth cyclorelease of macrocyclic enones 37. Parallel solution phase chemistry completed the sequence.

\section{Polyketides}

Polyketides are a large family of natural products with a wide range of pharmacological activity (antibiotics, antituberculosis agents, immunosuppressants, cholesterollowering agents, antifungal, cancer chemotherapeutics), which occupies a relevant place in pharmaceutical industry ${ }^{88-91}$ Although combinatorial biosynthesis is the method of choice for the generation of polyketide libraries, ${ }^{92-96}$ a few examples of synthetic protocols have been reported.

Based on the biosynthesis of erythromycin, whose heptaketide precursor is assembled by a polyketide 


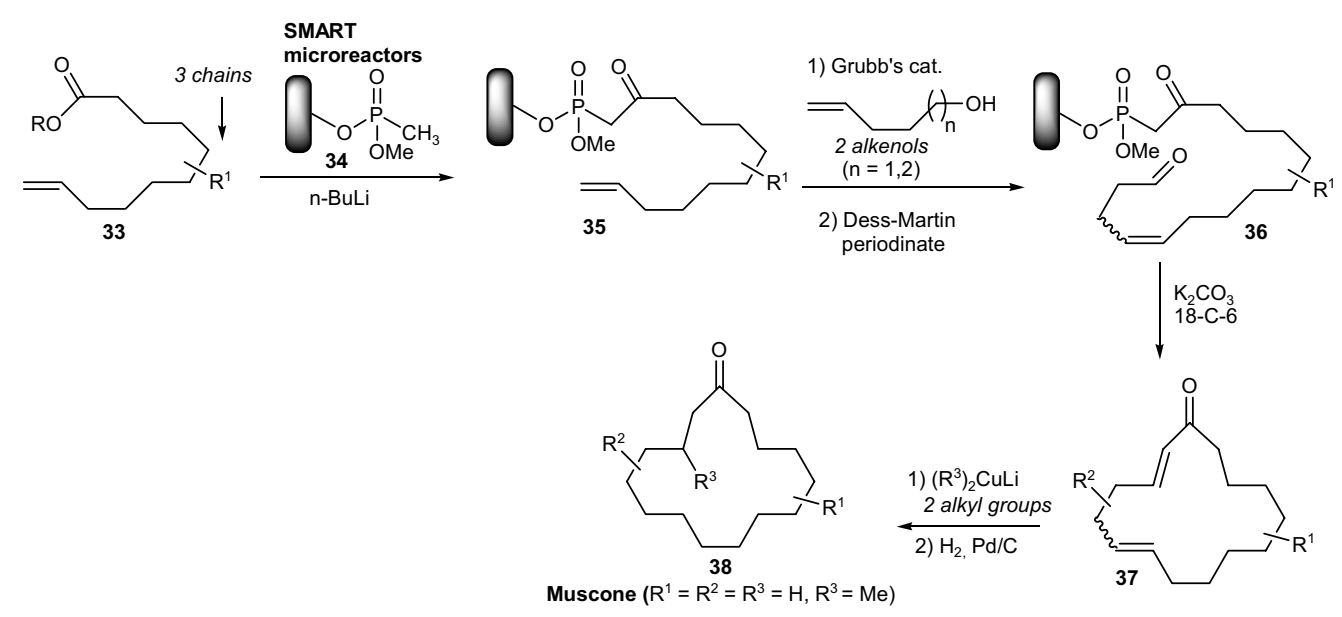

Figure 14. Muscone library.

synthase from a starter unit and six extender units, Paterson and co-workers ${ }^{97}$ developed a mimetic combinatorial synthesis using a greater variety of chain extending units, leading to much greater molecular diversity (Figure 15). In this new approach, an aldehyde starter unit (39) attached to a polystyrene support which functions as a surrogate for the acyl carrier protein (ACP), reacts with the chiral ketones 40 to produce the 1,3-diol 41, after ketone reduction. Following the regenaration of the aldehyde functionality,

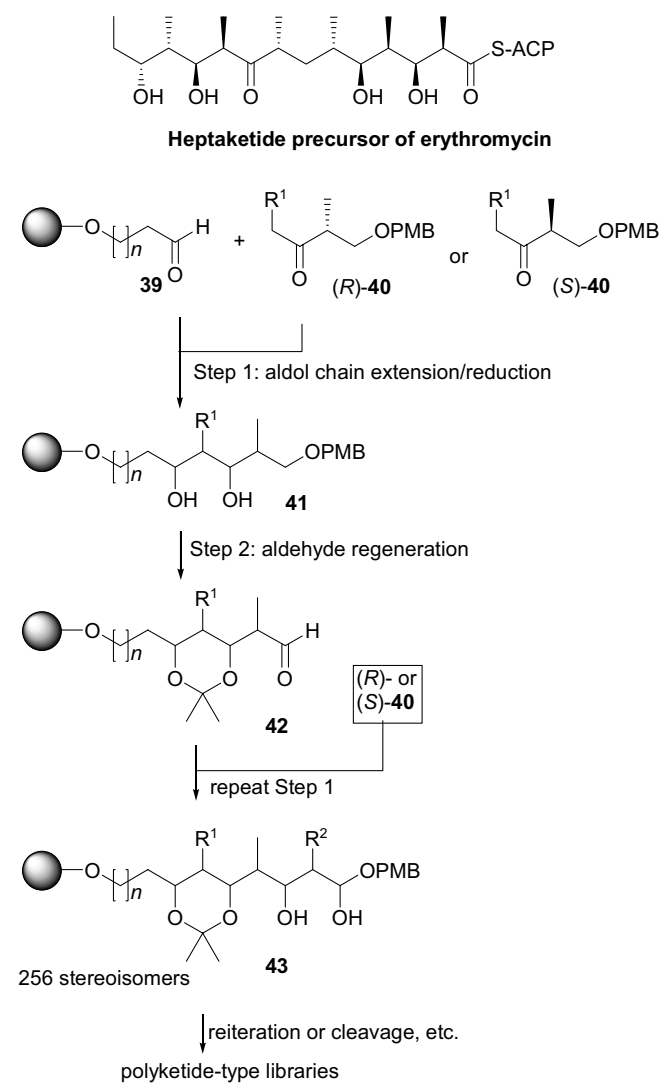

Figure 15. Generation of polyketide-type libraries. repetition provides the more elaborate 1,3-diol $\mathbf{4 2}$. This leads progressively to the synthesis of polyketide sequences of increasing complexity, where the spacer $\left(\mathrm{HOCH}_{2} \mathrm{CH}_{2} \mathrm{CH}_{2}\right.$ for $\left.n=2\right)$ is incorporated into the final product. After a single iteration, the resulting sequence has four contiguous stereocenters, while a second iteration introduces eight contiguous stereocenters corresponding to 256 stereoisomers. By varying the substituents $\mathrm{R}^{1}$ and $\mathrm{R}^{2}$ on the reagent module $\mathbf{4 0}$ in a combinatorial sense, many additional opportunities for structural diversification in $\mathbf{4 1}$ and $\mathbf{4 2}$ are possible, leading potentially to even larger libraries.

In a complementary approach to the aldol method, Misske and Hoffman ${ }^{98}$ used one simple racemic substance as starting product for library generation of stereoisomeric bicyclic, monocyclic, and acyclic building blocks, that may be taken as precursors for segments of natural products, such as the marine metabolites phorboxazole A and B, (+)discodermolide, and spongistatin 1 (Figure 16). In a sequence of 32 steps from simple racemic trans-2,4dimethyl-8-oxabicyclo[3,2,1]oct-6-en-3-one (44), a series of twenty-four homochiral buiding blocks was generated, comprising eight stereochemical pentades of anomeric $[3,3,1]$ lactone acetals, eight stereochemical tetrades of anomeric carbohydrate mimics, and eight stereotetrades of acyclic polypropionate units (Figure 17). Each type of these bicyclic, monocyclic, and acyclic builiding blocks, can be easily transformed in segments of polyoxygenated marine natural products, here illustrated for the case of (+)discodermolide (Figures 16 and 18). Further progress towards automated procedures and methodology is expected.

Curran and Furukawa ${ }^{99}$ have applied the concept of mixture synthesis with separation tags, to synthesize four truncated analogues of discodermolide (Figure 19). 

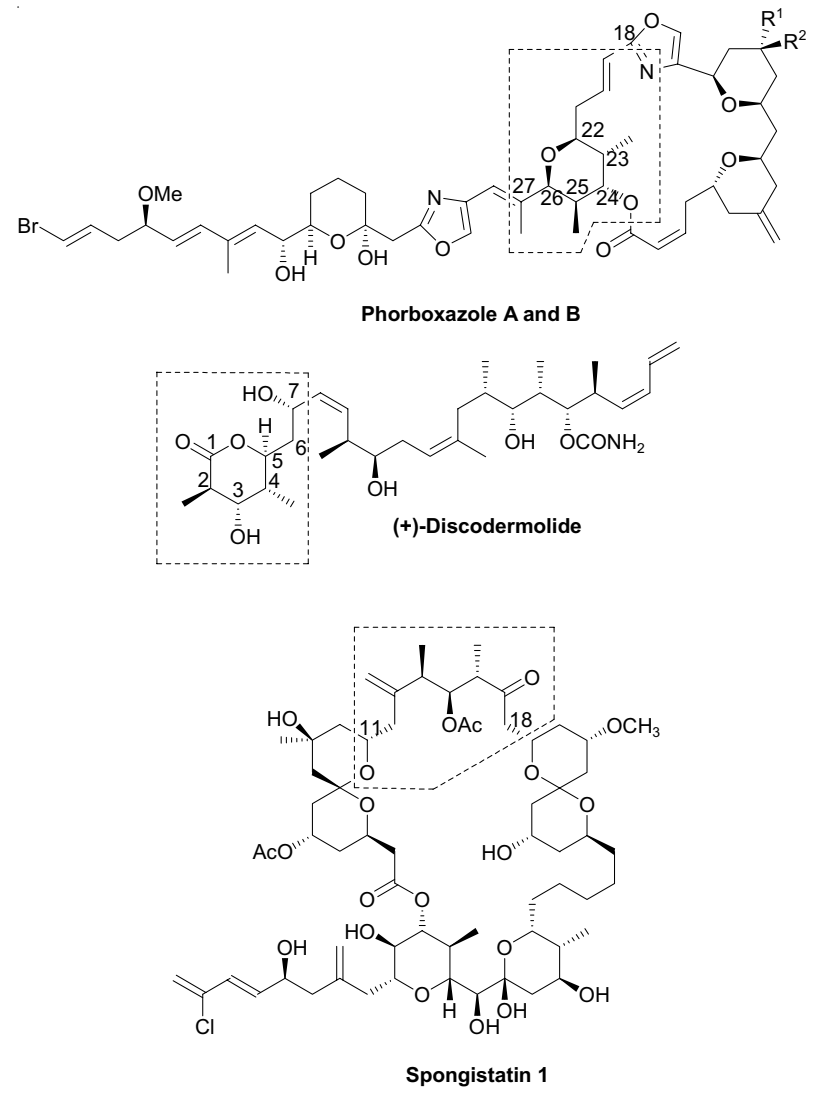

Figure 16. Synthetic polyketide and carbohydrate segments of phorboxazole A and $\mathrm{B},(+)$-discodermolide and spongistatin 1 .

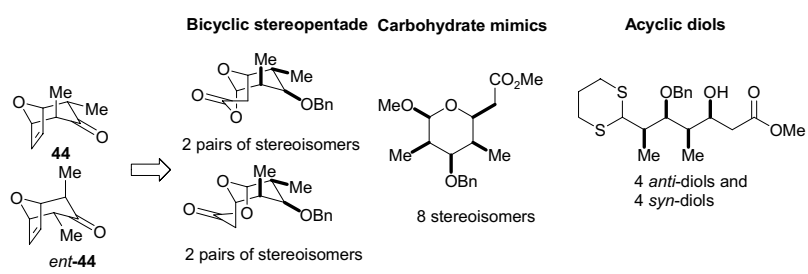

Figure 17. Library of polyketide fragments and carbohydrate mimics.

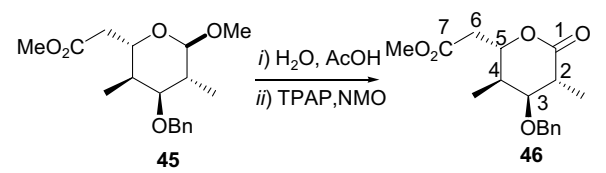

Figure 18. C1-C7 segment of (+)-discodermolide.

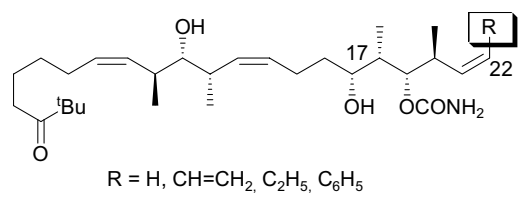

Figure 19. Truncate analogues of (+)-discodermolide.
Precursors bearing four different groups at C-22, each with an unique fluorous $p$-methoxybenzyl substituent on the C-17 hydroxy group, were mixed and taken through a nine step sequence. Demixing by fluorous chromatography followed by deprotection and purification provided the individual analogues.

A relatively large number of compounds with various sizes of macrolide rings have been isolated from microbial sources, as a result of screening campaigns in the antibiotic industry. Alternative to the biological approach of combinatorial biosynthesis for the production of macrolide antibiotic libraries, ${ }^{30,95,96,100-102}$ methods for the construction of macrocycles have been developed by Nicolaou and coworkers. ${ }^{103,104} \mathrm{~A}$ recent example includes epothilones, which are among the most interesting metabolites isolated from bacteria (Sorangium sps.) over the last few years. ${ }^{1}$ Their potential as novel anticancer drug candidates justified an intense effort on the design of classical and combinatorial synthetic strategies that have led to third and fourth generation compounds now heading towards clinical development. ${ }^{105,106}$ Based on chemistry utilized in the synthesis of epothilone $\mathrm{A},{ }^{104} \mathrm{Nicolaou}$ et al. synthesized a split-pool library of 180 12,13-desoxyepothilones A from the three key building blocks $\mathrm{R}^{1}, \mathrm{R}^{2}$ and $\mathrm{R}^{3}$, using a radiofrequency enconding of microreactors (SMART microreactors) (Figure 20). ${ }^{107}$ Two types of macrocycles were obtained (47 and $\mathbf{4 8}$ ), each containing 45 compounds with $(R)$ and $(S)$ C-7 configurations, that were epoxidized in solution to deliver the final epothilone library. Further screening of the library to both tubulin assays as well as cytotoxicity assays against human ovarian and breast cancer cells, led to the identification of nine epothilone analogues with $\mathrm{IC}_{50}$ values below $10\left(\mathrm{nmol} \mathrm{L}^{-1}\right) \mathrm{nM}$. Following the biological results, SAR could be deduced for epothilones.

\section{Peptides}

The search for new clinically antimicrobial agents led to intense efforts in exploiting the chemistry and biology of glycopeptide antibiotics, ${ }^{108}$ a group of highly complex molecules whose structural features include cyclopeptide units with recognized potential as scaffolds for the generation of combinatorial libraries. With this purpose, methodologies have been applied to the synthesis of natural cyclopeptides and analogues, as dolastatin $\mathrm{E}$ (49), ${ }^{109}$ dendroamide C (50), ${ }^{110}$ bistatramide D (51), ${ }^{110}$ westiellamide $(\mathbf{5 2})^{110}$ oscillamide $\mathrm{Y}(\mathbf{5 3}),{ }^{111}$ and actinomycin D (54) (Figure 21). ${ }^{112}$ The viability of using teicoplanin aglycone (55) as a molecular scaffold for library construction was investigated by Seneci and co- 


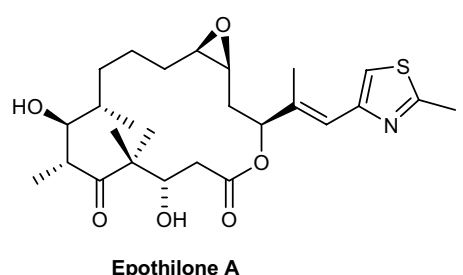

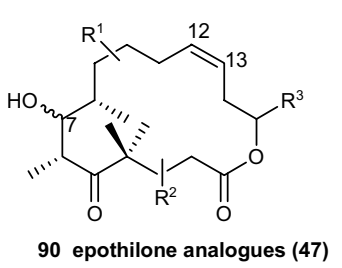

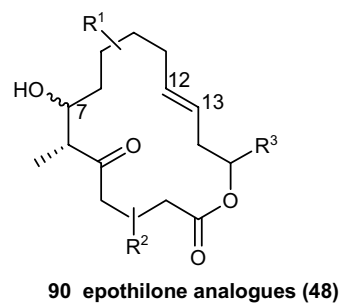<smiles>CC(CO)CCCC=O</smiles><smiles>[Y7]CCC(=O)C(C)(C)[C@H](O)CC(=O)O</smiles><smiles>[R7]CC(O)C(C)/C(=C\c1csc(C)n1)C(=C)CC=C</smiles>

Figure 20. Epothilone-based library.<smiles>CCC(C)NC(=O)C1CSC([C@H](C)NC(=O)c2csc(C(C)NC(=O)c3coc(C(C)CC)n3)n2)=N1</smiles>

49

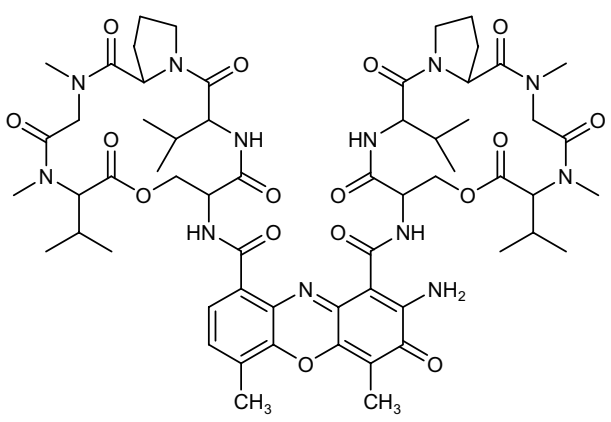

53

50<smiles>Cc1cnc([C@@H](C)NC(=O)c2csc([C@@H](CCS(C)=O)NC(=O)c3csc([C@@H](C)NC(=O)c4nc(C)oc4C)n3)n2)o1</smiles><smiles></smiles>

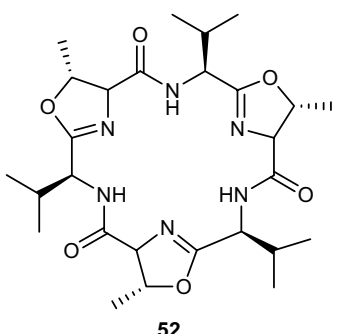

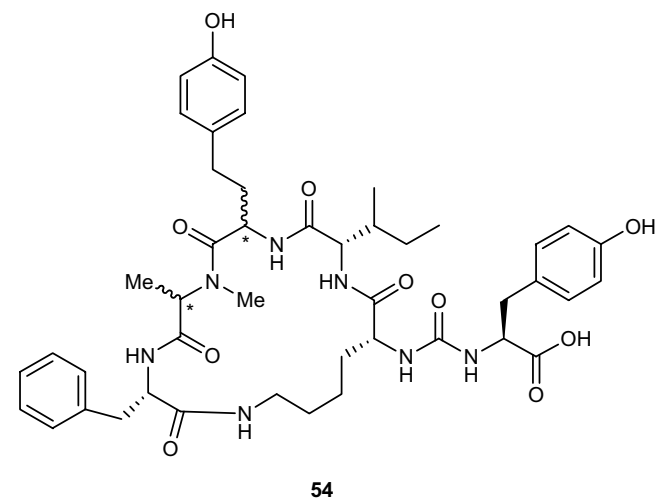

Figure 21. Natural cyclopeptides with recognized potential as scaffolds for the generation of combinatorial libraries.

workers, ${ }^{113}$ who developed two methods for the attachment of $\mathbf{5 6}$ to resin beads by means of double cleavage linkers selectively attached to the carboxyl functional group. These resin bound derivatives could be used for library generation through randomisation on the $\mathrm{NH}_{2}$ or the $\mathrm{OH}$ groups via acylation or reductive amination of the amino group, and acylation or alkylation of the phenol (Figure 22).

Besides teicoplanin, vancomycin (57) is another popular glycopeptide antibiotic against Gram-positive pathogens. However, after four decades of its clinical use, resistant pathogens to vancomycin have appeared, in 


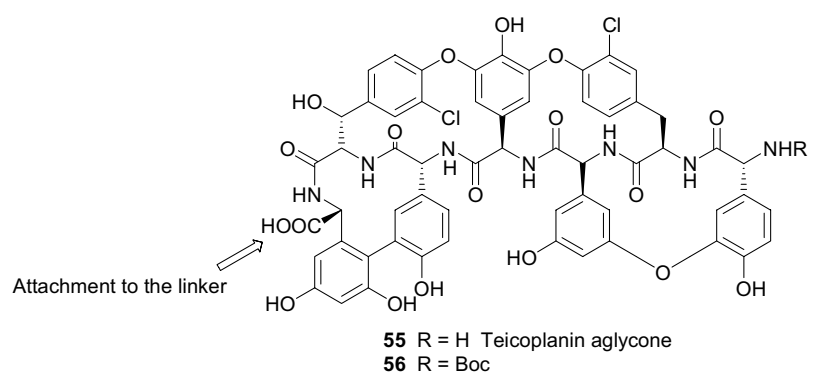

Figure 22. Teicoplanin aglycone as scaffold for the generation of combinatorial libraries.

addition to vancomycin-resistant Staphylococcus aureus strains. ${ }^{114}$ The molecular basis for vancomycin resistance is the replacement of the D-Ala-D-Ala terminus of the bacterial cell wall peptidoglycan precursor by a D-Ala-DLac residue, that results in a $\sim 1000$-fold reduction in binding affinity to the antibiotic (Figure 23). A combinatorial approach to synthetic receptor molecules targeting vancomycin-resistant bacteria was therefore designed to bind to the mutated sequence D-Ala-DLac. ${ }^{21,115}$ Using the biaryl ether core macrocycle $\mathbf{5 8}$ as an invariant building block, a library of 39304 theoretical members was prepared by split synthesis on solid support with 34 amino acids inputs used to introduce diversity (Figure 24). The amino-acids chosen for the tripeptide unit were selected on the basis of the side chain display found in the proteinogenic amino acids and on their ability to enhance the rigidity of the receptors. Screening of the resin bound library against tripetides $\mathrm{N}-\mathrm{Ac}_{2}$-L-Lys-D-Ala-D-Lac (59) and $\mathrm{N}$-Ac $\mathrm{Ac}_{2}$-L-Lys-D-Ala-D-Ala (60) labeled with the fluorophore nitrobenzodioxazole, led to the identification of the active receptors $\mathbf{6 1}$ and $\mathbf{6 2}$, both exhibiting slightly lower binding affinity toward $\mathbf{5 9}$ than vancomycin, yet they showed greater binding affinity toward $\mathbf{6 0}$, with compound 62 having approximately 5 times greater affinity. The significance of these results is that receptors less structurally complex than vancomycin can exhibit comparable and even enhanced binding affinity toward the same target. ${ }^{21,115}$

A strategy for the construction of macrocycles containing the nonsymmetrical biaryl ether moiety bore by vancomycin and teicoplanin, was developed by Kiselyov et al. ${ }^{116}$ In this approach, an assembly of twenty 14-membered macrocycles was achieved utilizing $\mathrm{S}_{\mathrm{N}} \mathrm{Ar}$ coupling of fluorine in 3-fluoro-4-nitrobenzoic acid (67) with the hydroxyl group of 3-hydroxytyrosine (66), using an acrylate resin modified with piperazine as solid support (63). Diversity was introduced by $N$-alkylation of $\mathbf{6 5}$ and 68 with $\mathrm{R}^{1} \mathrm{CH}_{2} \mathrm{NH}_{2}$ and $\mathrm{R}^{2} \mathrm{CH}_{2} \mathrm{Br}$, respectively (Figure 25).

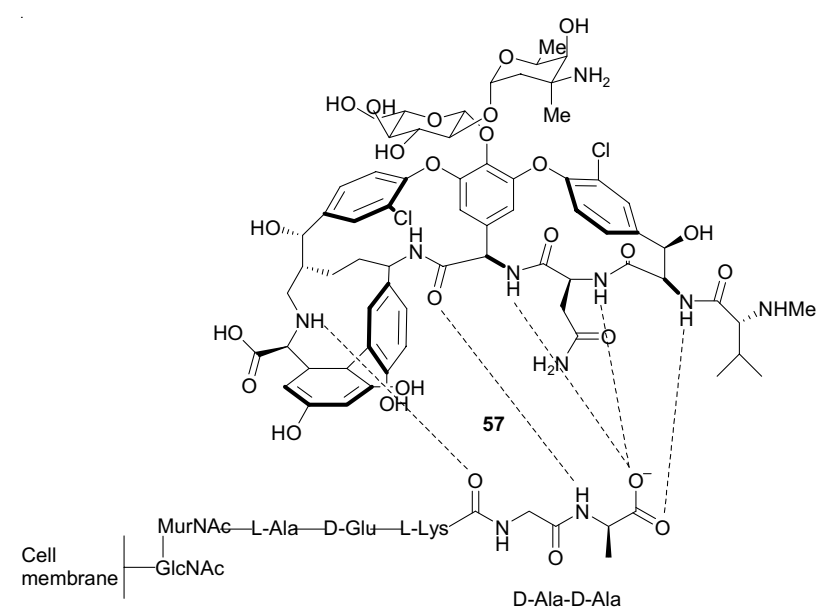

Figure 23. Binding of vancomycin to the D-Ala-D-Ala terminus of a peptidoglycan precursor.

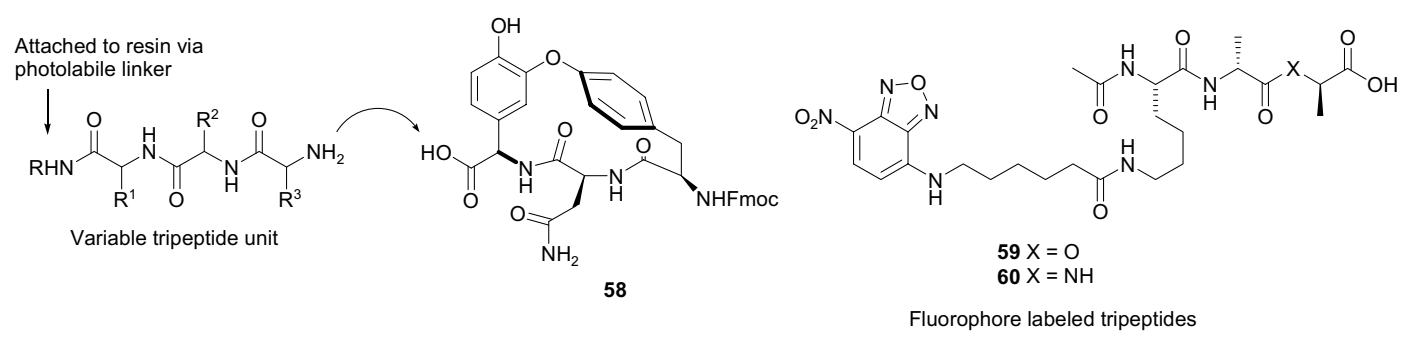

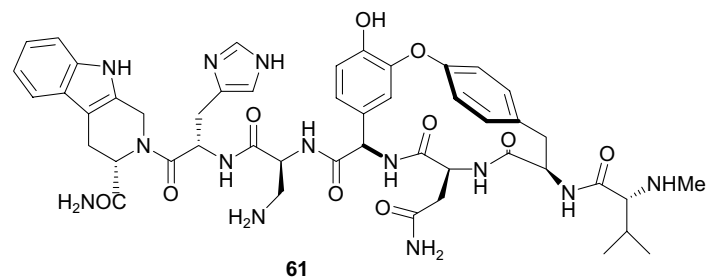

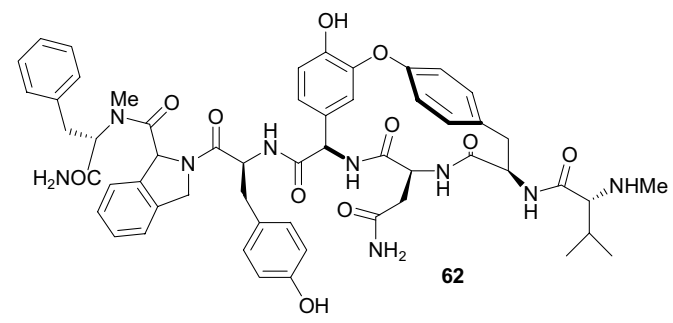

Figure 24. Vancomycin-based receptor library. 


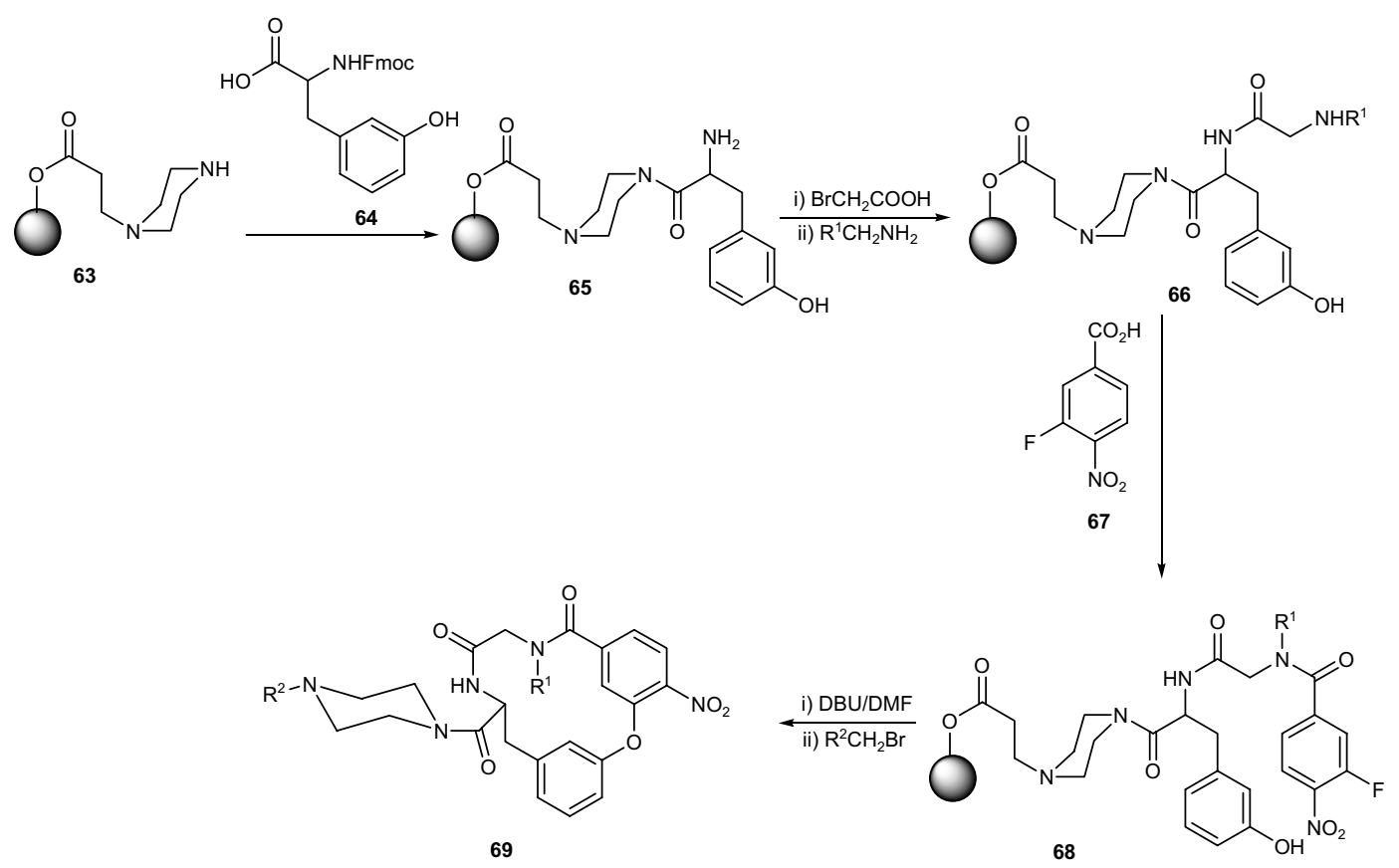

Figure 25. Library generation of 14-membered biaryl macrocycles.

A general methodology for the construction of cycloserine pharmacophore libraries was presented by Gordeev et al. ${ }^{117}$ D-cycloserine (70) is a natural antibiotic isolated from fermentation broths of Streptomyces sps., ${ }^{118}$ that inhibits the bacterial cell wall biosynthesis via two mechanisms involving L-alanine racemase and D-alanyl-D-alanine synthetase inhibition. ${ }^{119}$ Its enantiomeric L-cycloserine structure is featured as a subunit in lactivicin (71) ${ }^{120}$ which is the first non- $\beta$-lactam penicillin-binding protein (PBP) broad- spectrum antibacterial agent with a mode of action similar to that of $\beta$-lactams. ${ }^{121}$ Using Fmoc chemistry and split-and-mix methodology, protected D-cycloserine was immobilized on Sasrin or 2-chlorotrityl linker resins, and successively coupled with ten and eight amino acids in parallel reactions, to generate a library of 80 dipeptidic D-cycloserine derivatives (Figure 26). At the final stage, immobilized derivatives were Fmocdeprotected and cleaved from the solid support. The same methodology was also applied to L-cycloserine.<smiles>NC1CONC1=O</smiles>

D-Cycloserine (70)

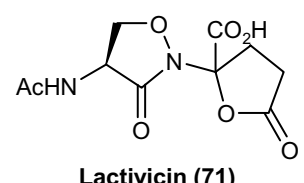

Lactivicin (71)<smiles>N[C@H]1CONC1CCCCN[C@H]1CON(I)C1=O</smiles>

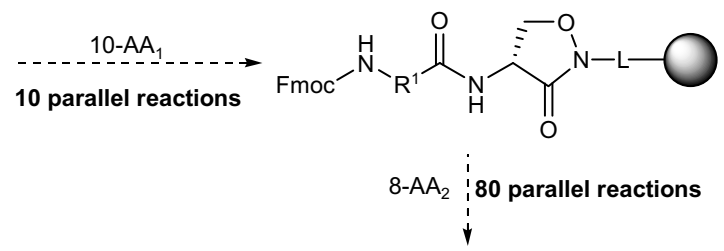<smiles></smiles>

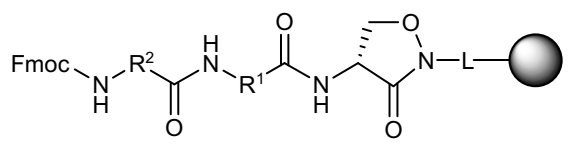

80 Member Library

Figure 26. Library construction of D-cycloserine derivatives. 
Aiming the discovery of new antifungal compounds, Tsukuda and co-workers ${ }^{122}$ synthesized a nikkomycin analogue library using the Ugi condensation with the uridine derivative 72, 59 carbocyclic acids (73), 15 isocyanides (74), and an amino component attached to a Rink amide resin (75) (Figure 27). After cleavage from the solid support, the crude samples $\mathbf{7 7}$ were tested for the enzyme inhibitory activity against Candida albicans chitin synthase 1. Among them, 246 samples exhibited more than $50 \%$ inhibition against this enzyme at the concentration of $10 \mu \mathrm{g} \mathrm{mL}^{-1}$. To confirm the structure of the active component in the crude product, the corresponding Ugi products were re-synthesized and purified by HPLC. The purified compounds 78-80 (Figure 28), obtained as a mixture of diastereomers at C-5', were as potent as nikkomycin $\mathrm{Z}$ against Candida albicans chitin synthase 1 , with $\mathrm{IC}_{50}$ values of $6.07 \mu \mathrm{M}\left(\mu \mathrm{mol} \mathrm{L}^{-1}\right)$, $\left.15.0 \mu \mathrm{M}(\mu \mathrm{mol} \mathrm{L})^{-1}\right)$, and $16.8 \mu \mathrm{M}\left(\mu \mathrm{mol} \mathrm{L}^{-1}\right)$, respectively. Among these three compounds, only compound $\mathbf{7 8}$ showed inhibitory activity against Candida albicans chitin synthase $2\left(\mathrm{IC}_{50}=4.78 \mu \mathrm{M}\left(\mu \mathrm{mol} \mathrm{L}^{-1}\right)\right)$.

Natural products that mimic sterically the bioactive conformation of peptide or protein ligands can be envisioned as privileged frameworks for the design of secondary structure-templated libraries. This conceptual procedure was exemplified by Müller and Giera, ${ }^{123}$ who introduced a set of rules for the transformation of molecular frameworks of the natural cyclopeptides $\mathbf{8 1}$ and $\mathbf{8 2}$, to generate peptidomimetic libraries (Figure 29). These two cyclopeptides were isolated from Rubia akane and posses potent antutumor activity by inhibiting protein synthesis through eukaryotic $80 \mathrm{~S}$ ribosomal binding. ${ }^{124}$

Small molecules that are able to selectively bind DNA and activate (block a repressor) or inhibit (block an activator) gene expression hold great promise as therapeutics, as is the case for the natural antibiotic distamycin A. ${ }^{125}$ Aiming the discovery of new bioactive DNA binding agents, Dale and co-workers ${ }^{126}$ used distamycin A as a lead structure to the development of solution phase combinatorial strategies to prepare 2640 analogues. Two prototypical libraries of potential DNA binding agents were prepared in a small mixture format (Figure 30). Using eleven $N$-BOC heterocyclic amino acids and twelve amino esters, the individual subunits were coupled to provide all possible 132 individual dipeptides in parallel. These dimers were deprotected and coupled to a mixture of $10 \mathrm{~N}$-BOC carboxylic acids to give 132 mixtures of $10 \mathrm{~N}$-BOC trimers where only the last position (subunit A) is undefined (1320 compounds). This first generation library was further coupled to the basic side chain $N, N$-dimethylaminobutyric acid (DMABA), affording a second generation DMABA-trimer library. For screening of DNA binding affinity, a rapid high-throughput assay was developed based on the loss of fluorescence from a target oligonucleotide presaturated with ethidium bromide. Deconvolution of the most potent mixtures by resynthesis led to the identification of compounds that are 1000 times

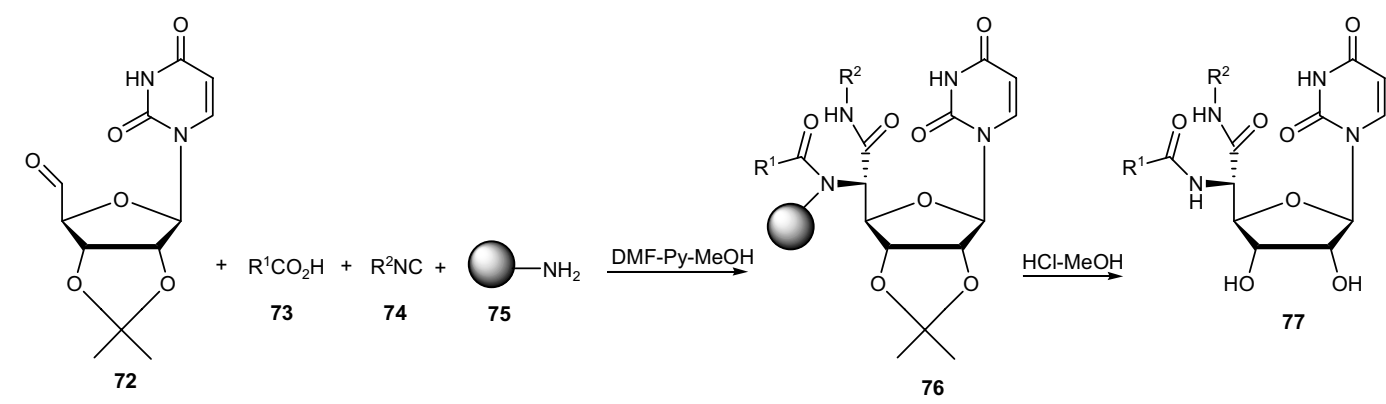

Figure 27. Combinatorial synthesis of nikkomycin derivatives using Ugi reaction.
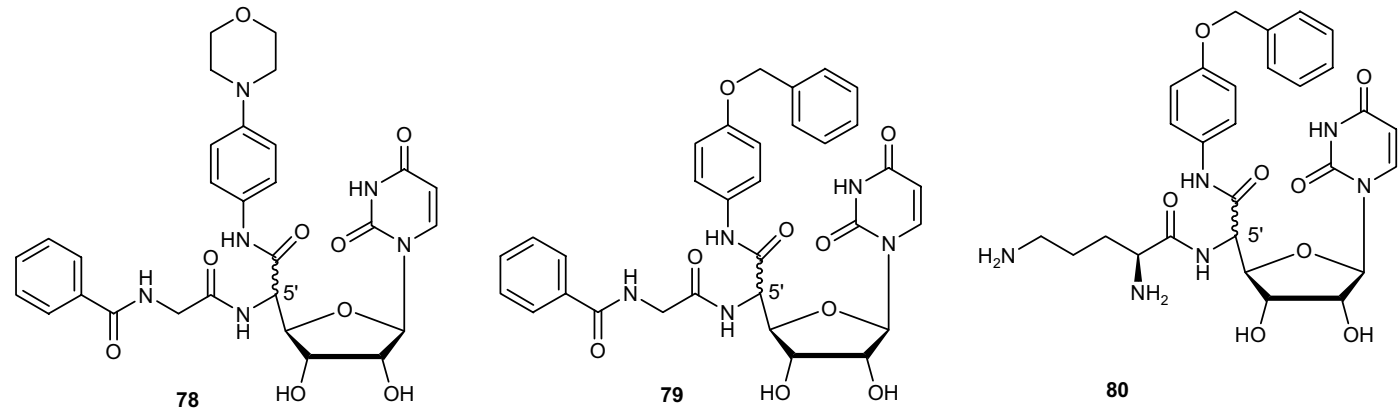

80

Figure 28. Nikkomycin analogues with enzyme inhibitory activity against Candida albicans chitin synthase 1. 


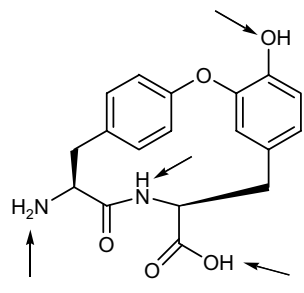

81

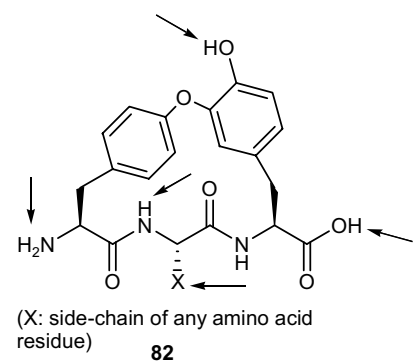

82
Figure 29. Potential functional groups $(\rightarrow)$ for library construction from the natural templates $\mathbf{8 1}$ and $\mathbf{8 2}$.
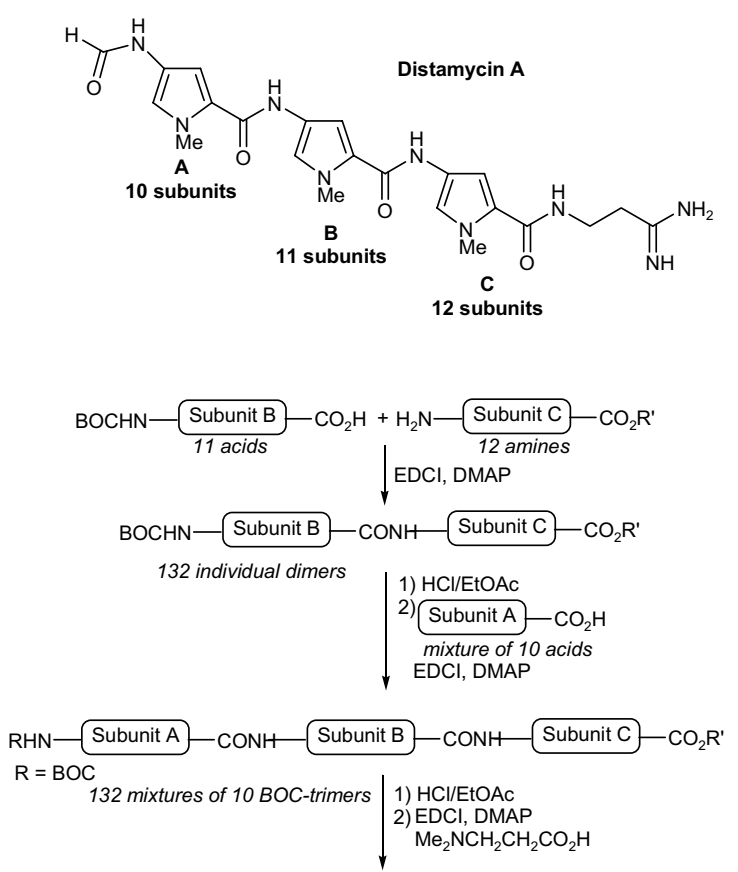

$$
\underset{\mathrm{R}=\mathrm{Me}_{2} \mathrm{NCH}_{2} \mathrm{CH}_{2} \mathrm{CH}_{2} \mathrm{CO}-}{\mathrm{RHN}-}-\underbrace{\text { Subunit }}_{132 \text { mixtures of } 10 \text { DMABA-trimers }}
$$

Figure 30. Reaction sequence for preparation of distamycin A analogues.

more potent than distamycin $\mathrm{A}$ in cytotoxic assays $\left(\mathrm{IC}_{50} 29\right.$ $\left.\mathrm{nM}(\mu \mathrm{mol} \mathrm{L})^{-1}\right)$ in the L1210 assay), that bind to poly[dA]poly $[\mathrm{dT}]$ with comparable affinity, and that exhibit an altered DNA binding sequence selectivity. One component demonstrated high affinity $\left(K_{\mathrm{d}}=4.5 \mu \mathrm{M}\right)$ to the androgen response element (ARE)-consensus sequence, which contains a GC base-pair interrupted five-base-pair AT-rich site relevant to the expression of a gene implicated in cases of prostate cancers that are unresponsive to hormone antagonists..$^{21,126}$

\section{Terpenoids}

The diterpenoid paclitaxel $\left(\operatorname{taxol}^{\circledR}\right)(\mathbf{8 3})$, first isolated from the bark of the Pacific Yew, Taxus brevifolia Nutt. (Taxaceae), has proved to be the most important drug introduced in the last ten years, with sales of over $\$ 1.5$ billion in 1999. The chemistry of taxol has been thoroughly investigated in view of determining its SAR (Figure 31) and thus to defining the pharmacophore in chemical terms. ${ }^{127,128}$ The search for taxol analogues with improved pharmacological properties led to the design and synthesis of taxoid libraries. Using radiofrequency encoded combinatorial chemistry, Xiao et al. ${ }^{129}$ synthesized a 400membered taxoid library from baccatin III (84) following criteria that included the potential enhancement of water solubility, possible modulation of biological activity, and novel solid phase synthesis. The projected solid phase synthesis of the targeted library 87 required the preparation of the core structure $\mathbf{8 5}$ from baccatin III, attached onto 2chlorotrityl resin (86) (Figure 32). The loaded resin was distributed into 400 microreactors, Fmoc-deprotected, and subject to successive split and coupling with a set of 20 carboxylic acids $\left(\mathrm{R}_{1} \mathrm{CO}_{2} \mathrm{H}\right.$ and $\left.\mathrm{R}_{2} \mathrm{CO}_{2} \mathrm{H}\right)$ at the side-chain amino group and another set of 20 carboxylic acids at $\mathrm{C}-7$ and C-2', yielding 87 .

An automated solution phase synthesis of a 26memberd library of paclitaxel C-7 esters was accomplished by Georg and co-workers. ${ }^{130}$ Condensation of the 2'-O(tert-butyldimethylsilyl)paclitaxel (88) with a set of 26 carboxylic acids in the presence of the dehydrating agent 1-(3-dimethylaminopropyl)-3-ethylcarbodiimide (EDCI) and DMAP afforded the corresponding C-7 esters, leading to the desired paclitaxel library (89) after deprotection of the 2'-O-TBS group (Figure 33). The paclitaxel C-7 esters were purified by HPLC and evaluated for their ability to initiate the polymerization of tubulin in the tubulin assembly assay, and screened against the human breast cancer cell line MCF7 and the resistant human breast cancer cell line MCF7-R. Higher activity then that of paclitaxel was found for compounds derivatized with acetic, $p$-toluic, valeric, and methylthioacetic acids.

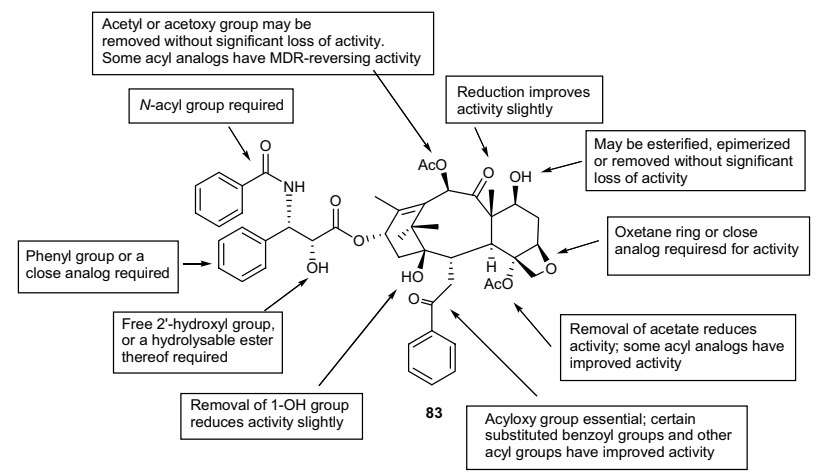

Figure 31. Some structure-activity relationships of taxol. 


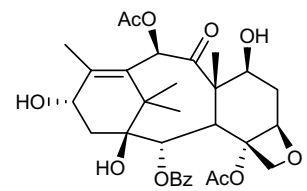

84<smiles>C=CCN[C@@H](CCC(=O)OCC(C)(C)C)C(N)=O</smiles>

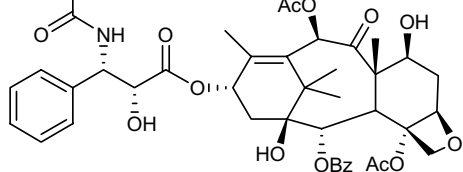

85
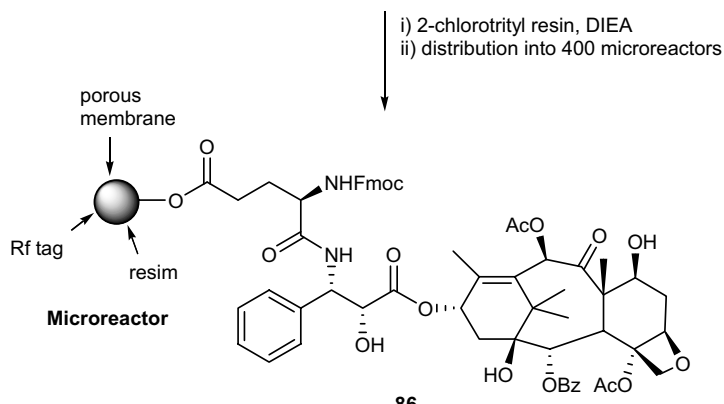

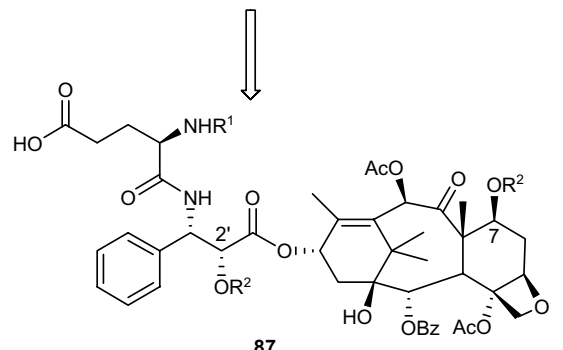

Figure 32. Taxoid library.
To further understand the SAR at C-10, especially the cytotoxicity against drug resistant cancer cell lines, the same research group prepared a library with 63 paclitaxel analogues modified at this position, using parallel solution-phase synthesis. The library $\mathbf{9 1}$ was synthesized in three steps from the 2',7-bis-protected 10-deacetylpaclitaxel 90 (Figure 33) in a one-flask procedure. The new C-10-modified taxanes were evaluated for their ability to promote tubulin polymerization and for their cytotoxicities against the B16 melanoma cell line, the drug resistant human breast cancer cell line MCF7-ADR, and the drug sensitive human breast cancer cell line MCF7. About $50 \%$ of the analogues demonstrated better activity against MCF7-ADR than paclitaxel, thus suggesting that their P-glycoprotein affinities change with structural modification at $\mathrm{C}-10$. The derivative 91a was found to be the most active against MCF7-ADR cells with a 10-fold improved potency when compared to paclitaxel.

On the basis of the known SAR of paclitaxel and previous resin-based approaches to the synthesis of its analogues, an attachment to the 2'-hydroxyl group appeared to be the most desirable, since modifications at this position are usually deleterious to activity. Nevertheless, the steric hindrance caused by THP ether linker or related alkoxy linkers precluded the synthesis of analogues with a normal $\mathrm{N}$-benzoyl function. To overcome this limitation Kingston and co-workers ${ }^{132}$ used as alternative solid-support a polystyrene-divinyl benzene resin functionalized with a butyldiethylchlorosilane linker (93) (Figure 34). Treatment of 93 with 10-deacetylpaclitaxel (92) provided the resinbound compound $\mathbf{9 4}$, which was converted to the correspondent 10-acyl analogues 95 using Holton's method. Acylation at the C-7 position was achieved by the

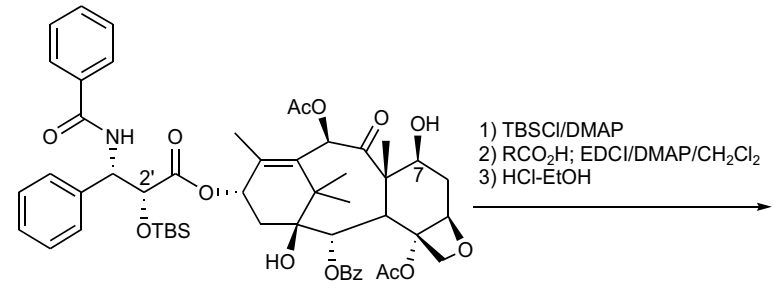

88

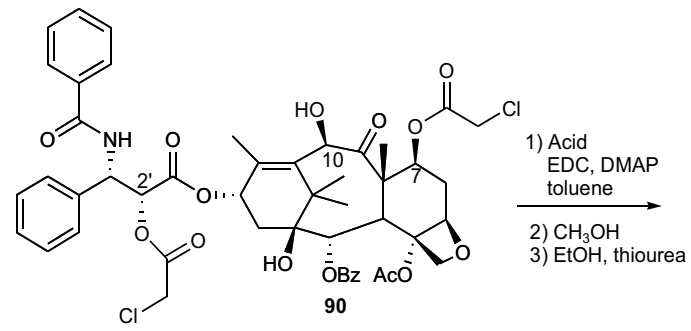

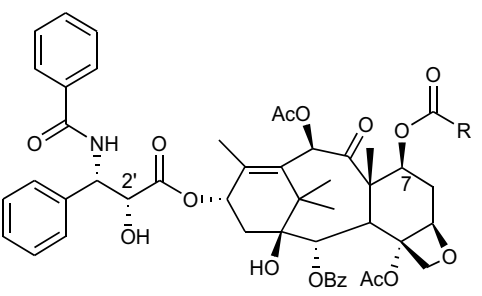

89

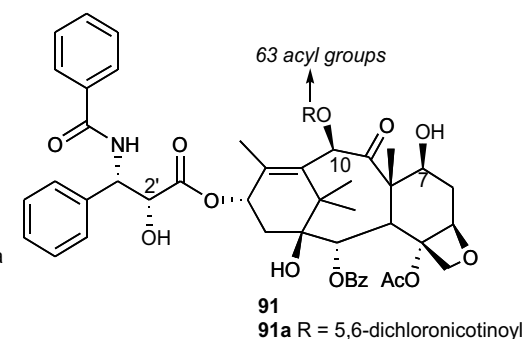

Figure 33. Solution-phase synthesis of paclitaxel C7 esters and C10 modified paclitaxel analogues. 


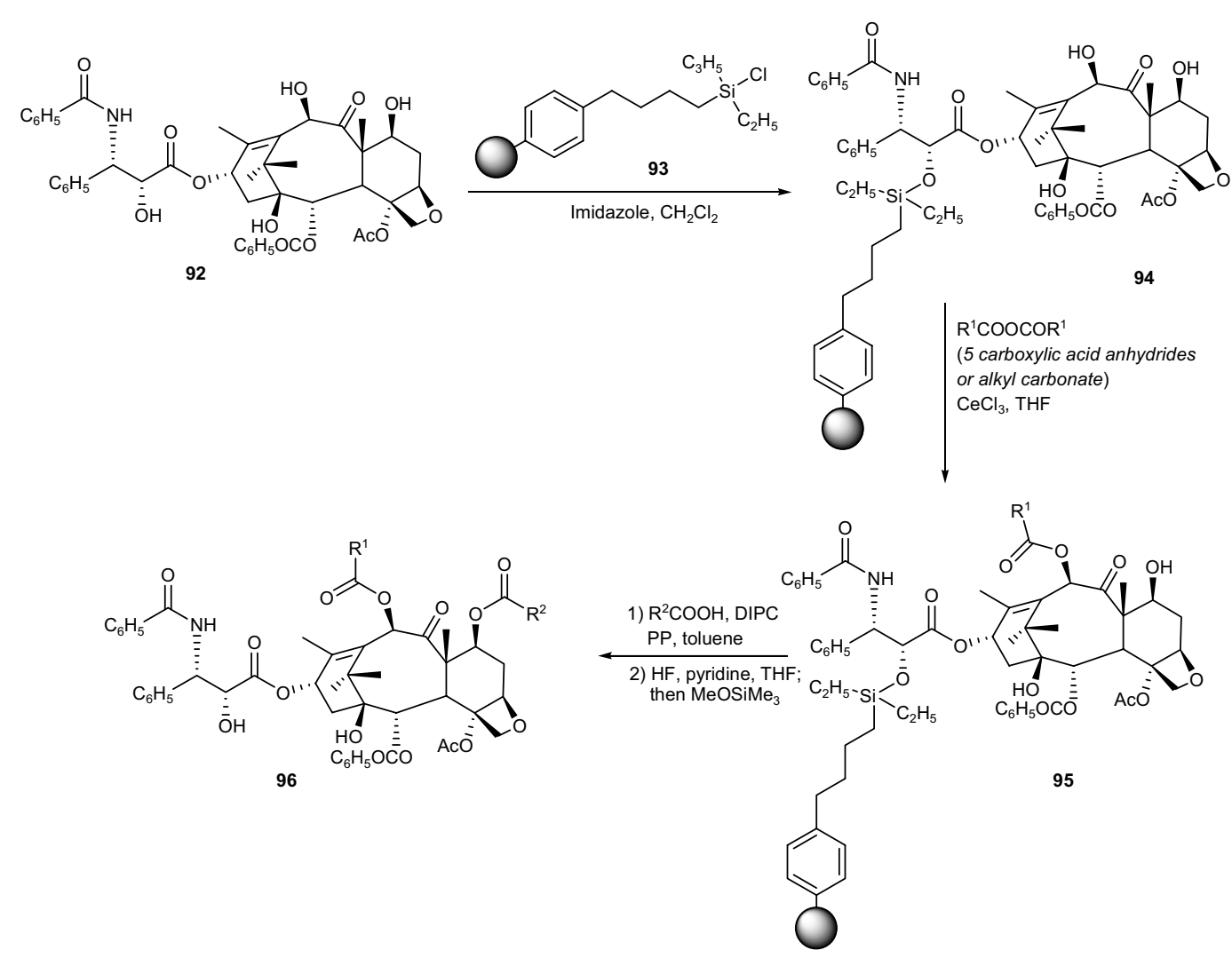

Figure 34. Solid-phase synthesis of 7,10-diacyl analogues of placlitaxel.

carbodiimide route using 1,3-diisopropylcarbodiimide (DIPC) and acid to generate a 21-member library (96). The authors developed a methodology to determine the tubulinassembly of compounds thus synthesized, which led to the discovery of three 10-acyl derivatives $\left(\mathbf{9 5}, \mathrm{R}_{1}=\mathrm{COC}_{6} \mathrm{H}_{5}\right.$, $\mathrm{COCH}=\mathrm{CHCH}_{3}$ and $\mathrm{COOCH}_{2} \mathrm{C}_{6} \mathrm{H}_{5}$ ) and one 7,10-diacyl derivative $\left(\mathbf{9 6}, \mathrm{R}_{1}=\mathrm{COCH}_{2} \mathrm{CH}_{3}, \mathrm{R}_{2}=\mathrm{COCH}_{2} \mathrm{Cl}\right)$ with improved tubulin-assembly activity as compared with paclitaxel.

Sarcodictyins, isolated from certain species of soft corals, ${ }^{133,134}$ constitute a group of diterpenoids displaying potent antitumor activity and taxol-like mode of action, which have became important synthetic targets. ${ }^{135,136}$ In order to discover analogues possessing activities superior to those of the natural products, Nicolaou and co-workers have accomplished the generation of sarcodictyin-based libraries, ${ }^{137,138}$ which have been the subject of detailed discussion in previous reviews. ${ }^{19,21,81}$

Starting from the resin attached scaffold 97, a combinatorial library of about 100 sarcodictyin analogues of the general structures 99, 100 and $\mathbf{1 0 1}$ was constructed by modifying the C-8 ester, C- 15 ester, and C- 4 ketal functionalities (Figure 35). ${ }^{139}$ The esterification of the hydroxyl group at $\mathrm{C}-8$ with acetic anhydride, acid chloride, carboxyclic acid or isocyanate, is the first step for introducing diversity in the library, yielding $\mathbf{9 8}$, which constitutes the intermediate for further molecular diversification at C-15 and C-4. In some cases low yields were observed for DCC-coupled products on solid phase, and these compounds had to be prepared in solution. On the basis of the screening results of the synthesized library for induction of tubulin polymerisation, and cytotoxicity studies with ovarian cancer cell lines, SAR of sarcodictyins, here illustraded for sarcodictyin A (102), could be proposed (Figure 35).

The most active analogues found in the above library were the same ones identified by the authors in a previous solution-phase combinatorial approach, ${ }^{137}$ which employed the key intermediate $\mathbf{1 0 3}$ to generate a small library of 15 compounds (104) by a series of standard linear transformations (Figure 35). Analogue 104a was the most active in the tubulin polymerization assay (induction of tubulin polymerization of $85 \%$ ), whereas $\mathbf{1 0 4 b}$ displayed higher antitumor activity against the parental ovarian carcinoma cell line 1A9 and the taxol-resistant tumor cell lines 1A9PTX10 and 1A9PTX22, with $\mathrm{IC}_{50}$ values of 2.0, 0.6 and $6 \mathrm{nM}$, respectively.

The labdane diterpenoid 14-deoxyandrographolide (105), one of the active principles of the medicinal plant Andrographis paniculata, ${ }^{139}$ has been identified as scaffold 
for the generation of combinatorial libraries using solidphase methods. ${ }^{140}$ The first step of the reported synthesis involved the coupling of the C-19 hydroxyl group of $\mathbf{1 0 5}$ on to 2-chlorotrityl resin, to form the precursor 106, from which diversification was introduced via the oxime esters 108. A small library of 20 derivatives (109) as generated from 108 using five alkyl and five aryl carbocyclic acids (Figure 36).

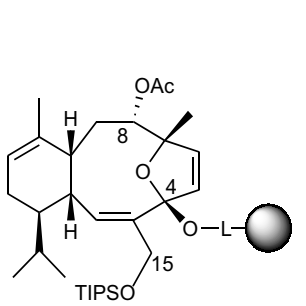

97

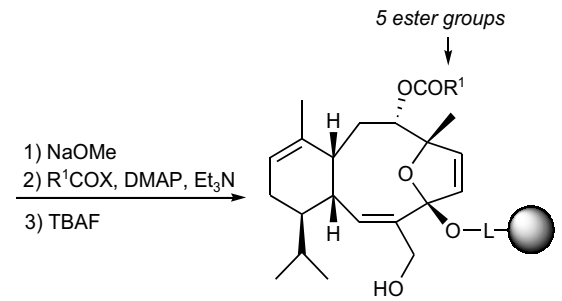

98

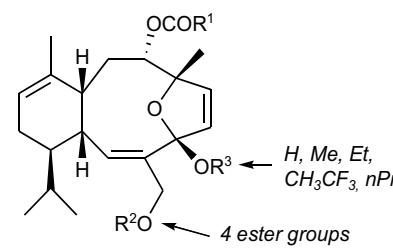

99

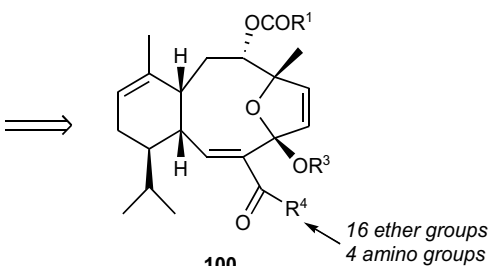

100<smiles>[R7]C[R10](=O)OO[Na]</smiles>

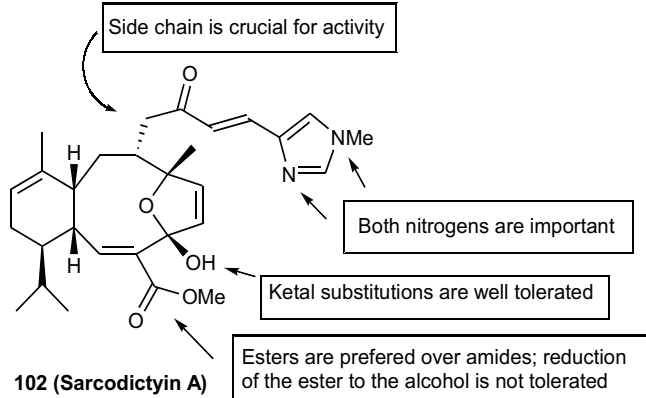<smiles></smiles>

103

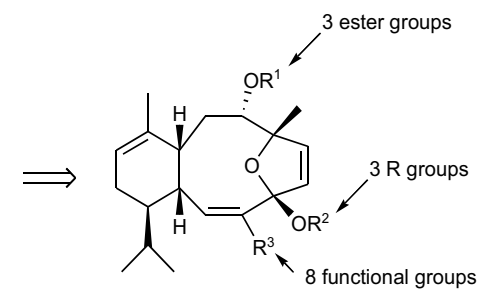

104

104a $R^{1}=$ urocanoyl $R^{2}=E t R^{3}=\mathrm{CO}_{2} \mathrm{Me}$ 104b $R^{1}=$ urocanoyl $R^{2}=M e R^{3}=\mathrm{CO}_{2} E t$

Figure 35. Solid- and solution-phase sarcodyctins libraries, and SAR of sarcodyctin A.
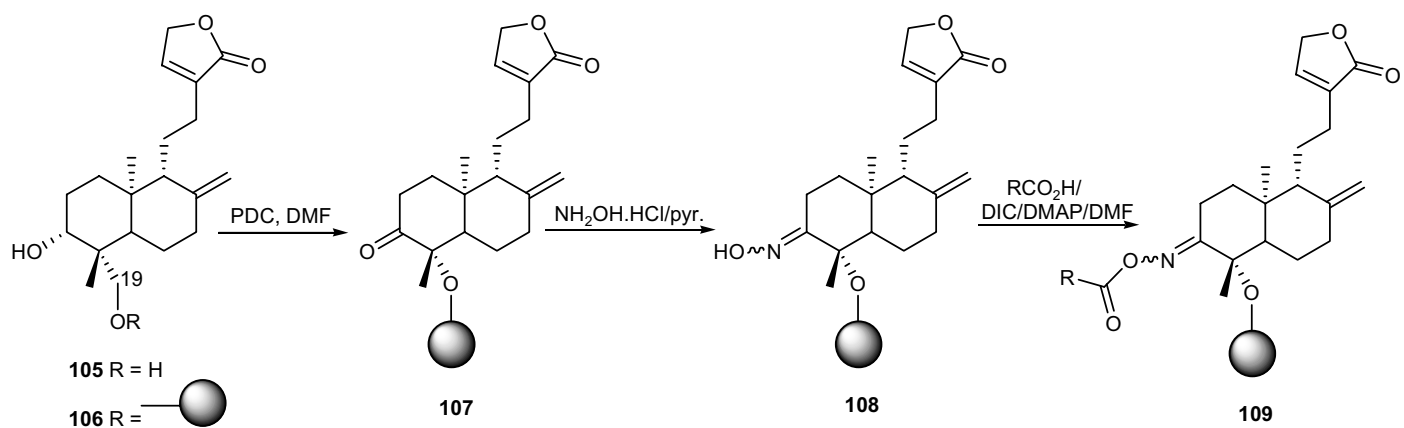

Figure 36. Library generation from the labdane diterpenoid 14-deoxyandrographolide (105). 
An identical approach was followed for the preparation of combinatorial libraries from ursolic acid and betulinic acid, two pentacyclic triterpenes which have been the subject of numerous biological investigations. ${ }^{141-145}$ The triterpene scaffold (110) was immobilized onto a prederivatized amino acid 2-chlorotrityyl or Sieber amide resins, and then treated with a variety of aliphatic, aromatic and amino acids, to generate a library of C-3 and C-28 derivatives (111) (Figure 37). ${ }^{146} \mathrm{In}$ another series of diversity, the C-3 oxime esters $\mathbf{1 1 2}$ were prepared from the immobilized triterpenoid keto scaffolds 113. Two betulinic acid and two ursolic acid derivatives exhibited five-fold increase in the antimalarial activity (MIC $10 \mu \mathrm{g} / \mathrm{ml}$ ) in comparison to the parent molecules.

The marine sesterterpene dysidiolide, ${ }^{147}$ whose absolute configuration has been established by total synthesis, ${ }^{148}$ is the first naturally occurring inhibitor of the dual-specificity cdc25 protein phosphatase family, which plays a crucial role in the regulation of the cell cycle. To determine if the solid-phase synthesis delivered biologically active analogues, 6-epi-dysidiolide 121a and four other diastereomers were synthesized on a Merrified resin by means of a Diels-Alder cycloaddition route. ${ }^{149}$ The diene $\mathbf{1 1 6}$, prepared by addition of an aldehyde linker (114) to a triphenylphosphonium salt of the iodide $\mathbf{1 1 5}$, reacted with the dienophile 117 to yield the Diels-Alder product 118. After hydrolysis of the acetal, the carbon chain of aldehyde 118 was elongated by means of a Wittig reaction and subsequent hydrolysis of the resulting ether, to yield aldehyde 119. Nucleophilic addition of 3-lithiofuran resulted in a mixture of the 2:1 epimeric alcohols $\mathbf{1 2 0}$. Finally, the furan unit was oxidized with singlet oxygen to form $\gamma$ - hydroxybutenolides 121a and $\mathbf{1 2 1 b}$, which were released from the polymeric carrier (Figure 38). Based on the above strategy, seven analogues (122-127) were synthesized from the intermediate aldehydes $\mathbf{1 1 9}$ and $\mathbf{1 2 0}$, and further tested as inhibitors of the protein phosphatase cdc25C and in cytotoxicity assays. The ketone $\mathbf{1 2 3}$ proved to be the strongest inhibitor of cdc $25 \mathrm{C}\left(\mathrm{IC}_{50} 0.8 \mu \mathrm{M}\left(\mu \mathrm{mol} \mathrm{L}^{-1}\right)\right)$, whereas alcohol 122 showed the highest activity in the colon cancer SW480 assay ( $\left.\mathrm{IC}_{50} 1 \mu \mathrm{M}(\mu \mathrm{mol} \mathrm{L}-1)\right)$. Cytotoxicity tests performed on the colon cancer cell line HCT116, the prostate cell line PC3 and the breast cell line MDA-MB2312, indicated 6-epi-dysidiolide as the most active compound, with $\mathrm{IC}_{50}$ values of $1.2,1$ and $1.6 \mu \mathrm{M}$ $(\mu \mathrm{mol} \mathrm{L}-1)$, respectively.

\section{Flavonoids}

The benzopyran moiety is a structural motif of flavonoids, one of the largest group of naturally occurring phenols, and can be labeled as a privileged structure, ${ }^{150,151}$ a term originally introduced to describe select structural types that bind to multiple, unrelated class of proteins receptors at high affinity ligands. ${ }^{152}$

Employing a cycloloading strategy that relies on the use of a polystyrene-based selenenyl bromide resin, Nicolaou and co-workers ${ }^{151}$ synthesized the 2,2-dimethylbenzopyran motif 131 (Figure 39), to be used as template for the construction of libraries of chalcones, pyranocoumarins, chromene glycosides, stilbenoids, polycyclic steroid biosynthesis inhibitors, $N$-heterocycles, and pyranoflavones.

A family of chalcones (132) with important biological activities, which includes the Cubé resin components
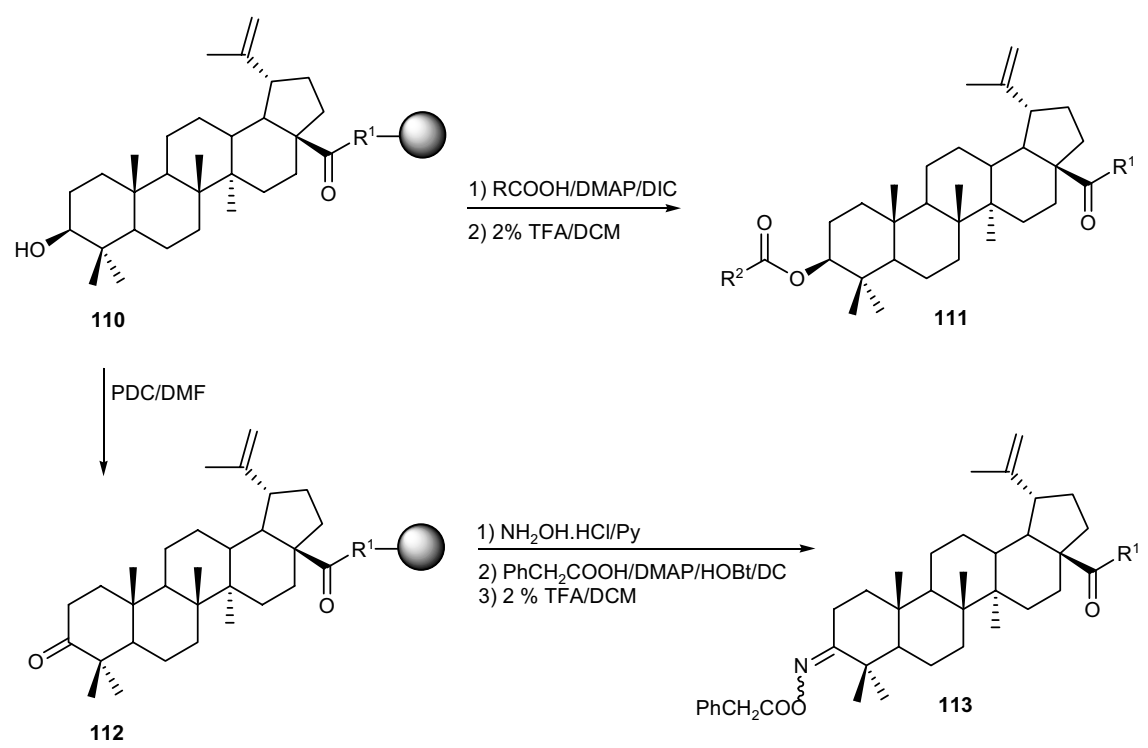

Figure 37. Betulinic acid library. 

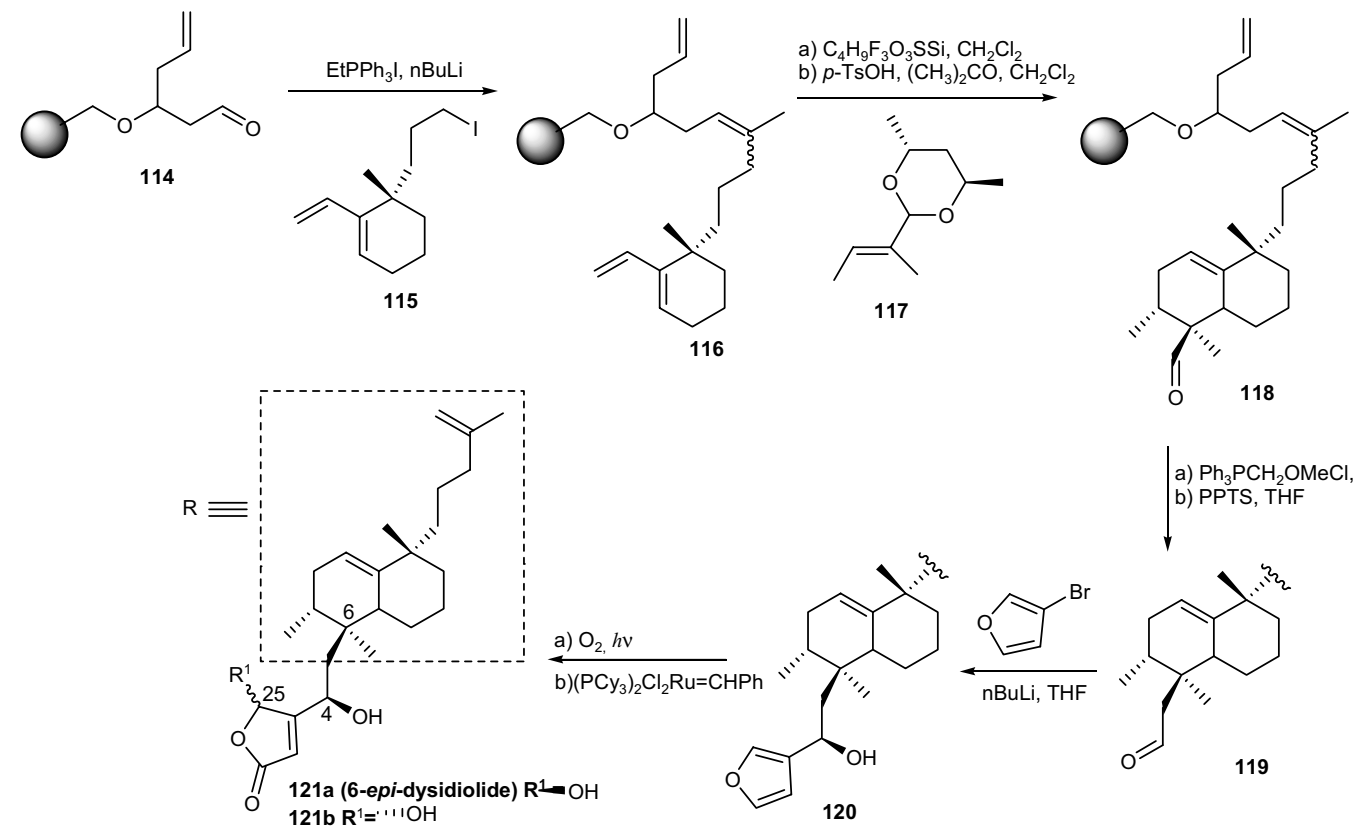

a) $\mathrm{Ph}_{3} \mathrm{PCH}_{2} \mathrm{OMeCl}, \mathrm{KOtBu}$, THF b) PPTS, THF<smiles>[R]C(O)C1=CC(=O)O[C@@H]1O</smiles><smiles>[R]CC(=O)C1=CC(=O)O[C@@H]1O</smiles><smiles>[R]C(=O)C1=CC(=O)O[C@@H]1O</smiles>

124<smiles>[R]C=CC1=CC(=O)O[C@@H]1O</smiles>

125<smiles>[R]C/C=C/[C@H]1C=C([OH2+])O[C@@H]1O</smiles>

126<smiles>O=C1C=C(CC(O)O)[C@H](O)O1</smiles><smiles>[R]C[C@@H](O)CC1=CC(=O)O[C@@H]1O</smiles>

128

Figure 38. Dysidiolide analogues obtained in solid-phase synthesis.

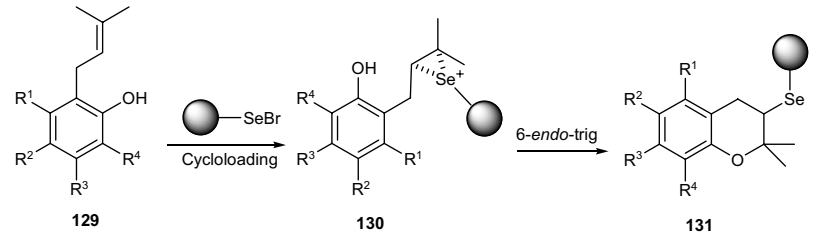

Figure 39. Synthesis of 2,2-dimethylbenzopyran scaffolds.

lonchocarpin, 4-hydroxylonchocarpin, 4-hydroxy-3methoxy-lonchocarpin, and paratocarpin, ${ }^{153-155}$ was synthesized by condensation of a variety of 11 aldehydes (133) with a set of resin-bound benzopyrans bearing a methyl ketone substituent (132), followed by cleavage from the resin by hydrogen peroxide promoted selenoxide elimination (Figure 40). ${ }^{151}$

Another natural product-based library demonstrates the construction of linear and angular pyranocoumarins similar to the Sri Lankan bioactive metabolites seselin, xanthyletin and xanthoxyletin. ${ }^{151,156,158}$ The library was prepared by a split-pool strategy with the aid of a radiofrequency encoding using IRORI tags and MacroKan technologies. ${ }^{158,159}$ Reaction pathways commenced from a set of five resin-bound benzopyrans possessing an $o$-hydroxy aldehyde functionality (135), which were treated with aryl, alkyl or alkoxy $\beta$-ketoesters (136) to provide the lactones 139 or 140 , through a Knoevanagel condensation and concomitant transesterification (Figure 40). Alternatively, these lactones were formed by coupling 135 to four different phenylacetic acids (137) or stabilized Wittig reagents (138). At this stage, structures containing no further functionality were cleaved under standard conditions, whereas any phenol substituents on the scaffold were further derivatized with bromide 141 or by a Mitsunobu reaction with alcohol $\mathbf{1 4 2}$.

A third library was constructed based on a chromene glycoside isolated from Ageratum conyzoides. ${ }^{160}$ Using IRORI radiofrequency tagging and MacroKans, trichloroacetimidates of D-glucose, D-xylose and L-rhamnose (146) were coupled onto three types of phenol-containing scaffolds (145), to afford selectively the $\beta$-glycosides 147 , which, after deacetylation and cleavage from the resin, gave the chromene glycoside plus eight analogues 148 (Figure 41). ${ }^{151}$ In alternative to the radiofrequency tagging, the authors introduced the IRORI NanoKan optical encoding system for the high-throughput nonchemical tagging and sorting of library members during split-and- 


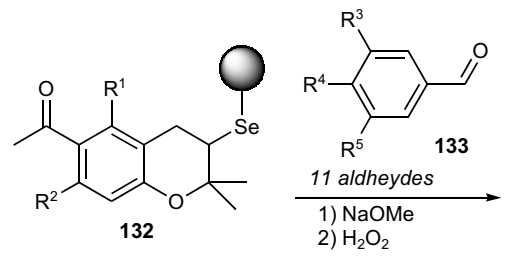<smiles>[R]c1cc(/C=C/C(=O)c2c([R])cc3c(c2[R])C=CC(C)(C)O3)cc([R])c1[R]</smiles>

Lonchocarpin $\mathrm{R}^{1}=\mathrm{OH} ; \mathrm{R}^{2}=\mathrm{R}^{3}=\mathrm{R}^{4}=\mathrm{R}^{5}=\mathrm{H}$

4-Hydroxylonchocarpin $\mathrm{R}^{1}=\mathrm{OH} ; \mathrm{R}^{2}=\mathrm{R}^{3}=\mathrm{H} ; \mathrm{R}^{4}=\mathrm{OH} ; \mathrm{R}^{5}=\mathrm{H}$

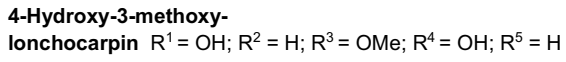<smiles>CC1(C)C=Cc2cc(/C=C/C(=O)c3ccc4c(c3O)C=CC(C)(C)O4)ccc2O1</smiles>

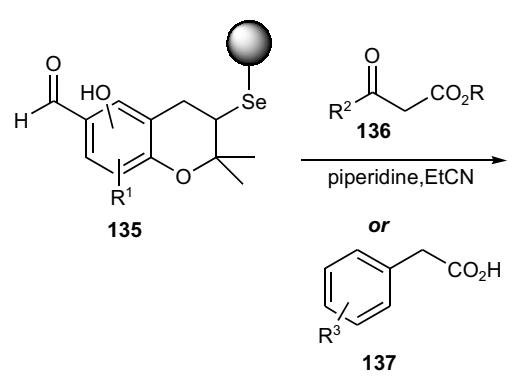

DCC, DMAP, DMSO<smiles>CCCCCCCCCCC(C)=P</smiles>

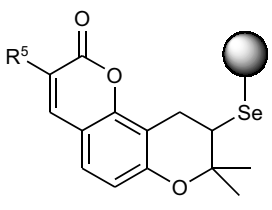

139

$R^{5}=R^{2,} R^{3}$ or $R^{4}$ $\left(R^{1}=H\right)$

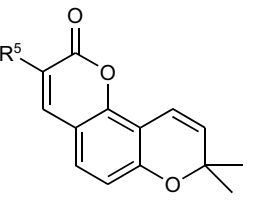

143

Seselin $\left(R^{5}=H\right)$<smiles>[R]c1cc2c([R])c3c(cc2oc1=O)OC(C)(C)C([Se][13CH]=C)C3</smiles>

140

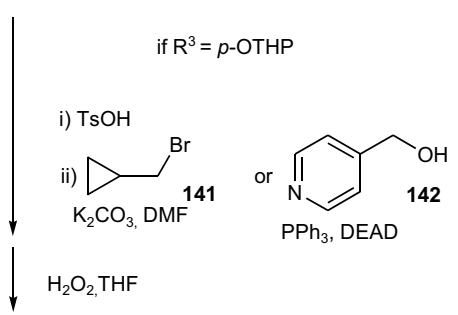

or<smiles>[R]c1cc2c([R])c3c(cc2oc1=O)OC(C)(C)C=C3</smiles>

144

Xanthyletin $\left(\mathrm{R}^{1}=\mathrm{R}^{5}=\mathrm{H}\right)$ Xanthoxyletin $\left(R^{1}=\mathrm{OMe}, \mathrm{R}^{5}=\mathrm{H}\right)$

Figure 40. Chalcone and pyranocoumarin libraries.

pool synthesis. The integration of the NanoKan microreactors in the solid-phase method described above, allowed the rapid construction of a 10000-membered benzopyran libraries, whose constituents were obtained in quantities of 1-2 mg each. ${ }^{161}$

In addition to these natural and natural product-like libraries based on the benzopyrans scaffold, other molecules of biological interest, which includes an aldosterone biosynthesis inhibitor and related analogues, and a phosphodiesterase IV inhibitor, were also synthesized according the selenoether linking strategy. ${ }^{151}$

Based on the fact that many natural and designed benzopyrans that contain modifications of the pyran olefin exhibit higher and/or different activity than that of the parent molecule (ex. $\beta$-lapachone, (+)-kellactone) (Figure 41), ${ }^{162-164}$ the Nicolaou group ${ }^{165}$ developed a solution-phase "library-from-library" strategy ${ }^{166}$ in which the previous libraries were employed for further derivatization at the pyran olefin, thereby increasing the structural diversity. Starting from scaffolds 149 released from the selenenyl resin into 96-well plates, the new library $\mathbf{1 5 0}$ was prepared by epoxidation of $\mathbf{1 4 9}$, followed by nucleophilic cleavage of the epoxide and derivatization of the resulting secondary alcohol with electrophiles.

Some naturally occurring flavonoids, as well as the flavone nucleus itself, were found to be ligands to central benzodiazepine receptors (BDZ-Rs). In the search for new compounds with affinity for the BDZ-Rs, Marder and coworkers ${ }^{167}$ have described a solution synthesis of small libraries of flavone derivatives. In a three-step sequence, mixtures containing equimolar amounts of four 5'substituted-2'-hydroxyacetophenones $\mathbf{1 5 1}$ were independently reacted in pyridine with one of nine different benzoyl chlorides $\mathbf{1 5 2}$, to yield ester intermediates which 


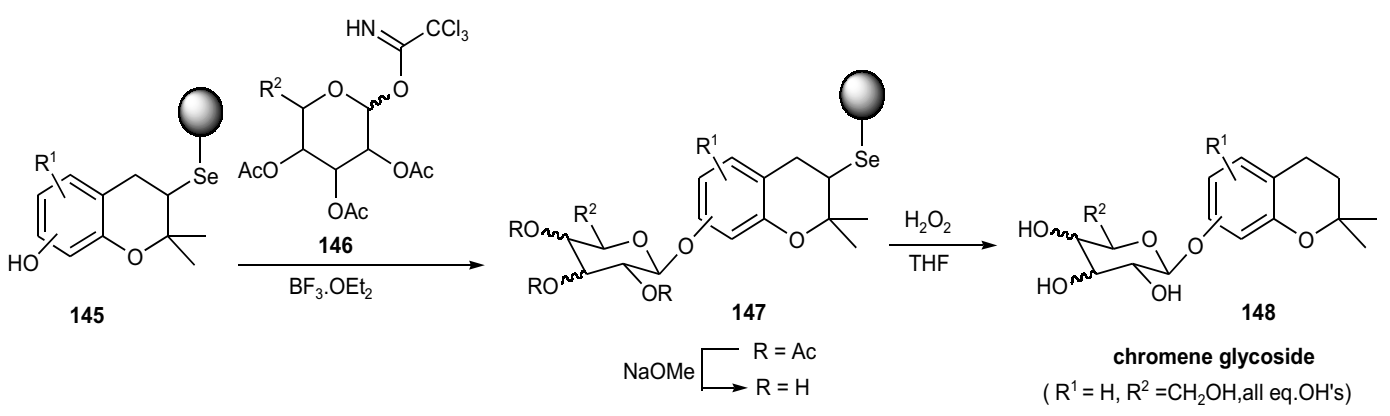<smiles>CC1(C)CCC2=C(O1)c1ccccc1C(=O)C2=O</smiles>

$\beta$-Lapachone<smiles>CC1(C)C[C@H](O)C2=C(C=CC3C=CC(=O)OC23)O1</smiles>

(+)-Khellactone<smiles>CCC1[C@H](N)c2ccccc2OC1(C)C</smiles>

149
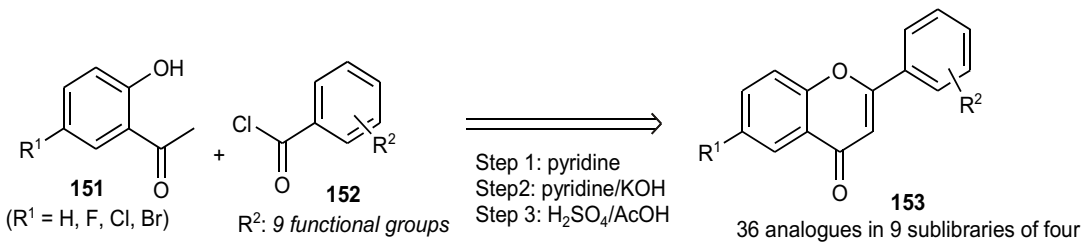

Figure 41. Chromene glycoside, benzopyran, and flavonoid libraries.

cyclized into flavone derivatives $\mathbf{1 5 3}$ by successive addition of hydroxide base (step 2) and heating with acid (step 3) (Figure 41). ${ }^{167}$ Several library members showed high binding affinity to rat cerebral cortex BDZ-Rs with $\mathrm{K}_{\mathrm{i}} \mathrm{s}$ in the range of $17-23 \mathrm{nM}\left(\mu \mathrm{mol} \mathrm{L}^{-1}\right)$, whereas pharmacological experiments in mice revealed that 6,3'-dibromoflavone has anxiolytic effect.

A combinatorial biocatalysis approach has also been used in the generation of 600-member library of bergenin derivative, in an automated two-step synthesis involving independent biotransformations by 16 purified enzymes and 25 microorganisms. ${ }^{168}$

\section{Alkaloids}

In recent years, a nearly exponentially increasing number of polymer supported syntheses providing a variety of $\mathrm{N}$-heterocyclic compounds amenable for the combinatorial synthesis has emerged, as can be recognized by numerous reviews that have been published previously. ${ }^{169-173}$ However, most of them describe reaction conditions for only a limited number of building blocks without being used for real library synthesis but merely, for parallel synthesis of single compounds. In this section, we highlight combinatorial chemistry strategies leading to different alkaloid ring systems that were used for library generation.

One of the earliest reports on the combinatorial modification of natural products describes the derivatization of the Rauwolfia indole alkaloids yohimbine (154) and rauwolscine (155). ${ }^{174}$ These compounds have been shown to have activity as antihypertensive agents, anti-arrythmics, and as adrenoreceptor antagonists, ${ }^{175}$ making them attractive targets for library synthesis. The alkaloid templates were attached to Tentagel resin-bound $\alpha$-amino acids via the Ering carboxyl group, to yield intermediates $\mathbf{1 5 6}$, which were then acylated with a range of carboxylic acids to afford a 792-member library (157) (Figure 42). 13,21,174

Fumitremorgin C (158) and related analogues constitute a group of alkaloid mycotoxins with an indolyl diketopiperazine core, ${ }^{176}$ that are considered lead compounds for cancer chemotherapy. ${ }^{177}$ Koomen and co-workers ${ }^{178}$ reported a solid-phase synthesis towards fumitremorgin structural analogues, based on a cyclization/cleavage strategy. Starting with resin-bound $L$-tryptophan (159), a 


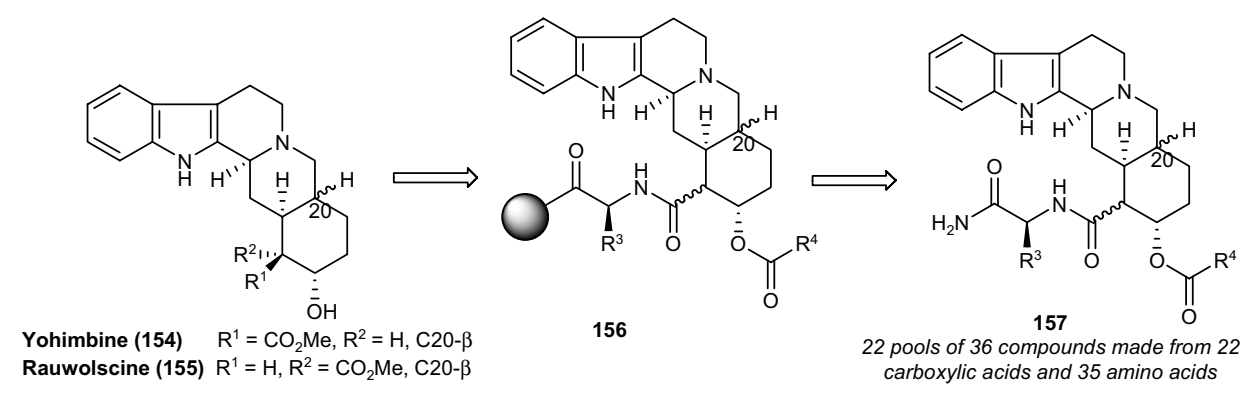

Figure 42. Rauwolfia alkaloids library.

42-member combinatorial library (as diastereomeric mixtures) was prepared by parallel synthesis via a PictetSpengler condensation with six aldehydes, subsequent coupling of $\mathbf{1 6 0}$ with seven Fmoc-protected amino-acids and cyclization/cleavage reaction of Fmoc-deprotected 161 with THF/piperidine (Figure 43). ${ }^{21,178}$ A similar solidphase approach has been described for the synthesis of demethoxyfumitremorgin (158a), the most active of this series of alkaloids, allowing the use of a larger variety of aldehydes for the Pictet-Spengler condensation with $\mathrm{N}$ acyliminium species. ${ }^{179}$

With the aim to generate libraries of potential activators and/or inhibitors of protein kinase C (PKC), ${ }^{180,181}$ Waldmann and co-workers ${ }^{182}$ established a methodology for the solidphase synthesis of analogues of (-)-indolactam V (163), a metabolite that possess the core structure of the tumor promoting teleocidins and has been recognised as a PKC activator. ${ }^{100,183}$ Based on known structural requirements of indolactams to their binding ability to PKC, these authors have prepared a 31-membered library of analogues (166) with diversified substituents at C-12, C-7 and N-13 (Figure 44). ${ }^{21,182}$ The formation of the nine membered lactam ring and the introduction of three substituents at C-12 was performed in solution from the synthesized intermediate 164. The combinatorial incorporation of $R_{2}$ and $R_{3}$ substituents in $\mathbf{1 6 5}$, previously attached to chloro-<smiles>[R]c1ccc2c3c([nH]c2c1)[C@@H](C=C(C)C)N1C(=O)[C@@H]2CCCN2C(=O)[C@H]1C3</smiles>

Fumitremorgin $\mathrm{C}(158) \mathrm{R}=\mathrm{OMe}$ Demethoxyfumitremorgin $C$ (158a) $R=H$

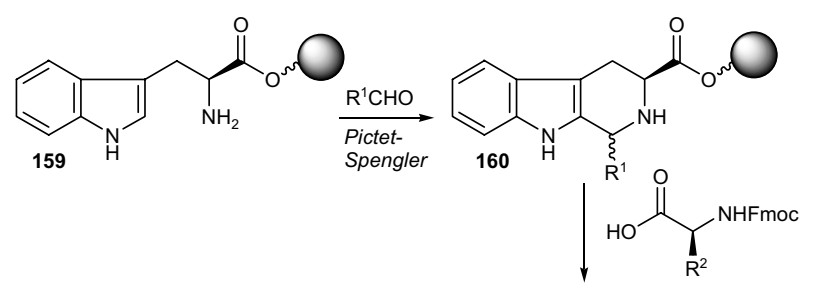

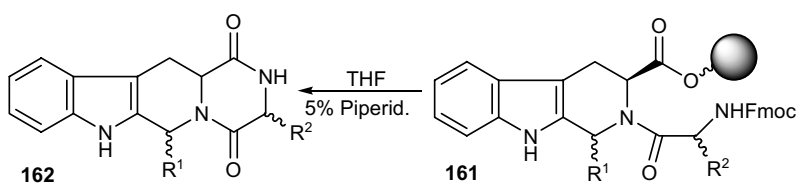

Figure 43. Library of fumitremorgin $\mathrm{C}$ analogues.

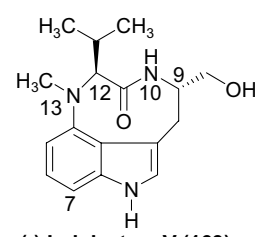

(-) Indolactam V (163)

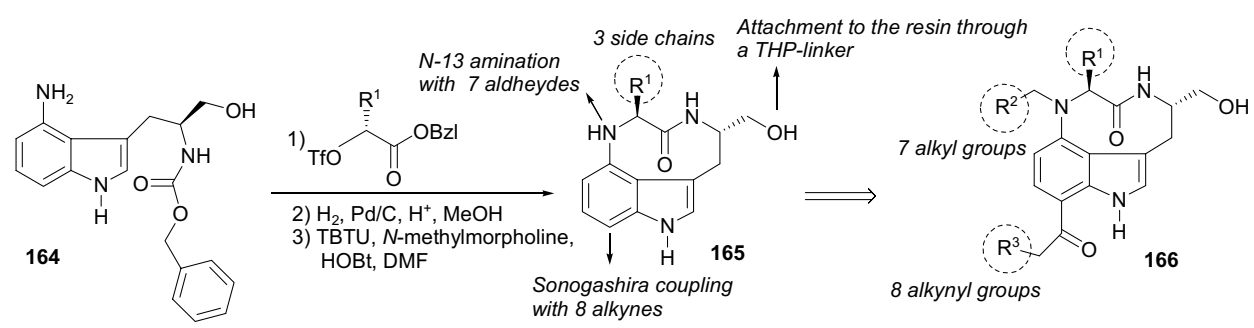

Figure 44. Indolactam library. 
methylated polystyrene beads through a THP-based linker, was achieved by reductive amination of N-13 and Sonogashira coupling at C-7, respectively. Eleven library members were further assayed for PKC activation on Swiss $3 \mathrm{~T} 3$ cells. Although all these analogue induced PKC activity, they proved to be less active than (-)-indolactam $\mathrm{V}$ itself.

Smith and co-workers ${ }^{184}$ report the use of a new carbamate linker which has proven to be extremely useful for immobilizing indole cores to resin allowing further functionalization prior to cleavage. This allowed the authors to prepare a small library of 2-aryltryptamines $(\mathbf{1 7 0})$ from the tryptophol derivative $\mathbf{1 6 7}$, whose constituents were screened in various assays within Merck (Figure 45). 2-Aryl-indole $\mathbf{1 7 1}$ was identified as a high affinity selective antagonist for the cloned human $\mathrm{h} 5-\mathrm{HT}_{2 \mathrm{~A}}$ receptor with good selectivity over $\mathrm{hD}_{2}$ activity, comparable to the selective $\mathrm{h} 5-\mathrm{HT}_{2 \mathrm{~A}}$ antagonist MDL 100,907 reported to be in phase III clinical trials for chronic schizophrenia.

Another group of fungal alkaloids bearing the indole nucleus are fumiquinazolines (ex. Fumiquinazoline F), ${ }^{185}$ which exhibit cytotoxicity activity against P388 leukemia cells. Based on the solid-phase synthesis of the quinazoline skeleton, ${ }^{186}$ Ganesan and Wang ${ }^{187}$ prepared a 27 -membered library of fumiquinazoline analogues in order to demonstrate the generality of the reported synthetic strategy. The tripeptide 174, obtained by coupling of five sets of anthranilic acids with three Wang resin-bound amino acids (172) followed by acylation of the aniline 173, was subjected to dehydration by treatment with $\mathrm{PPh}_{3}$ in the presence of iodine and Hünig's base (Figure 46). Removal of the Fmoc group led to cyclization-release of the fumiquinazoline analogues $\mathbf{1 7 6}$ in high purity.

Several indolyloxazoles previously isolated from algae and microorganisms have been reported as having interesting biological activities. For example, Martefragin A (177) is a strong inhibitor of lipid peroxidation, ${ }^{188}$ Pimprinine (178) inhibits monoamine oxidase (MAO) and as an anti-epiletic effect, ${ }^{189}$ and WS-30581 A and B (179 and 180) are reported to have inhibitory effects on platelet aggregation. ${ }^{190,191}$ Based on the fact that the synthetic analogue 181 showed stronger activity than the mother compound itself, Nakagawa and co-workers ${ }^{192}$ used a solid-

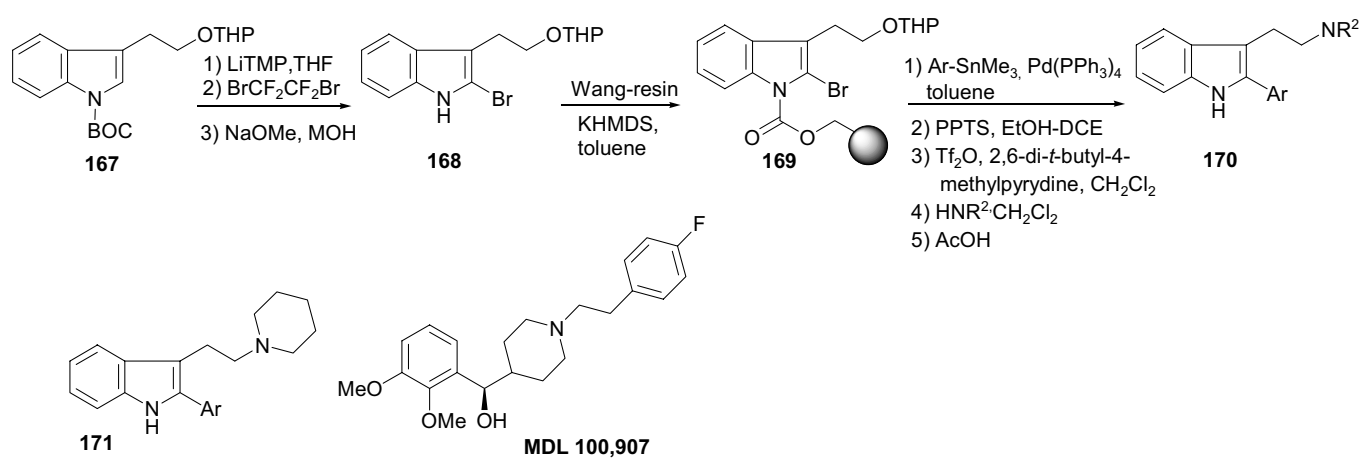

Figure 45. Solid-phase synthesis of tryptophol derivatives.
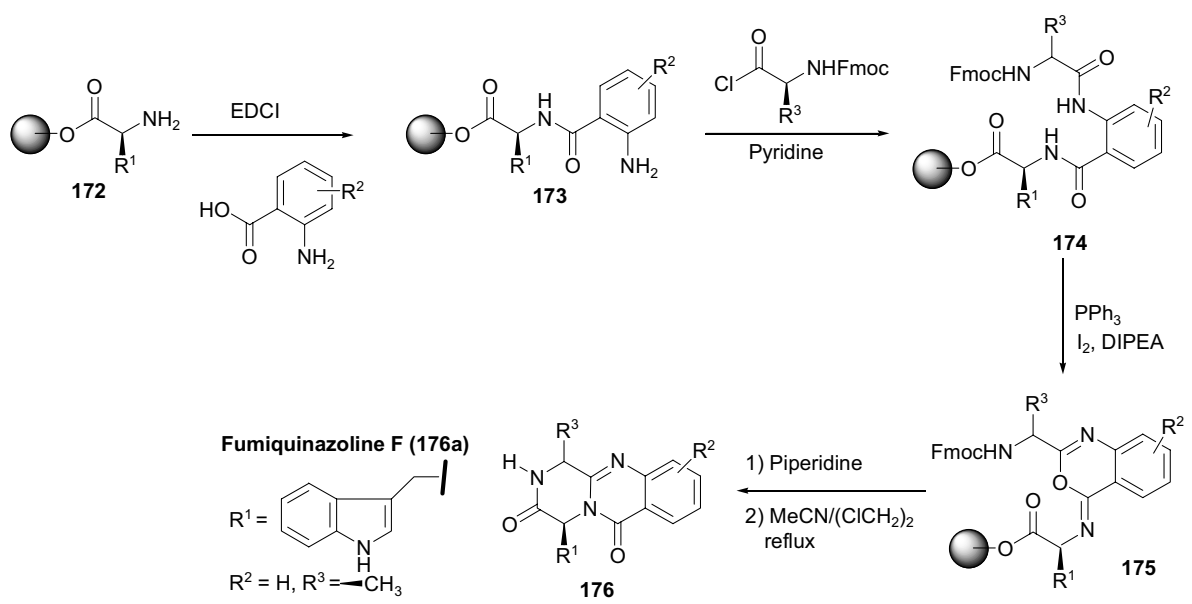

Figure 46. Fumiquinazolines-based library. 


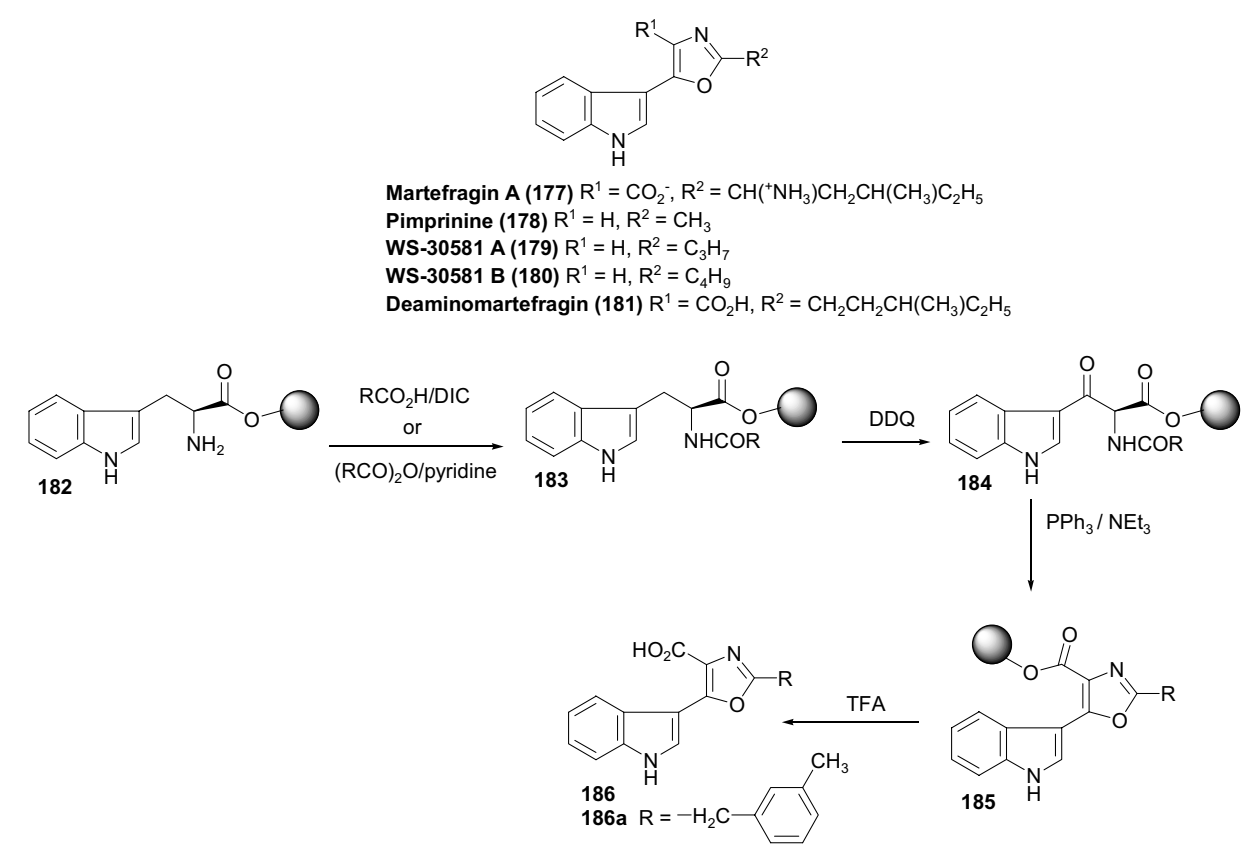

Figure 47. Solid-phase synthesis of 5-(3-indolyl)oxazoles.

phase synthesis to obtain derivatives with the 5-(3indolyl)oxazole skeleton (Figure 47). Resin-bound tryptophan (182) was condensed with a set of six carboxylic acids and two carboxylic anhydrides, and the correspondent acyl derivatives (183) oxidized with DDQ. The ketoesters thus obtained were then reacted with triethylamine and $\mathrm{PPh}_{3}$ to give the indolyl-oxazole compounds 184, which were cleaved from the resin to yield the 8membered library 186. Preliminar results of inhibitory activity against lipid peroxidation using rat liver microsome showed that 186a was the most potent inhibitor among the compounds obtained by this method.

Tetrahydroquinoline alkaloids and its synthetic analogues found a wide range of pharmaceutical and industrial applications which have been recently reviewed. ${ }^{193}$ Besides, their structures offer most of the required properties for a combinatorial scaffold: rigid, having hydrogen bound donor/acceptor sites and aromatic rings. Baudelle et al. ${ }^{194}$ developed a parallel synthesis of polysubstituted tetrahydroquinolines involving threecomponent cycloaddition (aldehydes, amines and alkenes) that could be performed in solution using readily available aldehydes and anilines. The iminium ion initially formed as the key intermediate undergoes cycloaddition reaction with alkenes, that form the third partner in the reaction providing additional diversity. According with the developed strategy and on the basis of the results from qualification studies with a diverse range of building blocks, a lead-seeking library containing 1920 pairs of diastereoisomeric tetrahydroquinolines (187) was prepared under a 96-well plates format, using a high throughput robot starting with 80 aldehydes, 24 anilines and one alkene (2,3-dihydropyran) (Figure 48). A similar methodology for library construction in liquid phase of quinoline derivatives (188), which is based on lanthanide triflate [ $\left.\operatorname{Ln}(\mathrm{OTf})_{3}\right]-$ catalyzed three-component reactions of aldehydes, amines and alkenes, has been developed by Kobayashi and coworkers (Figure 48$).{ }^{195}$ The key is to use $\mathrm{Ln}(\mathrm{OTf})_{3}$ as a Lewis acid catalyst, which is not decomposed during the work-up and purification steps, and is easily separated from products. The authors reported the parallel synthesis of several tetrahydroquinoline derivatives obtained in high yields (83-99\%) and high purities (85-97\%).

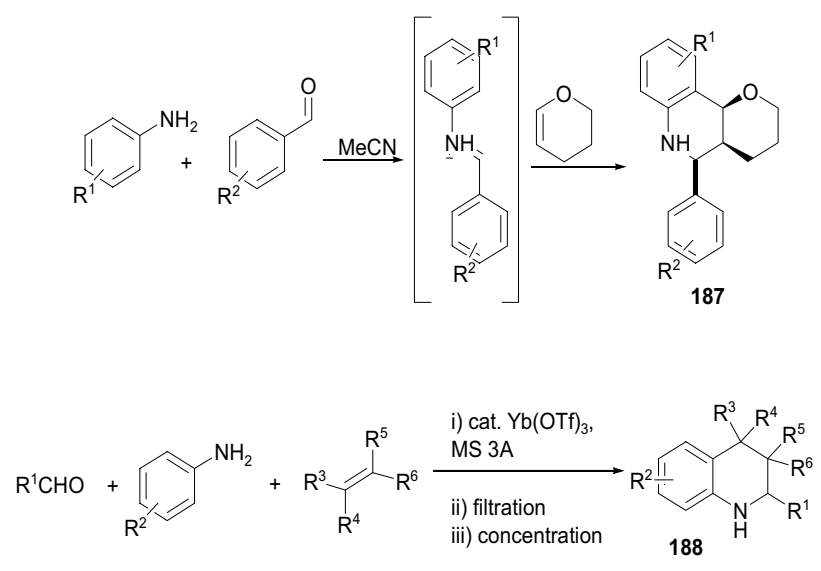

Figure 48. Solution-phase synthesis of polysubstituted tetrahydroquinolines. 
The 2,4-diaminoquinazoline ring system exhibit a wide range of pharmacology, including $\alpha-1 b$ receptor antagonism, ${ }^{196}$ antibacterial activity, ${ }^{197}$ dihydrofolate reductase inhibition ${ }^{198}$ and others. Wilson ${ }^{199}$ proposed a traceless synthesis of these heterocycles which involves the sequential condensation of 2-aminobenzonitriles (190) and amines (191) starting from an acyl isothiocyanate (189) (Figure 49). Following guanidine formation, the cleavage would result in cycloaromatization involving the cyanide group. The libraries were based on nine amines with 2amino-4,5-dimethoxy benzonitrile or eight 2-aminobenzonitriles with morpholine. Best results were obtained with secondary amines while primary amines failed to give the desired products. This procedure was applied to the synthesis of Prazosin, which is used to treat hypertension in man.

Several imidazole alkaloids of marine origin, as naamine $\mathrm{D},{ }^{200}$ leucettamine $\mathrm{A}^{201}$ and leucetatamidine ${ }^{201}$ have proved to possess interesting biological activities, including antifungal and nitric oxide synthase inhibitory activity, leukotriene B4 receptor binding activity, and LTB4 receptor antagonism. Aiming the discovery of new antifungal agents, Saha and co-workers ${ }^{202}$ described a combinatorial chemistry approach to 4-substituted imidazole sulfonamides using 4-formyl-imidazole (193) as the starting material. The imidazole $\mathrm{N}-1$ atom was first attached to support prior to synthesis and cleaved after synthesis, thus allowing for traceless synthesis of target compounds. Reaction with 2-chlorotrityl chloride PS resin in the presence of triethyl amine gave the immobilized aldehyde 194. Reductive amination of resin bound aldehyde with primary amines gave secondary amines $\mathbf{1 9 5}$, which, by coupling with sulfonyl chlorides afforded the sulfonamide products $\mathbf{1 9 6}$, after cleaveage from the resin (Figure 50). Results of antifungal assays indicated compound 197 as the most potent inhibitor of key Candida strains $\left(\mathrm{MIC}<100 \mathrm{nM}\left(\mathrm{nmol} \mathrm{L}^{-1}\right)\right)$.

$(S)$-Mappicine (198) $)^{203}$ and its ketone analogue nothapodytine B (199) ${ }^{204}$ are two tryptophan-derived alkaloids with antiviral activity against herpes viruses (HSV) and human cytomegalovirus (HCMV). ${ }^{205}$ Curran and Frutos $^{206}$ reported the generation of a 128-member library of mapicine analogues (64 racemates) and a 48 member library of nothapodytine B analogues, by solution phase parallel synthesis, based on a radical cascade annulation. The radical cascade strategy to mappicine is summarized in Figure 51. A pyridone D-ring (200) is first alkylated with a suitable propargylating agent bearing the B-ring
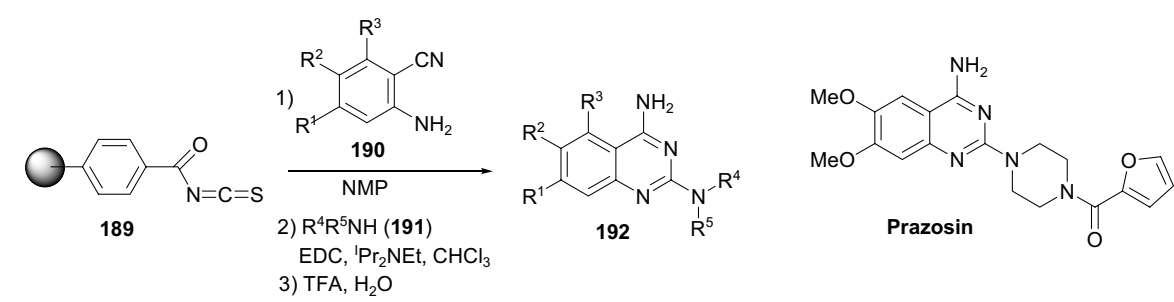

Figure 49. Solid-phase synthesis of 2,4-diamoniquinazolines.

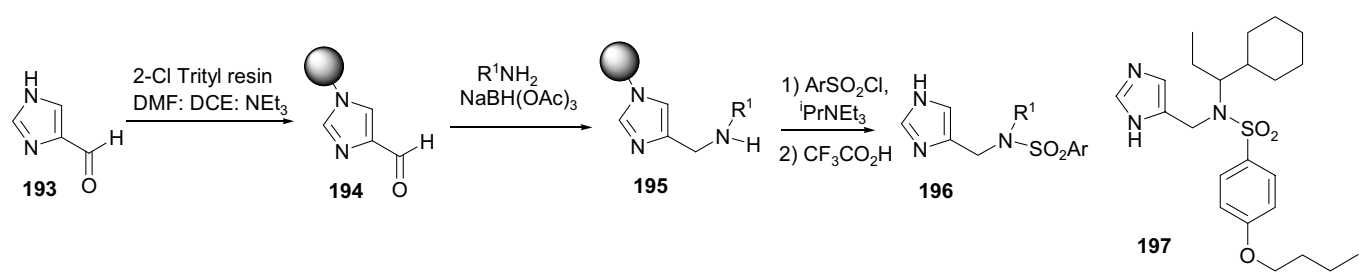

Figure 50. Solid-phase synthesis of $1 H$-imidazole-4-methyl amino sulfonamides.

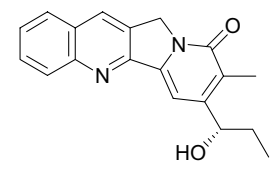

(S)-Mappicine (198)

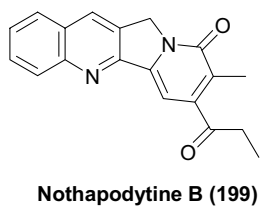

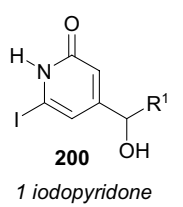

1 iodopyridone

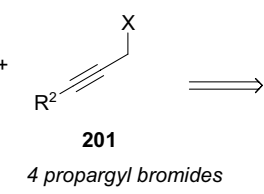

4 propargyl bromides
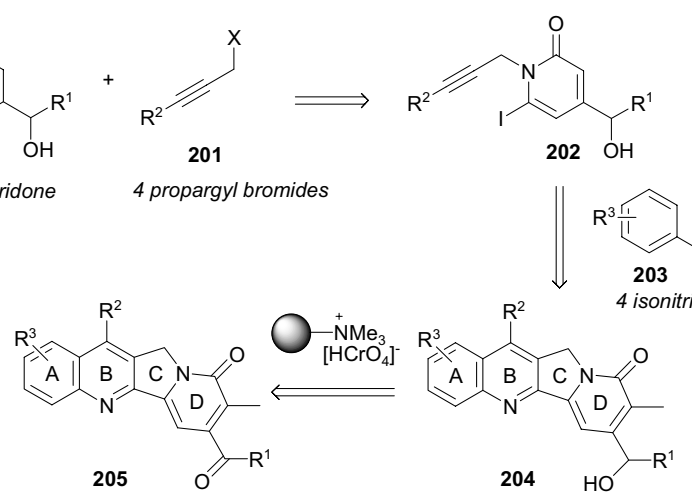

Figure 51. Mappicine-based library. 
substituent (201). Cascade radical annulation with an isonitrile (202) bearing the A-ring substituent then produces the mappicine analogues. The above route was conducted in four separate parallel synthesis experiments in a $4 \times 4 \times 1$ manner by using 4 different isonitriles, 4 different propargyl bromides, and one iodopyridone. Each of the four library experiments with a different iodopyridone employed the same four propargyl bromides and four isonitriles, which resulted in a 4 x 4 x 4 library of 64 mappicine analoges. Racemic iodopyridones were used so the resulting 64 products are racemates. Using the library-from-library concept, mapicine analogues (204) were oxidized to mappicines ketones (205) with a polymersupported chromate reagent.

Synthetic analogues of benzodiazepine alkaloids are an important group of therapeutic agents and constitute a widely prescribed class of psychoactive drugs. ${ }^{207} \mathrm{Houghten}$ and co-workers ${ }^{208}$ described an efficient approach for the parallel solid-phase synthesis of a new class of benzodiazepin derivatives, benzodiazepin-2,3-diones. Starting from $p$-methylbenzhydrylamine resin-bound N-tertbutyloxycarbonyl (Boc) amino acid 206, and after the Boc group was removed, the free amine was reductively alkylated with different substituted $o$-nitrobenzaldehydes in the presence of sodium cyanoborohydride (Figure 52). The resulting secondary amine 207 which was then acylated with methyl chlorooxoacetate to provide 208 . During the nitro group reduction in the presence of tin chloride an in situ intramolecular cyclization occurred allowing the formation of the desired resin bound seven membered ring benzodiazepine $\mathbf{2 0 9}$ that was further cleaved from the resin. Using 40 amino acids (natural and non-natural) and five aldehydes, the authors prepared 200 individual 4,5-dihydro-1 $\mathrm{H}$-1,4-benzodiazepin-2,3-diones using the "tea-bag" methodology. ${ }^{209}$

The tambjamine alkaloids belong to the 4-methoxypyrrolic family of natural products, and are derived from bacterial and marine sources. In the search for new bioactive analogues, Quinn and co-workers ${ }^{210}$ employed the tambjamine natural product $\mathbf{2 1 2}$ as template in the generation of a high-purity enamine library. The aldehyde 212, which is an artefact of the extraction and isolation procedure, was treated with 10 primary amines in ten parallel reactions to afford the enamine salts $\mathbf{2 1 3}$ (Figure 53).

A biomimetic solid-phase synthesis of 2527 compounds based on the Amaryllidaceae alkaloid galanthamine, was reported by Shair and co-workers. ${ }^{211}$ The library synthesis commenced with attachment of a tyrosine derivative to polystyrene beads through a $\mathrm{Si}-\mathrm{O}$ bond, to generate $\mathbf{2 1 5}$ upon deprotection (Figure 54). Reductive amination and protecting-group adjustments produced 216, which was transformed into the phenolic building block 218 by exposure to $\mathrm{PhI}(\mathrm{OAc})_{2}$, followed by Pd-mediated deprotection and spontaneous cyclization. Oriented diversity was then introduced on the core structure $\mathbf{2 1 8}$ by means of four successive reactions: coupling the phenol with five

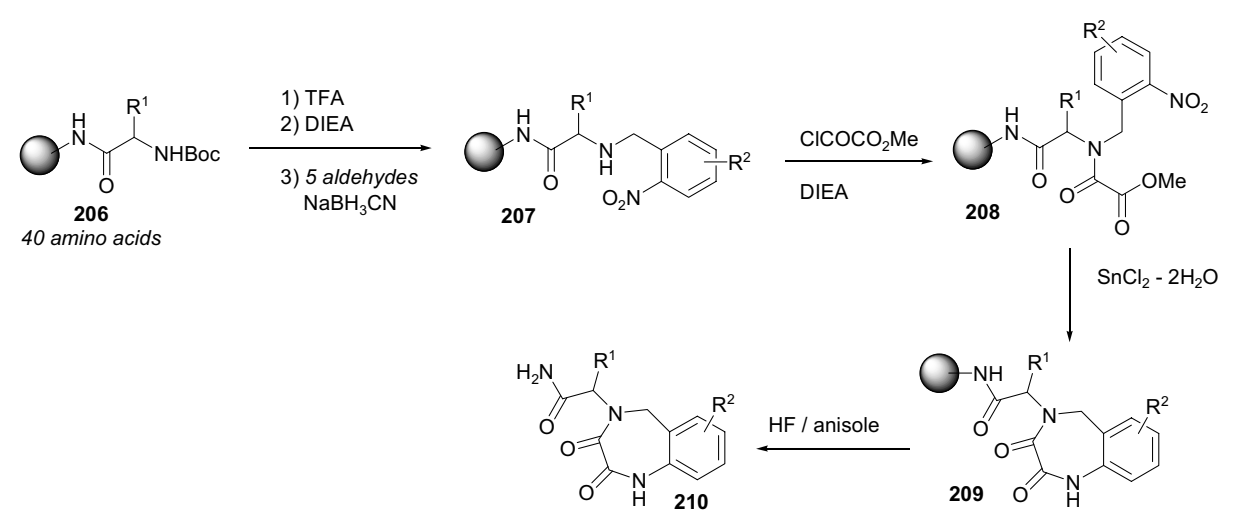

Figure 52. Parallel solid-phase synthesis of 4,5-dihydro-1H-1,4-benzodiazepine-2,3-diones.

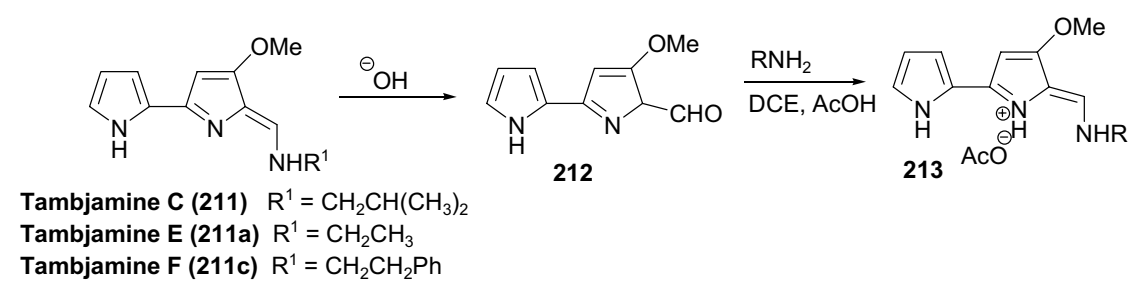

Figure 53. Tambjamine-based enamine library. 


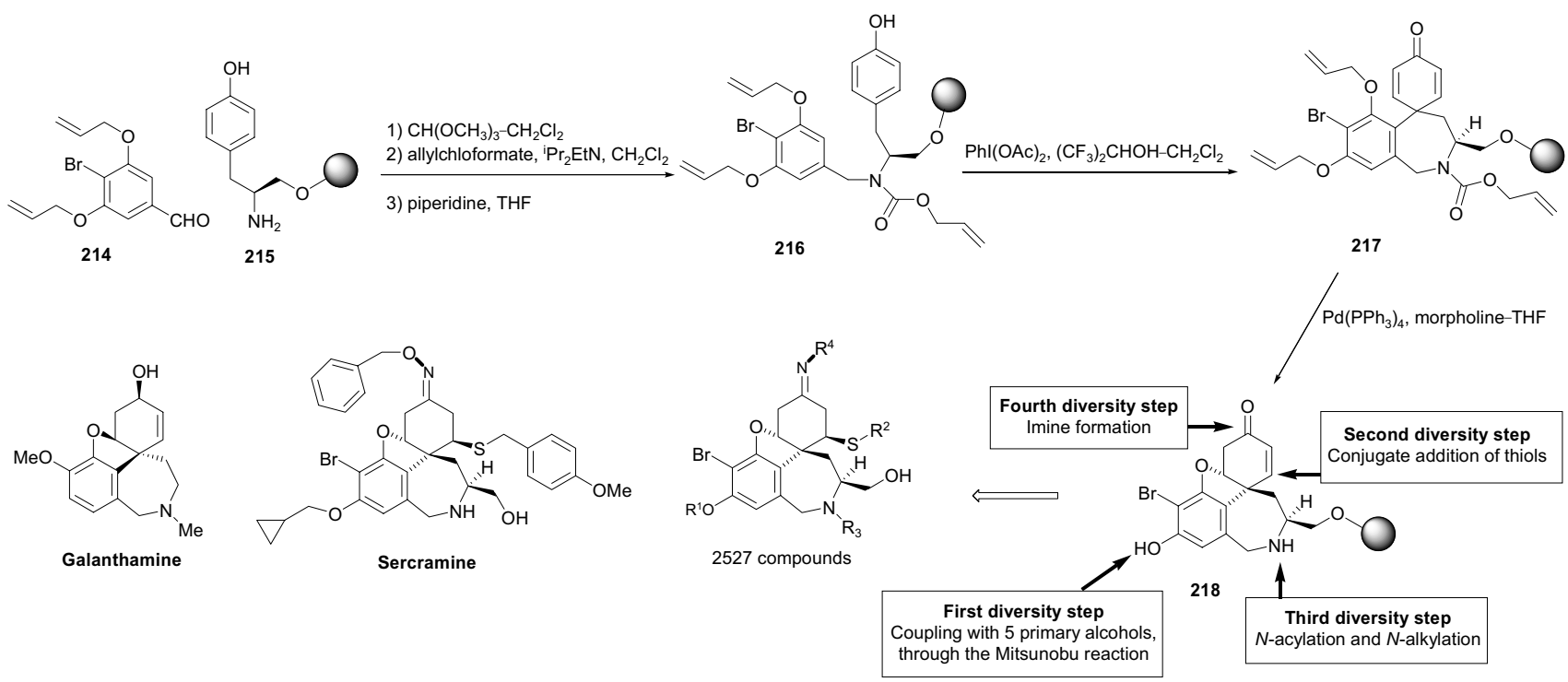

Figure 54. Diversity-oriented synthesis of a galanthamine-based library.

primary alcohols; treatment with thiols in the presence of ${ }^{n} \mathrm{BuLi} ; \mathrm{N}$-acylation or $\mathrm{N}$-alkylation; and treatment with hydrazines and hydroxylamines. Further evaluation of library constituents for their ability to block protein trafficking in the secretory pathway in mammalian cells, led to the discovery of sercramine as a potent inhibitor of the protein VSVG-GFP movement from the Golgi apparatus to the plasma membrane.

\section{Other Natural Products}

A number of other libraries have been reported for natural product analogues of diverse biosynthetic origin.

The adenine derivative olomoucine ${ }^{212}$ was found to inhibit several cyclin dependent kinases, such CDK2cyclin A, a group of enzymes suspected to be implicated in several diseases, including cancer. From the crystal structure of the olomoucine-CDK2 complex, it was reasoned that the diversification of substituents at C-6, C2 , and N-9 of the purine scaffold may allow an improvement in the binding affinity and selectivity with the enzyme. ${ }^{21}$ Aiming this objective, Schultz and co-workers ${ }^{213}$ described a solid-phase approach for the generation of a library of olomoucine analogues, from the purine scaffold 219 coupled to Rink-linker. After acylation of the exocyclic amine using 5 acid chlorides, the second element of diversity was introduced by aromatic substitution on C-6 with 58 amines, yielding 220. Cleavage from the resin afforded a 348-membered library of purine analogs (221) (Figure 55a). One compound was found to possess inhibitory activity 10 times superior to olomoucine. On a different approach, the same authors ${ }^{214}$ attached the purine scaffold $\mathbf{2 2 2}$ to the solid support via the $\mathrm{N}-9$ position (Figure 55b). Mitsunobu alkylation of the C-2 trifluoroacetanilide and aromatic amination at $\mathrm{C}-6$, followed by aminolysis of the trifluoroacetamide and cleavage from the solid support, provided the 2-hydroxyethyl purine analogues 226. Other approaches from 2-fluor-6chloropurine as template led to the discovery of purvalanol B (2-(1R-isopropyl-2-hydroxyethyl-amino)-6-(3-chloro-4carboxyanilino)-9-isopropylpurine), a highly potent (6 $\left.\mathrm{nM}\left(\mathrm{nmol} \mathrm{L} \mathrm{L}^{-1}\right)\right)$ inhibitor of the human CDK2-cyclin A.

Hydantoins constitute a group of L-histidine derivatives which have been isolated from sponges. Several of these small heterocyclic compounds exhibit insecticidal and anticancer activity, ${ }^{214,215}$ which led to the search for new synthetic analogues. Based on the "libraries from libraries" concept, Houghten and co-workers ${ }^{216}$ have developed a synthetic route to the solid-phase synthesis of hydantoin and thiohydantoin compounds and libraries from resin-bound dipeptides 227 (Figure 56). Using 54 different amino acids for the first site of diversity $\left(\mathrm{R}_{1}\right), 60$ different amino acids for the second site of diversity $\left(\mathrm{R}_{3}\right)$ and four different alkyl groups, a library of 38880 compounds has been prepared and examined in a sigma opioid radioreceptor binding assay. The screening results revealed the importance of basic or $N$-benzylated hydrophobic amino acids in the $\mathrm{R}_{1}$ position $\left(\mathrm{IC}_{50}\right.$ values in the 1 to $10 \mu \mathrm{M}\left(\mu \mathrm{mol} \mathrm{L}^{-1}\right)$ range) and $N$-benzylated basic amino acids in the $\mathrm{R}_{2}$ position $\left(\mathrm{IC}_{50}\right.$ values in the $100-500 \mathrm{nM}\left(\mu \mathrm{mol} \mathrm{L}^{-1}\right)$ range). From these results, 12 individual hydantoins were synthesized and tested. The resulting hydantoins showed significant improvement in their binding affinities compared to the mixtures, with two 

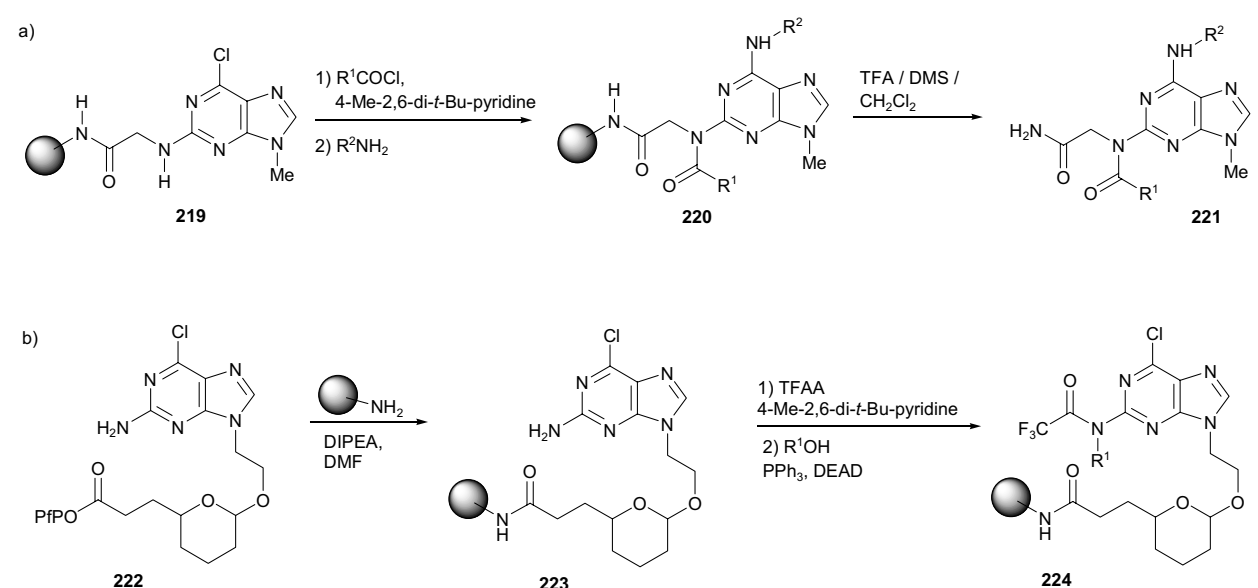<smiles>Nc1nc(Cl)c2ncn(CCOC3CCCC(CCC(=O)NO)O3)c2n1</smiles>

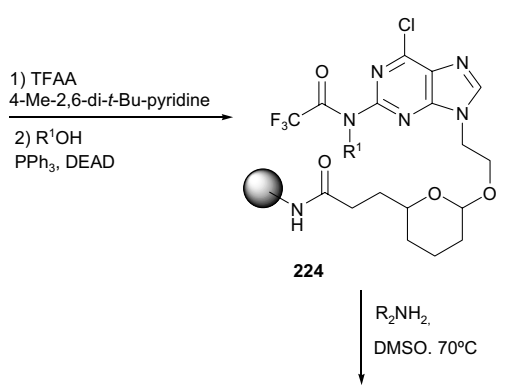<smiles></smiles><smiles>Cc1nc(N)c2ncn(CCO)c2n1</smiles>

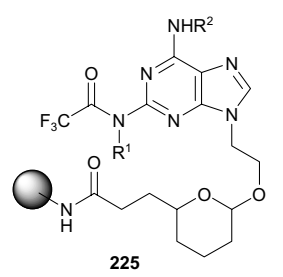

Figure 55. Solid-phase olomucine-related libraries.

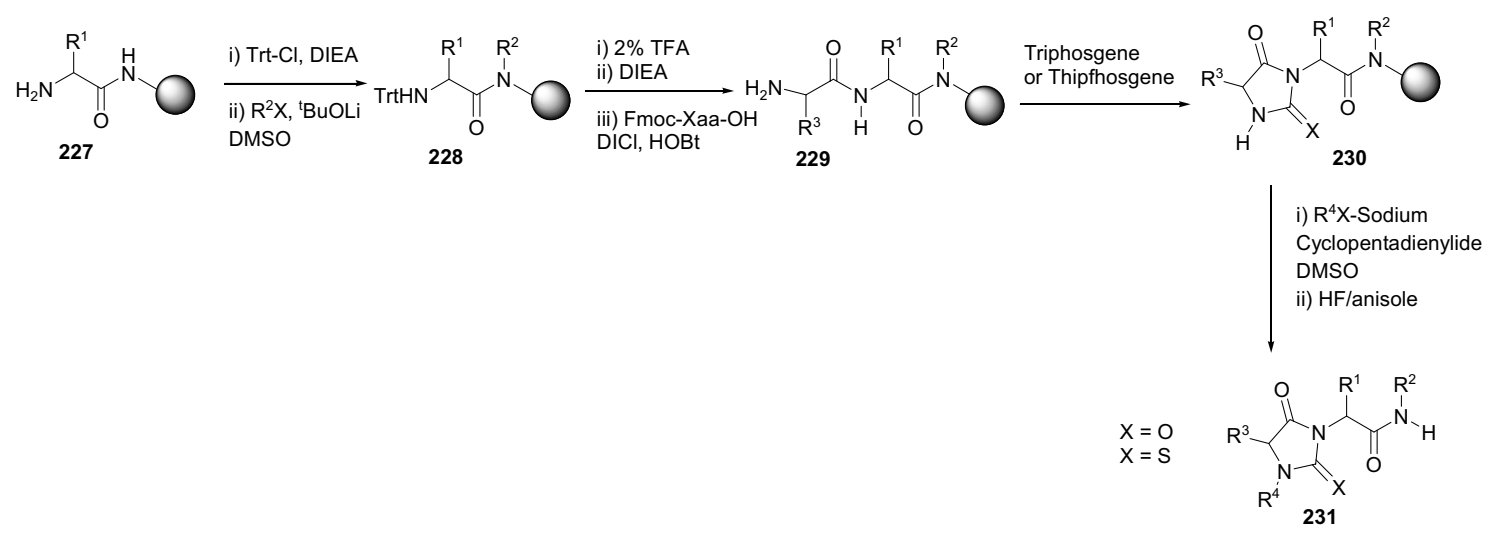

Figure 56.Solid-phase synthesis of hydantoin and thiohydantoin libraries.

of the individual di-alkylated hydantoins having $\mathrm{IC}_{50}$ values close to $60 \mathrm{nM}\left(\mathrm{nmol} \mathrm{L} \mathrm{L}^{-1}\right)$. An identical approach was used in the generation of libraries of other small molecules, such as polyamines, linear and cyclic urea, cyclic thiourea, and bicyclic guanidine. ${ }^{216}$

One of the earliest examples of a natural product based combinatorial library was provided by the solid-phase synthesis of lavendustin A and analogues (Figure 57). ${ }^{217}$ Lavendustin A is a potent tyrosine kinase inhibitor isolated from Streptomyces griseolavendus, ${ }^{218,219}$ whose framework is synthetically accessible from three subunits (X, Y and $\mathrm{Z}$ ), making combinatorial synthesis a useful technique for the generation of a large number of its analogues. Using the carboxyl group of subunit $X$ for resin attachment, subunits $\mathrm{Y}$ and $\mathrm{Z}$ were successively incorporated in $\mathbf{2 3 2}$ to afford a library of 60 lavendustin analogues (234).

Another fungal metabolite with high protein kinase $\mathrm{C}$ inhibiting activity, is balanol, whose solution phase synthesis is well documented. ${ }^{220}$ In the search for analogues with specificity to other kinases, Nielson and Lyngs $\emptyset^{220}$ achieved a combinatorial solid phase synthesis based on the retrosynthetic analysis of balanol (Figure 58). Starting from structural analogues of three key balanol building blocks (mono-protected diacids, protected amino alcohols, 


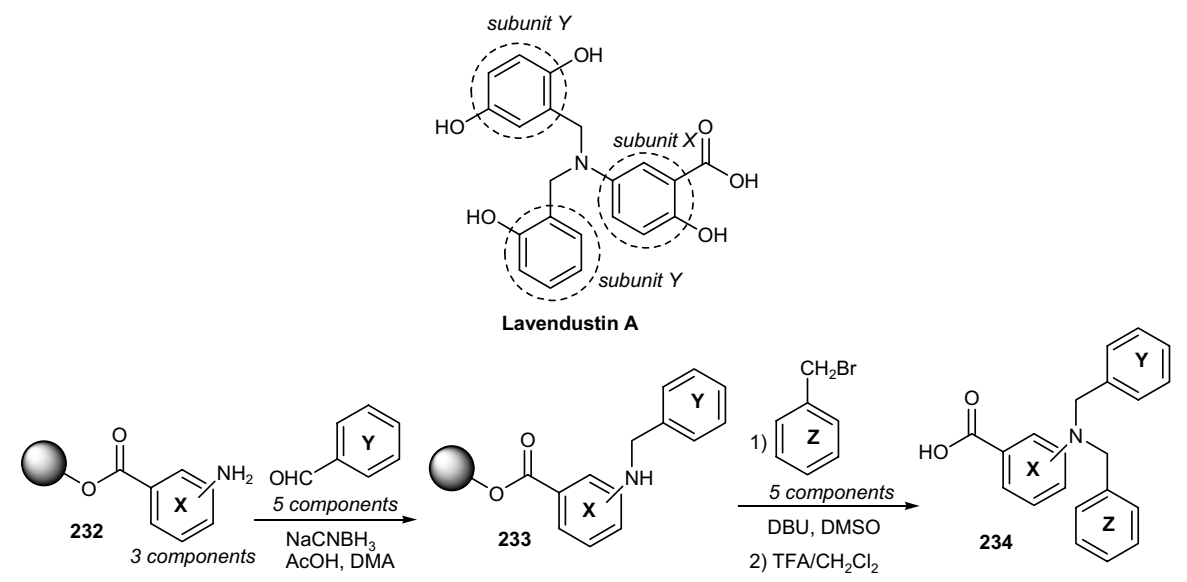

Figure 57. Lavendustin A-based library.

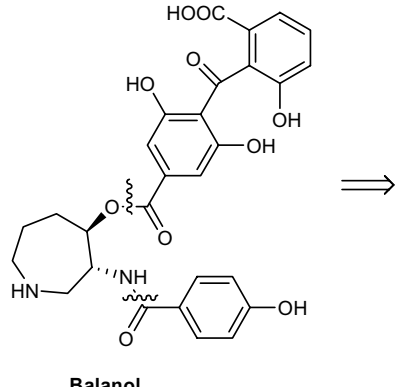

Balanol

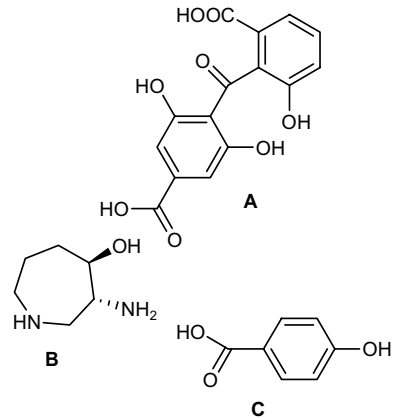

c

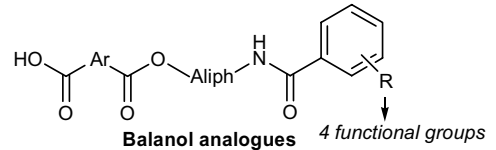

Figure 58. Retrosynthetic analysis of balanol and balanol library.

and benzoic acid derivatives), a library of 36 natural analogues was assembled through routine transformations.

As part of a program to discover new anticancer drugs and antibiotics with novel mechanism of action, Dömling et al. ${ }^{221}$ reported the construction of libraries of aspergillamide analogues using a solution phase Ugi multi component reaction (MCR). ${ }^{222}$ On the basis of the retrosynthetic analysis of aspergillamide, a pool of eight Schiff-bases, four carboxylic acids, and seven isocyanides were selected as MCR building blocks, yielding a 224member library (Figure 59) Some of these compounds, further synthesized on a larger scale, exhibited antibiotic activity, and cytotoxic activity against MCF-7 cells.

The modular structure of philanthotoxins was exploited for construction of the first combinatorial library of these compounds, whose prototype structure is philanthotoxin433 (PhTX-433), a venom constituent of the Egyptien digger wasp Philanthus triangulum. ${ }^{223} \mathrm{PhTX}-433$, as well as some synthetic analogues, were found to antagonize various types

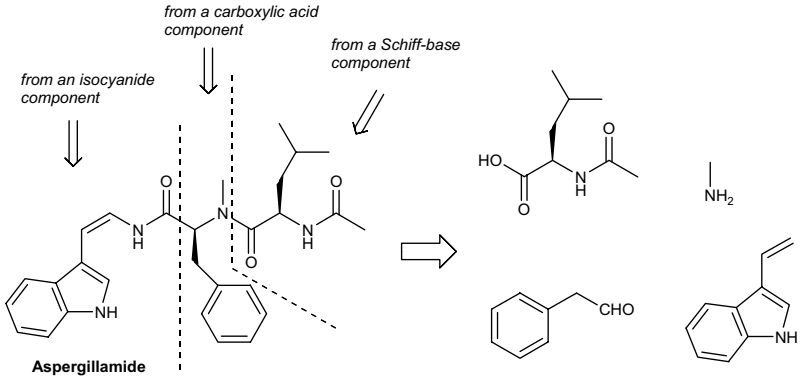

Figure 59. Retrosynthetic analysis of the aspergillamide A.

of nicotinic acetylcoline receptors (nAChRs) and ionotropic glutamate receptors (iGluRs), which led Strømgaard and co-workers ${ }^{224}$ to investigate the effect of structural changes of philanthotoxins in the biological activity. For this purpose, a combinatorial library of philanthotoxin analogues was constructed using ( $S$ )-tyrosine and ( $S$ )-3-hydroxylphenylalanine as amino acid components, spermine, 1,12dodecanediamine, and 4,9-dioxa-1,12-dodecanediamine as amine components, and butanoyl, phenylacetyl, and cyclohexylacetyl as $\mathrm{N}$-acyl groups. The amines were attached to trityl chloride resin and coupled with Fmocprotect amino acids to give the intermediates 236 . Deprotection of the primary amino group and subsequent $\mathrm{N}$-acylation and cleavage from the solid support, yielded the 18-member library $\mathbf{2 3 7}$ (Figure 60).

A solution phase synthesis of a combinatorial library of polyenes based on the natural antibiotic (-)-stipiamide ${ }^{225}$ and its evaluation for reversal of P-glycoprotein mediated multidrug resistance (MDR), has been reported by Andrus et al. ${ }^{226}$ These authors showed that (-)-stipiamide had moderate reversal activity with colchine resistant cells, while its truncated 6,7-dehydro derivative $\mathbf{2 3 8}$ is potent with a variety of drugs with resistant human breast cancer 


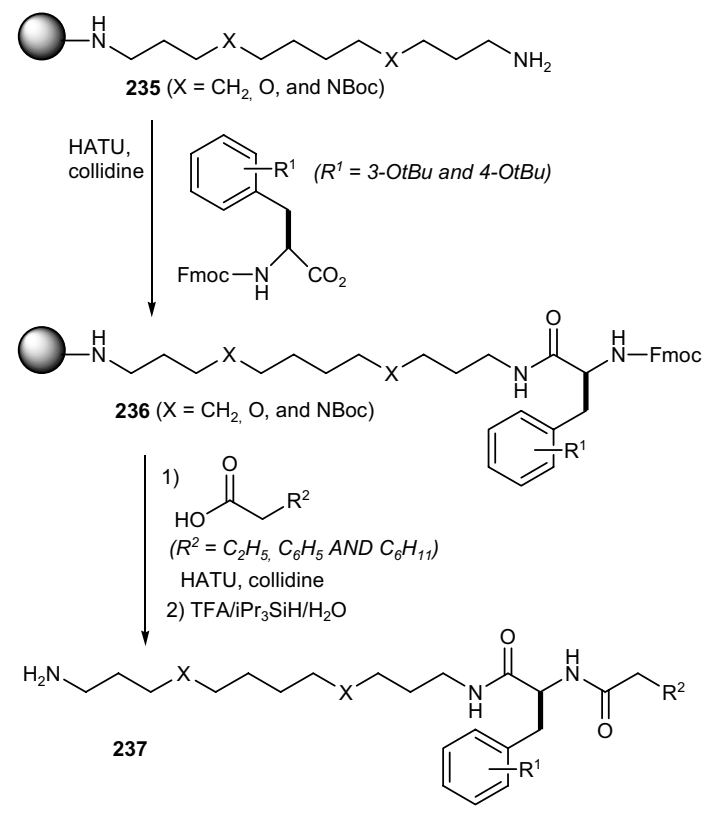

Figure 60. Solid-phase synthesis of philanthotoxin analogues.

MCF7-adrR cells and was found to bind to the Pglycoprotein expressed at the surface of these cells. The two end sites of $\mathbf{2 3 8}$ were chosen as diversification points, to be generated by the assembly of the two sublibraries 239 and 240 via a Sonagoshira cross-coupling reaction (Figure 61). Each individual acetylene reacted with the mixture of six vinyl iodides to create 13 pools indexed in two dimensions for a total of 42 compounds, which were isolated by radial chromatography and tested against MCF7-adrR cells. Library members with $\mathrm{R}=\mathrm{Ph}$ or naphtyl, and $\mathrm{R}^{\prime}$ = alaninol were among the most active ones.

Following the screening of a collection of about 1500 extracts of higher plants against Candida albicans, a group of antifungal neolignans were isolated from extracts of

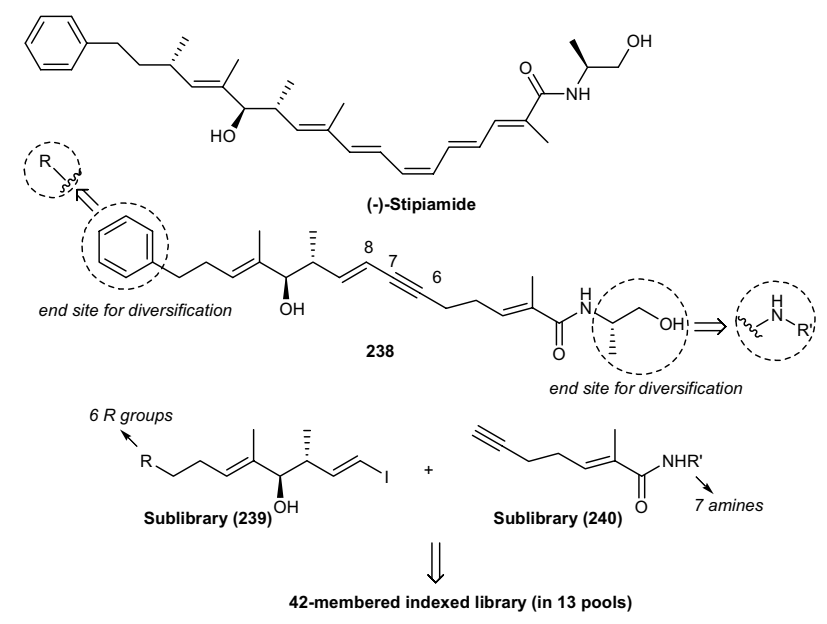

Figure 61. Stipiamide-based library.
Krameria species. One of these compounds, kramerixin, was found to be nearly equivalent in potency in vitro as amphotericin B. ${ }^{227}$ Fecik et al. ${ }^{227}$ prepared a library of 120 analogues of kramerixin by a solution phase strategy where the phenolic moiety $\mathbf{2 4 1}$ and the nature and number of substituents $X$ in $\mathbf{2 4 2}$ were varied. (Figure 62). The key step is the tandem base promoted reaction of acid chlorides 241 with the benzylidenephosphonium-containing phenols 242, which produces an intermediate that reacts by an intramolecular Wittig reaction to form the furan ring. Demethylation of the methoxy groups with $\mathrm{PyBr}-\mathrm{HBr}$ yield the final phenolic compounds 243. Further antifungal screening revealed the presence of several active compounds, with one (the 5,7-dichloro analogue with the conserved 2,4-dihydroxy-phenyl furan substituent) providing improved activity as compared to kramerixin (MIC $1.25 \mu \mathrm{g} / \mathrm{mL}$ vs. $3.12 \mu \mathrm{g} / \mathrm{mL}$ of respiration of $C$. albicans).
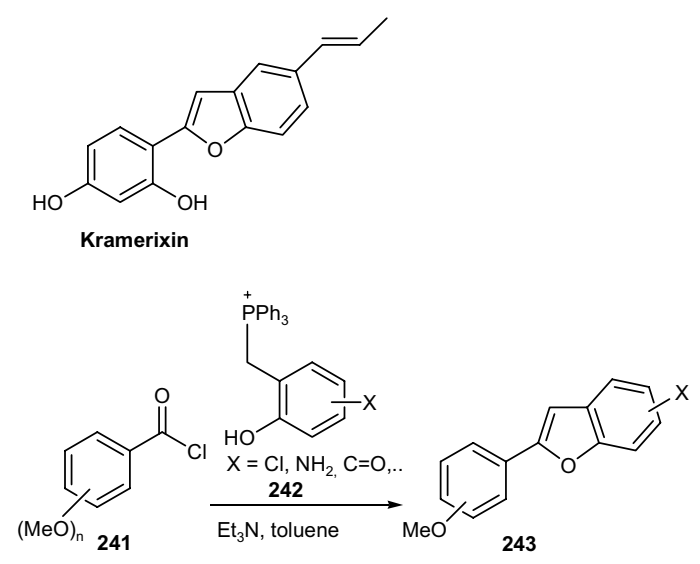

Figure 62. Multiple parallel synthesis of kramerixin and analogues.

The marine natural product curacin $\mathrm{A}^{228}$ is an antimiotic agent that promotes arrest of the cell cycle at $\mathrm{G} 2 / \mathrm{M}$ check point and competitively inhibits the binding of $\left[{ }^{3} \mathrm{H}\right]$ colchicine to tubulin, and it can therefore be considered a colchicine site agent. ${ }^{229}$ Since curacin A binds on the colchicine site on tubulin, and the alkenyl thiazoline moiety of the molecule is largely responsible for the chemical instability of the natural product, Wipf and coworkers ${ }^{229}$ have planned to replace the heterocycle with electron-rich arenes which are reminiscent of the trimethoxyphenyl ring A of colchicine. Furthemore, the homoallylic methyl ether terminus of curacin A was substituted by a broad range of more hydrophilic benzylic alcohols, while keeping the diene unit, which has proven to be essential in SAR studies. In accordance with these structural requirements, a solution-phase library based on curacin A was prepared in three mixtures of six compounds 
by reacting the three key building blocks 244 separately with the lithiated arenes (A-F) (Figure 63). A streamline purification of the benzylic alcohol products 245 was achieved using a fluorous trapping protocol. To this end, the mixture $\mathbf{2 4 5}$ is attached to a vinyl ether tag and extracted with the perfluorinated solvent FC-72.
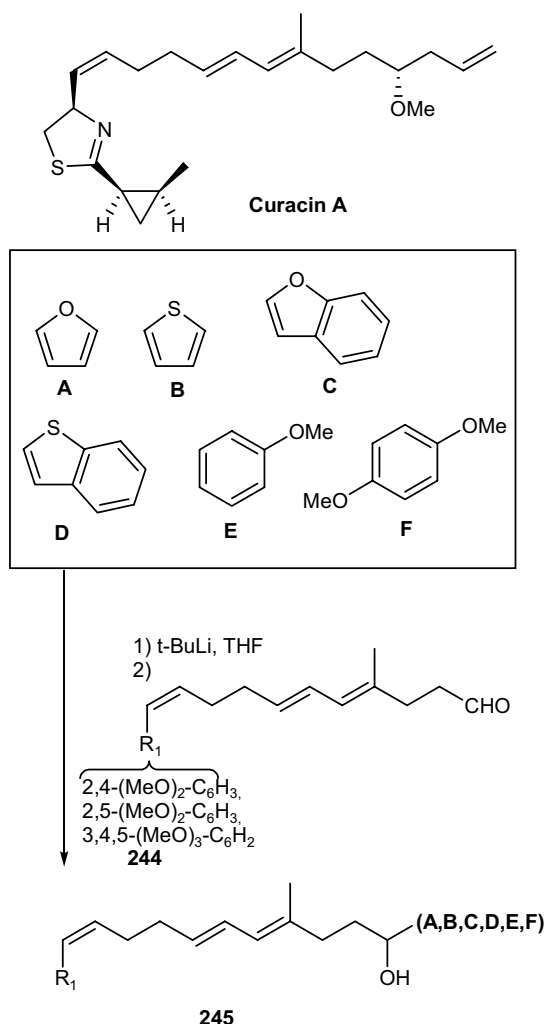

18-membered mixture library (in 3 pools of 6)

Figure 63. Curacin A-based library.
Hydrolysis and elimination of the fluorinated acetal afford the pure final mixtures. The most active of the library components [245, $\left.\mathrm{R}_{1}=3,4,5-(\mathrm{MeO})_{3} \mathrm{C}_{6} \mathrm{H}_{2}\right), \mathbf{B} ; \mathrm{R}_{1}=3,4,5$ $\left.(\mathrm{MeO})_{3} \mathrm{C}_{6} \mathrm{H}_{2}\right), \mathbf{D}$ ] inhibited tubulin polymerization with an $\mathrm{IC}_{50}$ of $c a .1 \mu \mathrm{M}(\mu \mathrm{mol} \mathrm{L}-1)$, showed an average growth inhibition activity $\mathrm{GI}_{50}$ of ca. $250 \mathrm{nM}\left(\mu \mathrm{mol} \mathrm{L}^{-1}\right)$, inhibited colchicine binding to tubulin, and blocked mitotic progression at nanomolar concentrations. These compounds represent some of the most potent synthetic curacin A analogues identified to date but have simplified structures, greater water solubility, and increased chemical stability.

In a recent publication Porco and co-workers ${ }^{230}$ described the preparation of highly functionalised spiroketals with general structure 253 (Figure 64), using a scaffold (248) that is reminiscent of spiroketal subunits found in the spiroketal macrolide antibiotics cytovaricin, spongistatins (altohyrtins), and the rutamycins/oligomycins. The strategy consisted in the introduction of diversity at three sites of spriroketal $\mathbf{2 4 8}$, prepared from condensation of chiral ketone 246 and aldehyde 247. In the first diversity step, ketone $\mathbf{2 4 8}$ was reduced after silyl protection and the resulting secondary alcohol converted to the corresponding $p$-nitrophenyl carbonate 249. Treatment of $\mathbf{2 4 9}$ with three primary amines $\left(\mathrm{R}_{1} \mathrm{NH}_{2}\right)$ yielded carbamates 250. For the incorporation of the second element of diversity $\left(\mathrm{R}_{2}\right)$ onto the spiroketal scaffold, the terminal olefin of $\mathbf{2 5 0}$ was previously converted to acid in three steps by osmylation, oxidative cleavage using $\mathrm{Pb}(\mathrm{OAc})_{4}$, and chlorite oxidation. The second diversity step was then accomplished using amide bond formation. Coupling of acid $\mathbf{2 5 1}$ with three esterified amino acids hydrochlorides gave the amides $\mathbf{2 5 2}$.

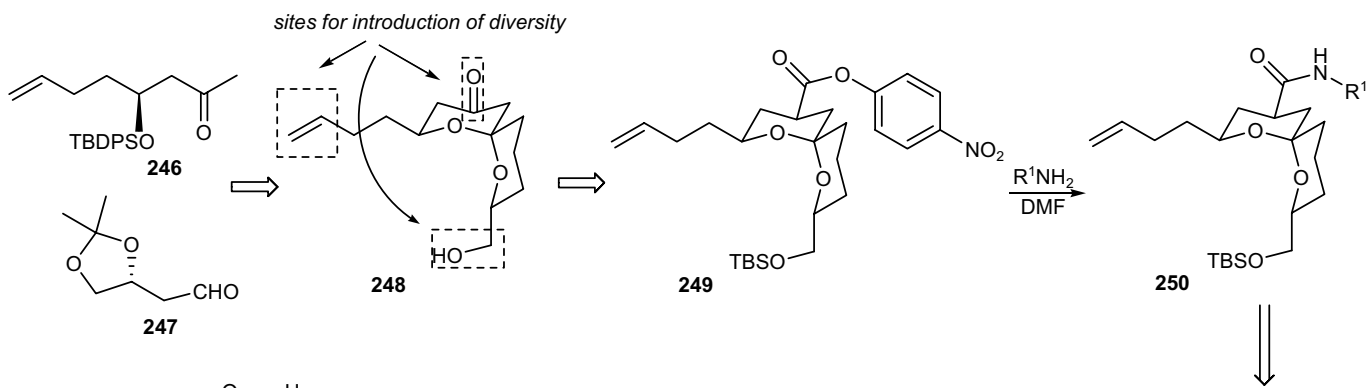<smiles>[R]NC(=O)CCC1CCC2CCOC1CCC(COC(=O)N[R])O2</smiles>

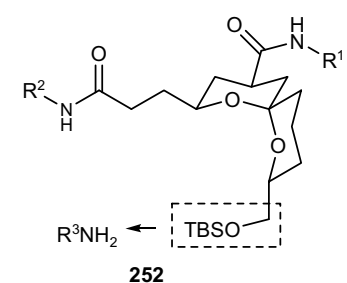

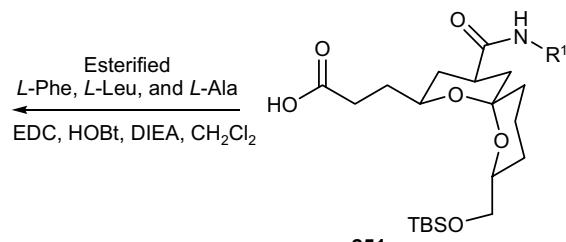

Figure 64. Spiroketal library. 


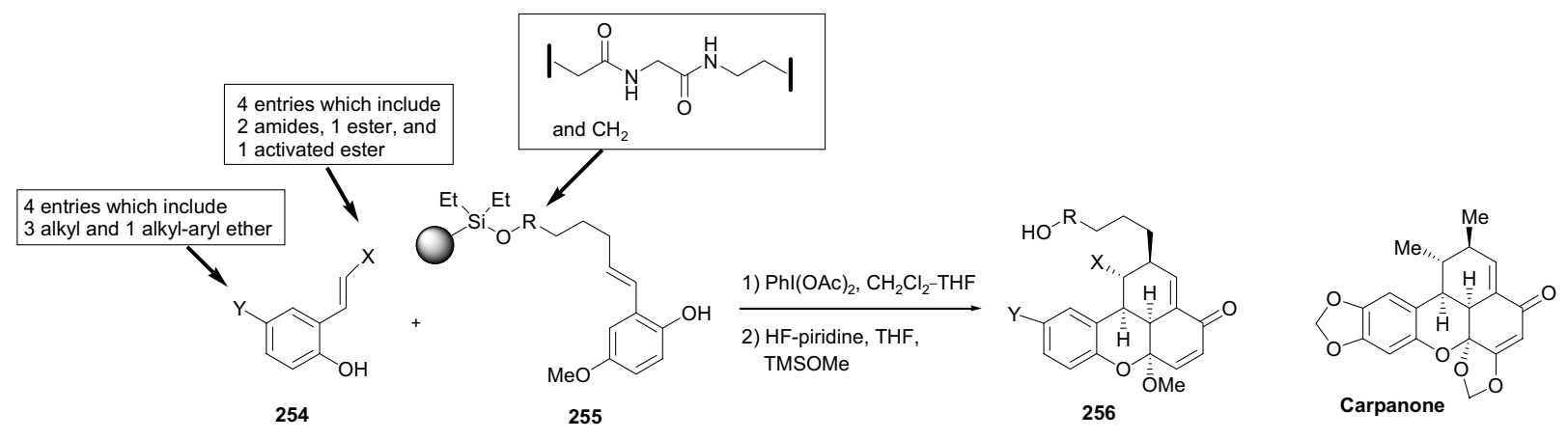

Figure 65. Solid-phase biomimetic synthesis of carpanone-like molecules.

Introduction of the $\mathrm{R}^{3}$ diversity element required silyl deprotection of $\mathbf{2 5 3}$ and carbamate formation of the pendant hydroxymethyl group, via the formation of an intermediate carbazole, which reacted with ten primary amines to generate a 90-membered spiroketal library (253). The evaluation of these compounds as prospective anatagonists of protein-protein interactions is in progress.

Based on the reactions implicated in the biosynthesis of carpanone, a lignan isolated from Cinnamomum species, ${ }^{231}$ Shair and co-workers exploited the generality of the solid-phase biomimetic reaction, aiming the construction of a 100 000-member library of carpanonelike molecules and high-throughput screens. ${ }^{232}$ The outlined strategy involved a solid-phase heterocoupling between electron-deficient phenols $\mathbf{2 5 4}$, with an electronrich phenol immobilized on a silicon-linked resin (255), using $\mathrm{PhI}(\mathrm{OAc})_{2}$ as oxidant (Figure 65). The tetracyclic adducts $\mathbf{2 5 6}$ were obtained as single isomers resulting from complete electronic control during the inverse electron demand Diels-Alder cycloadditions.

\section{Conclusions}

The combinatorial approach to the synthesis and derivatization of natural products, using either solid- or solution-phase methods, has already proved its potential in drug development strategies, including optimisation of lead structures. On the other hand, the introduction of semiautomatic combinatorial synthesis systems using microreactors, radio-frequency tagging and directed sorting, ${ }^{233}$ as well as development of analytical and screening techniques, ${ }^{234-240}$ helped to overpass the immense task of identifying and isolate the bioactive agents from large libraries. More recently, advances in genetic engineering allowed the manipulation of genes involved in microbial biosynthetic pathways, which led to the formation of novel natural-product like molecules, particularly, polyketides and macrolide antibiotics. With the continuing need for novel drug-like lead structures and the difficulty of gaining access to large tracts of biodiversity in natural habitats, combinatorial chemistry of natural products is a promising area to be exploited.

\section{References}

1. Newman, D. J.; Cragg, G. M.; Snader, K. M.; Nat. Prod. Rep. 2000, 17, 215.

2. Harvey, A.; Drug Discov. Today 2000, 5, 294.

3. Grabley, S.; Thiericke, R.; Drug Discovery from Nature, Springer-Verlag: Berlin: Heidelberg, 1999.

4. Grabley, S.; Thiericke, R.; Adv. Biochem. Eng. Biotechnol. 1999, 64, 102.

5. Cragg, G. M.; Newman, D. J.; Snader, K. M.; J. Nat. Prod. 1997, 60, 52.

6. Cordell, G.; Phytochemistry 1995, 40, 1585.

7. Verral, M.; Downstream Processing of Natural Products, John Wiley \& Sons: Chichester, 1996.

8. Gordon, E. M; Kerwin Jr, J. F.; Combinatorial Chemistry and Molecular Diversity in Drug Discovery, Wiley-Liss, Inc: New York, 1998.

9. Beese, K. In Phytochemical Diversity: A Source of New Industrial Products; Wringley, S.; Hayes, M.; Thomas, R.; Chrystal, E., eds.; R. Soc. Chem.: Cambridge, 1997.

10. Devlin, J. P.; High Throughput Screening: The Discovery of Bioactive Substances; Marcel Dekker Inc.: New York, 1997, pp. 3-48.

11. Waterman, P. G. In Advances in Drug Discovery Techniques; Harvey, A. L., ed.; John Wiley \& Sons: Chichester, 1998.

12. Henkel, T.; Brunne, R. M.; Müller, H.; Reichel, F.; Angew. Chem., Int. Ed. 1999, 38, 643.

13. Bertels, S.; Frormann, S.; Jas, G.; Bindseil, K. U. In Drug Discovery from Nature; Grabley, S.; Thiericke, R., eds.; Springer-Verlag:: Berlin, Heidelberg, 1999, pp. 72-105.

14. Wessjohann, L. A.; Curr. Opin. Chem. Biol. 2000, 4, 303.

15. Schröder, F. C.; Farmer, J. F.; Attygalle, A. B.; Smedley, S. R.; Eisner, T.; Meinwald, J.; Science 1998, 281, 428. 
16. Schröder, F. C.; Farmer, J. F.; Smedley, S. R.; Attygalle, A. B; Eisner, T.; Meinwald, J.; J. Am. Chem. Soc. 2000, 122, 3628.

17. Paululat, T.; Tang, Y. -Q.; Grabley, S.; Thiericke, R.; Chimica Oggi 1999, 17, 52.

18. Weber, L.; Curr. Opin. Chem. Biol. 2000, 4, 295.

19. Wilson, L. J. In Solid-Phase Organic Synthesis; Burgess, K., ed.; John Wiley \& Sons, Inc: New York, 2000, pp. 247-267.

20. Thompson, L. A.; Curr. Opin. Biotechn. 2000, 4, 324.

21. Hall, D. G.; Manku, S.; Wang, F.; J. Comb. Chem. 2001, 3, 125.

22. Varki, A.; Glycobiol. 1993, 3, 97.

23. Dwek, R. A.; Chem. Rev. 1996, 96, 683.

24. Sofia, M. J. In Combinatorial Chemistry and Molecular Diversity in Drug Discovery; Gordon, E. M; Kerwin Jr, J. F., eds.; Wiley-Liss, Inc: New York, 1998; pp. 243-269.

25. Zhang, Z.; Ollmann, I. R.; Ye, X. -S.; Wischnat, R.; Baasov, T.; Wong, C. -H.; J. Am. Chem. Soc. 1999, 121, 734.

26. Karlsson, K. -A.; Trends Pharmacol. Sci. 1991, 12, 265.

27. Feizi, T. J.; Curr. Opin. Struct. Biol. 1993, 3, 701.

28. Sharon, N.; Lis, H.; Sci. Am. 1993, 268, 82.

29. Weymouth-Wilson, A. C.; Nat. Prod. Rep. 1997, 14, 99.

30. Bechthold, A.; Fernández, J. A. S. In Combinatorial Chemistry: Synthesis, Analysis, Screening; Jung, G., ed.; Wiley-VCH: Weinheim, 1999; pp. 381-439.

31. Sofia, M. J.; Net. Sci. 1996, http://www.netsci.org/Science/ Combichem/feature12.html Accessed at 2003/07/22.

32. Kahne, D.; Curr. Opin. Chem. Biol. 1993, 1, 130.

33. Arya, P.; Ben, R. N.; Angew. Chem., Int. Ed. 1997, 36, 1280. 34. Wang, Z. G.; Hindsgaul, O.; Glycoimmunol. 1998, 2, 219.

35. Sofia, M. J.; Molec. Div. 1998, 3, 75.

36. Obrecht, D.; Villalgordo, J. M. In Solid-Supported Combinatorial and Parallel Synthesis of Small-Molecular-Weight Compound Libraries - Tetrahedron Organic Chemistry Series, Baldwin, J. E.; Williams, F. R. S. \& R. M., eds.; Pergamon, Elsevier Science: Oxford, 1998, vol. 17.

37. Bunin, B. A.; The Combinatorial Index, Academic Press: San Diego, 1998.

38. Ito, Y., Manabe, S.; Curr. Opin. Chem. Biol. 1999, 2, 701.

39. Osborn, H. M. I.; Khan, T. H.; Tetrahedron 1999, 55, 1807.

40. Schweizer, F.; Hindsgaul, O.; Curr. Opin. Chem. Biol. 1999, 3 , 291.

41. Takuya, K.; Osamu, K.; Trends Glycosci. Glycotechnol. 1999, 11, 267.

42. Edwards, P. J.; Gardner, M.; Klute, W.; Smith, G. F.; Terret, N. K.; Curr. Opin. Curr. Drug Discov. Develop. 1999, 2, 321.

43. Fukase, K.; Kagaku Kogyo 2000, 3, 232. (CA132: 265351)

44. Haase, W. -C.; Seeberger, P. H.; Curr. Org. Chem. 2000, 4, 481.

45. Hilaire, P .M. St.; Meldal, M.; Angew. Chem., Int. Ed. 2000 39,1162

46. Hilaire, P. M. St.; Meldal, M. In Combinatorial Chemistry: Synthesis, Analysis, Screening; Jung, G., ed.; Wiley-VCH Weinheim, 1999; pp. 291-318.
47. Brown, F.; Gund, P.; Maliski, E.; Curr. Opin. Drug. Discov. Develop. 2000, 3, 268

48. Schriemer, D. C.; Hindsgaul, O.; Comb. Chem. High Throughput Screening 1998, 1, 155.

49. Tseng, K.; Hedrick, J. L.; Lebrilla, C. B.; Anal. Chem. 1999, $71,3747$.

50. Barkley, A.; Arya, P.; Chem. Eur. J. 2001, 7, 555.

51. Kanemitsu, T.; Kanie, O.; Comb. Chem. High Throughput Screening 2002, 5, 339.

52. Marcaurelle L. A.; Seeberger P. H.; Curr. Opin. Chem. Biol. 2002, 6, 289.

53. Nicolaou, K. C.; Watanabe, N.; Li, J.; Pastor, J.; Wissinger, N.; Angew. Chem., Int. Ed. 1998, 37, 1159.

54. Wong, C. -H.; Ye, X. -S.; Zhang, Z.; J. Am. Chem. Soc. 1998 , $120,7137$.

55. Christ, W. J.; Asano, O.; Robidoux, A. L. C.; Perez, M.; Wang, Y.; Dubuc; G. R.; Gavin, W. E.; Hawkins, L. D.; McGuiness, P. D.; Mullarkey, M. A.; Lewis, M. D.; Kishi, Y.; Kawata, T.; Bristol, J. R.; Rose, J. R.; Rossignol, D. P.; Kobayashi, S.; Hishinuma, I.; Kimura, A.; Asakawa, N.; Katayama, K.; Yamatsu, I.; Science 1995, 268, 80.

56. Fukase, K.; Liu, W. -C.; Suda, Y.; Oikawa, M.; Wada, A.; Mori, S.; Ulmer, A. J.; Rietschel, E. Th.; Kusumoto, S.; Tetrahedron Lett. 1995, 36, 7455

57. Oikawa, M.; Wada, A.; Yoshizaki, H.; Fukase, K.; Kusumoto, S.; Bull. Chem. Soc. Jpn. 1997, 70, 1435.

58. Fukase, K.; Fukase, Y.; Oikawa, M.; Liu, W. -C.; Suda, Y.; Kusumoto, S.; Tetrahedron 1998, 54, 4033.

59. Liu, W. -C.; Oikawa, M.; Fukase, K.; Suda, Y.; Kusumoto, S.; Bull. Chem. Soc. Jpn. 1999, 72, 1377.

60. Liang, R.; Yan, L.; Loebach, J.; Ge, M.; Uozumi, Y.; Sekanina, K.; Horan, N.; Gildeersleeve, J.; Thompson, C.; Smith, A.; Biswass, K.; Still, W. C.; Kahne, D.; Science 1996, 274, 1520

61. Sofia, M. J.; Allanson, N.; Hatzenbuhler, N. T.; Jain, R.; Kakarla, R.; Kogan, N.; Liang, R.; Liu, D.; Silva, D.; Wang, H.; Gange, D.; Anderson, J.; Chen, A.; Chi, F.; Dulina, R.; Buwen, K. M.; Wang, C.; Baizman, E.; Branstrom, A.; Bristol, N.; Goldman, R.; Han, K.; Longley, C.; Midha, S.; Axelrod, H. R.; J. Med. Chem. 1999, 42, 3193, and references cited therein.

62. Nicolaou, K. C.; Xiao, X. Y.; Parandoosh, Z.; Senyei, A.; Nova, M. P.; Angew. Chem., Int. Ed. 1995, 34, 2289.

63. Simanek; E. E.; McGarvey, G. J.; Jablonnowski, J. A.; Wong, C. -H.; Chem. Rev. 1998, 98, 833.

64. Sutherlin, D. P.; Stark, T. M.; Hughes, R.; Armstrong, R. W.; J. Org. Chem. 1996, 61, 8350

65. Tsai, C. Y.; Park, W. K. C.; Schmidt, G. W.; Ernst, B.; Wong, C. H.; Bioorg. Med. Chem. 1998, 8, 2333.

66. Ugi, I.; Angew. Chem., Int. Ed. 1982, 21, 810.

67. Wong, C. H.; Hendrix, M.; Manning, D. D.; Rosenbohn, C.; Greenberg, W. A.; J. Am. Chem. Soc. 1998, 120, 8319.

68. Park, W. K. C.; Auer, M.; Jaksche, H.; Wong, C. H.; J. Am. Chem. Soc. 1996, 118, 10150. 
69. Sun, C. -M.; Comb. Chem. High Throughput Screening 1999, $2,299$.

70. Hallis, T. M.; Liu, H. -W.; Acc. Chem. Res. 1999, 32, 579.

71. Izumi, M.; Ichikawa, Y.; Tetrahedron Lett. 1998, 40, 2849.

72. Callus, C.; Opatz, T.; Wunberg, T.; Schmidt, W.; Henke, S.; Kunz. H.; Tetrahedron Lett. 1999, 40, 2783.

73. Hirschmann, R.; Sprengler, P. A.; Kawasaki, T.; Leahy, J. W.; Shakespeare, W. C.; Smith, A. B.; Tetrahedron 1993, 40, 3665.

74. Jerini BioTools.; http://www.jerini.de/products/kombinat.htm. Accessed at 2000/09/21.

75. Tremblay, M. R ; Poirier, D.; J. Comb. Chem. 2000, 2, 48.

76. Maltais, R.; Tremblay, M. R ; Poirier, D.; J. Comb. Chem. 2000, 2, 604.

77. Hijikuro, I.; Doi, T.; Takahashi, T.; J. Am. Chem. Soc. 2001, $123,3717$.

78. Chen, S.; Janda, K. D.; J. Am. Chem. Soc. 1995, 119, 8724.

79. Chen, S.; Janda, K. D.; Tetrahedron Lett. 1998, 39, 3943.

80. Thompson, L. A.; Moore, F. L.; Moon, Y. -C.; Ellman, J. A.; J. Org. Chem. 1998, 63, 2066.

81. Watson, C.; Angew. Chem., Int. Ed. 1999, 38, 1903.

82. Suzuki, M.; Morita, Y.; Koyano, M.; Noyori, R.; Tetrahedron 1990, 46, 4809.

83. Lee, K. J.; Angulo, A.; Ghazal, P.; Janda, K. D.; Org. Lett. 1999, $1,1859$.

84. Alali, F. Q.; Liu, X. X.; McLaughin, J. L.; J. Nat. Prod. 1999, $62,504$.

85. Keinan, E.; Anjana, S.; Ahmad, Y.; Santosh, C.; Sinha, S. C.; Pure Appl. Chem. 1997, 69, 423.

86. Chang, Y. -T.; Choi, J.; Ding, S.; Prieschi, E. V.; Baumruker, T.; Lee, J. -M.; Chung, S. -K.; Schultz, P. G.; J. Am. Chem. Soc. 2002, 124, 1856.

87. Nicolaou, K. C.; Winssinger, N.; Vourloumis, D.; Ohshima, T.; Kim, S.; Pfefferkorn, J.; Xu, J. -Y.; Li, T.; J. Am. Chem. Soc. 1998, 120, 10814.

88. O’Hagan, D.; Nat. Prod. Rep. 1995, 12, 1.

89. Rawlings, B. J.; Nat. Prod. Rep. 1999, 16, 425.

90. Borchardt, J. K.; Modern Drug Discov. 1999, $2,22$.

91. Bentley, R.; Bennett, J. W.; Annu. Rev. Microbiol. 1999, 53, 411.

92. Tsoi, C. J.; Khosla, C.; Chem. Biol. 1995, 2, 355.

93. Fu, H.; Khosla, C.; Molecular Diversity 1996, 14, 335.

94. Stauton, J.; Curr. Opin. Chem. Biol. 1998, 2, 339.

95. Hutchinson, C. R. In Drug Discovery from Nature; Grabley, S.; Thiericke, E. eds.; Springer-Verlag: Berlin, Heidelberg, 1999; pp. 233-254.

96. Khosla, C.; Chemtr. Org. Chem. 1998, 11, 1.

97. Paterson, I.; Donghi, M.; Gerlach, K.; Angew. Chem., Int. Ed. 2000, 39, 18.

98. Misske A. M; Hoffmann, H. M. R.; Angew. Chem., Int. Ed. 2000, 6, 3313.

99. Curran, D. P.; Furukawa, T.; Org. Lett. 2002, 4, 2233.
100. Lowe, G.; Nat. Prod. Rep. 1999, 16, 641.

101. Khosla, C. In Combinatorial Chemistry and Molecular Diversity in Drug Discovery; Gordon, E. M; Kerwin Jr, J. F., eds.; Wiley-Liss, Inc: New York, 1998; pp. 401-417.

102. Reynolds, K. A.; Proc. Natl. Sci. USA 1998, 95, 12744.

103. Nicolaou, K. C.; Winssinger, N.; Pastor, J.; Murphy, F.; Angew. Chem., Int. Ed. 1998, 37, 2534.

104. Nicolaou, K. C; Winssinger, N; T.; Pastor, J.; Ninkovic, S.; Sarabia, F.; He, Y.; Vourloumis, D.; Yang, Z.; Li, T.; Giannakakou, P.; Hamel, E.; Nature 1997, 387, 268.

105. Nicolaou, K. C; Roshangar, F.; Vourloumis, D.; Angew. Chem., Int. Ed. 1998, 37, 2014.

106. Nicolaou, K. C.; Sorensen, E. J.; Winssinger, N.; J. Chem. Educ. 1998, 75, 1226.

107. Nicolaou, K. C; Vourloumis, D.; Li, T.; Pastor, J.; Winssinger, N.; He, Y.; Ninkovic, S.; Sarabia, F.; Vallberg, H.; Roschangar, F.; King, N.; Finlay, M. R. V.; Giannakakou, P.; Verdier-Pinard, P.; Hamel, E.; Angew. Chem., Int. Ed. 1997, 36, 2097.

108. Nicolaou, K. C; Boddy, C. N. C.; Bräse, S.; Winssinger, N.; Angew. Chem., Int. Ed. 1999, 38, 2096.

109. Mink, D.; Mecozzi, S.; Rebek Jr, J.; Tetrahedron Lett., 1998, 39, 5709.

110. Somogyi, L.; Haberhauer, G.; Rebek, Jr., J.; Tetrahedron, 2001, $57,1699$.

111. Marsh, I. R.; Bradley, M.; Teague, S. J.; J. Org. Chem. 1997, 62,6199

112. Tong, G.; Nielsen, J.; Bioorg. Med. Chem. 1996, 4, 693.

113. Seneci, P.; Sizemore, C.; Islam, K.; Kocis, P.; Tetrahedron Lett. 1996, 37, 6319.

114. Gao, Y.; Nat. Prod. Rep. 2002, 19, 100.

115. Xu, R.; Greiveldinger, G.; Marenus, L. E.; Cooper, A.; Ellman, J. A.; J. Am. Chem. Soc. 1999, 121, 4898.

116. Kiselyov, A. S.; Eisenberg, S.; Luo, Y.; Tetrahedron Lett. 1999, 40,2465

117. Gordeev, M. F.; Luehr, G. W.; Hui, H. C.; Gordon, E. M.; Patel, D. V.; Tetrahedron 1998, 54, 15879.

118. De Amici, M.; De Micheli, C. D.; Cateni, F.; Carrea, G.; Ottolina, G.; Tetrahedron: Assymetry 1993, 4, 1073.

119. Gale, I. F.; Cunclife, E.; Reynolds, P. E.; Richmond, M. H.; Warimng, M. J.; The Molecular Basis of Antibiotic Action, John Wiley \& Sons: London, 1981, p. 65.

120. Nozaki, Y.; Katayama, N.; Ono, H.; Tsubotani, S.; Nozaki, Y.; Katayama, N.; Okazaki, H.; Nakao, Y.; Nature 1987, 325, 179 .

121. Nozaki, Y.; Katayama, N.; Nozaki, Y.; Katayama, N.; Ono, H.; Okazaki, H.; J. Antibiot. 1989, 42, 84.

122. Suda, A.; Ohta, A.; Sudoh, M.; Tsukuda, T.; Shimma, N.; Heterocycles 2001, 551023.

123. Müller, G.; Giera, H.; J. Computer-Aided Mol. Des. 1998, 12, 1 .

124. Itokawa, H.; Takeya, K.; Heterocycles 1993, 351467. 
125. Arcamone, F.; Penco, S.; Orezzi, P.; Nicolella, V.; Pirelli, A.; Nature 1964, 203, 1064.

126. Dale, D. L.; Fink, B. E.; Hedrick. J. L.; J. Am. Chem. Soc. 2000, 122, 6382

127. Kingston, D. G. I.; J. Nat. Prod. 2000, 63, 726.

128. Kingston, D. G. I.; Chem. Comm. 2001, 867.

129. Xiao, X. -Y.; Parandoosh, Z.; Nova, M. P.; J. Org. Chem. 1997, 62, 6029.

130. Bhat, L.; Liu, Y.; Victory, S. F.; Himes, R. H.; Georg, G. I.; Bioorg. Med. Chem. Lett. 1998, 8, 3181.

131. Liu, Y.; Ali, S. M.; Boge, T. C.; Georg, G. I.; Victory, S.; Zygmunt, J.; Marquez, R. T.; Himes, R. H.; Comb. Chem. High Throug. Screen. 2002, 5, 39.

132. Jagtap, P. G.; Baloglu, E.; Barron, D. M.; Bane, S.; Kingston, D. G. I.; J. Nat. Prod. 2002, 65, 1136.

133. D’Ambrosio, M.; Guerriero, A.; Pietra, F.; Helv. Chim. Acta 1987, 70, 2019.

134. D’Ambrosio, M.; Guerriero, A.; Pietra, F.; Helv. Chim. Acta 1988, 71, 964.

135. Schiff, P. B.; Fant, J.; Horwitz, S. B.; Nature 1979, 277, 665.

136. Ciomei, M.; Albanese, C.; Pastori, W.; Grandi, M.; Pietra, F.; D’Ambrosio, M.; Guerriero, A.; Battistini, C.; Proc. Am. Cancer Res. 1997, 38, 5, Abstract 30.

137. Nicolaou, K. C.; Xu, J. -Y.; Kim, S.; Oshima, T.; Hosokawa, S.; Pfefferkorn, J.; J. Am. Chem. Soc. 1997, 119, 11353.

138. Nicolaou, K. C.; Winssinger, N.; Vourloumis, D.; Ohshima, T.; Kim, S.; Pfefferkorn, J.; Xu, J. -Y.; Li, T.; J. Am. Chem. Soc. 1998, 120, 10814.

139. Amroyan, E.; Gabrielian, E.; Panossian, A.; Wikman, G.; Wagner, H.; Phytomedicine 1999, 6, 27.

140. Biabani, M. A. F; Grover, R. K; Singh, S. K.; Kumar, S.; Raj, K.; Roy, R.; Kundu, B.; Tetrahedron Lett. 2001, 42, 7119.

141. Otsuka, H.; Fujioka, S.; Komiya, T.; Goto, M.; Hirmatsu, Y.; Fiujimura, H.; Chem. Pharm. Bull. 1981, 20, 3099.

142. Mayaux, J. -F.; Bousseau, A.; Pauwels, R.; Huet, T.; Henin, Y.; Dereu, N.; Evers, N.; Doler, F.; Paoujade, C.; Clercq, E. D.; Le Pecq, J. -B.; Proc. Natl. Acad. Sci. U.S.A. 1993, 91, 3564

143. Bringmann, G.; Saeb, W.; Akeassi, L.; Francois, G.; Narayanan, A. S. S.; Peters, K.; Peters, E. -M.; Planta Med. 1997, 63, 255.

144. Soler, F.; Paoujade, C.; Evers, M.; Carry, J. C.; Henin, Y.; Bousseau, A.; Pauwels, R.; De Clercq, E.; Le Pecq, J. -B.; Dereu, N.; J. Med. Chem. 1996, 39, 1069.

145. Evers, M.; Paoujade, C.; Soler, F.; Ribeil, Y.; James, C.; Lelievre, Y.; Gueguen, J. -C.; Reisdorf, D.; Morize, I.; Pauwels, R.; De Clercq, E.; Henin, Y.; Bousseau, A.; J. Med. Chem. 1996, 39, 1056.

146. Pathak, A.; Singh, S. K.; Biabani, M. A. F; Kulshreshtha, D. K.; Puri, S. K.; Srivastava, S.; Kundu, B.; Comb. Chem. High Throughput Screening 2002, 5, 241.

147. Gunasekera, S. P.; McCarthy, P. J.; Kelly-Borges, M.; Lobkovsky, E.; Clardy, J.; J. Am. Chem. Soc. 1996, 118, 8759
148. Corey, E. J.; Roberts, B. R.; J. Am. Chem. Soc. 1997, 119 , 12425.

149. Brohm, D.; Metzger, S.; Bhargava, A.; Müller, O.; Lieb, F.; Waldmann, H.; Angew. Chem., Int. Ed. 2002, 41, 307.

150. Nicolaou, K. C.; Pfefferkorn, J. A.; Cao. G.-Q.; Angew. Chem., Int. Ed. 2000, 39, 734.

151. Nicolaou, K. C.; Pfefferkorn, J. A.; Roecker, A, J.; Cao. G. -Q.; Barluenga, S.; Mitchell, H. J.; J. Am. Chem. Soc. 2000, 122, 9939

152. Evans, B. E.; Rittle, K. E.; Bock, M. G.; Di Pardo, R. M.; Freidinger, R. M.; Whitter, W. L.; Lundell, G. F.; Veber, D. F.; Anderson, P. S.; Chang, R. S.; Lotti, V. J.; Cerino, D. J.; Chen, T. B.; Kling, P. J.; Kunkel, K. A.; Springer, J. P.; Hirshfield, J.; J. Med. Chem. 1998, 31, 2235.

153. Fang, N; Casida, J. E.; Proc. Natl. Acad. Sci. U.S.A. 1998, 95 , 3380 .

154. Fang, N; Casida, J. E.; J. Nat. Prod. 1999, 62, 205.

155. Parmar, V. S.; Bracke, M. E.; Philippe, J.; Wengel, J.; Jain, S. C.; Olsen, C. E.; Bisht. K. S.; Sharma, N. K.; Courtens, A.; Sharma, S. K.; Vennekens, K.; Van Marck, V.; Singh, S. K.; Kumar, N.; Kumar, A.; Malhotra, S.; Kumar, R.; Rajwanshi, V. K.; Jain, R.; Mareel, M. M.; Bioorg. Med. Chem. 1997, 5 , 1609.

156. Gunatilaka, A. A. L.; Kingston, D. G. I.; Wijertne, E. M. K.; Bandara, B. M. R.; Hofmann, G. A.; Johnson, R. K.; J. Nat. Prod. 1994, 57, 518.

157. Bandara, B. M. R.; Gunatilaka, A. A. L.; Wijertne, E. M. K.; Mcleod, J. K.; Phytochemistry 1990, 29, 297.

158. Nicolaou, K. C.; Xiao, X. -Y.; Parandoosh, Z.; Senyei, A.; Nova, M. P.; Angew. Chem., Int. Ed. 1995, 34, 2289.

159. Moran, E. J.; Sarshar, S.; Cargill, J. F.; Shahbaz, M. J. M.; Lio, A.; Mjalli, A. M. M.; Armstrong, R. W.; J. Am. Chem. Soc. 1995, 117, 10787.

160. Ahmed, A. A.; Abou-Douh, A. M.; Mohamed, A. E. H. H.; Hassan, M. E.; Karschesy, J.; Planta Med. 1999, 65, 171

161. Nicolaou, K. C.; Pfefferkorn, J. A.; Mitchell, H. J.; Roecker, A. J.; Barluenga, S.; Cao. G. -Q.; Affleck, R. L.; Lillig, J. E.; J. Am. Chem. Soc. 2000, 122, 9954.

162. Wuerzberger, S. M.; Pink, J. J.; Planchon, S. M.; Byers, K. L.; Bornmann, W. G.; Boothman, D. A.; Cancer Res. 1998, 58 , 1876.

163. Li, C. J.; Li, Y. -Z.; Pinto, A. V.; Pardee, A. B.; Proc. Natl. Acad. Sci. U.S.A. 1999, 96, 13359.

164. Xie, L.; Takeuchi, Y.; Cosentino, M.; Lee, K. -H.; J. Med. Chem. 1999, 42, 2662

165. Nicolaou, K. C.; Pfefferkorn, J. A.; Barluenga, S.; Mitchell, H. J.; Roecker, A. J.; Cao. G. -Q.; J. Am. Chem. Soc. 2000, 122, 9968.

166. Ostrech, J. M.; Husar, G. M.; Blondelle, S. E.; Dörner, B.; Weber, P. A.; Houghten, R. A.; Proc. Natl. Acad. Sci. U.S.A 1994, 91, 11138. 
167. Marder, M.; Viola, H.; Bacigaluppo, J. A.; Colombo, M. I.; Wasowski, C.; Wolfman, C.; Medina, J. H.; Rúveda, E. A.; Paladini, A. C.; Biochem. Biophys. Res. Commun. 1998, 249, 481.

168. Michels, P. C.; Khmelnitsky, Y. L.; Dordick, J. S.; Clark, D. S.; Trends Biotechnol. 1998, 16, 210.

169. Thompson, L. A.; Ellman, J. A.; Chem Rev. 1996, 96, 555.

170. Brown, R. C. D.; J. Chem. Soc., Perkin Trans. 1 1998, 3293.

171. Maarseveen, J. H.; Comb. Chem. High Throughput Screening 1998, $1,185$.

172. Andres, C. J.; Denhart, D. J.; Deshpande, M. S.; Gillman, K. W.; Comb. Chem. High Throughput Screening 1999, 2, 191.

173. Franzén, R. G.; J. Comb. Chem. 2000, 3, 195.

174. Atuegbu, A.; Maclean, D.; Nguyen, C.; Gordon, E. M.; Jacobs, J. W.; Bioorg. Med. Chem. Lett. 1996, 4, 1097.

175. Lucas, R. A. In Progress In Medicinal Chemistry; Ellis, G.P.; West, G. B., eds; Butherworths: London, 1963, Vol 3, pp 146148.

176. Yamazaki, M.; Suzuki, S.; Miyaki, K.; Chem. Pharm. Bull. 1971, 19, 1739.

177. Cui, C. B.; Kakeya, H.; Osada, H.; Tetrahedron 1997, 53, 59.

178. Loevezijn, A.; Maarseveen, J. H.; Stegman, K.; Visser, G. M.; Koomen, G. -J.; Tetrahedron Lett. 1998, 39, 4737.

179. Wang, H.; Ganesan, A.; Org. Lett. 1999, 1, 1647.

180. Nishizuka, Y.; Science 1992, 258, 607.

181. Bradshaw, D.; Hill, C. H.; Nixon, J. S.; Wilkinson, S. E.; Agents Actions 1993, 38, 135.

182. Meseguer, B.; Alonso-Díaz, D.; Griedenow, N.; Herget, T.; Waldmann, H.; Angew. Chem., Int. Ed. 1999, 38, 2902.

183. Fugitzi, H.; Sugimura, T.; Adv. Cancer Res. 1987, 49, 223.

184. Smith, A. L.; Stevenson, G. I.; Lewis, S.; Patel, S.; Castro, J. L.; Bioorg. Med. Chem. Lett. 2000, 10, 2693.

185. Micheal, J. P.; Nat. Prod. Rep. 1998, 15, 595.

186. Wang, H. S.; Ganesan, A.; J. Org. Chem. 1998, 63, 2432.

187. Wang, H. S.; Ganesan, A.; J. Comb. Chem., 2000, 2, 186.

188. Takahashi, S.; Matsunaga, T.; Hasegawa, C.; Saito, H.; Fujita, D.; Kiuchi, F.; Tsuda, Y.; Chem. Pharm. Bull. 1998, 46, 1527.

189. Takeuchi, T.; Ogawa, K.; Iinuma, H.; Suda, H.; Ukita, K.; Nagatsu, T.; Kato, M.; Umezawa, H.; Tanabe, O.; J. Antibiot. 1973, 26, 162.

190. Umehara, K.; Yoshida, K.; Okamamoto, M.; Iwami, M.; Tanaka, H.; Kohsaka, M.; Imanaka, H.; J. Antibiot. 1984, 37, 1153.

191. Kelly, T. R.; Fu, Y.; Xie, R. L.; Tetrahedron Lett. 1999, 40, 1857.

192. Nishida, A.; Fuwa, M.; Naruto, S.; Sugano, Y.; Saito, H.; Nakagawa, M.; Tetrahedron Lett. 2000, 41, 4791.

193. Katritzky, A. R.; Rachwal, S.; Rachwall, B.; Tetrahedron 1996, 52, 15031.

194. Baudelle, R.; Melnyk, P.; Déprez, B.; Tartar, A.; Tetrahedron 1998, 54, 4125 .
195. Kobayashi, S.; Komiyama, S.; Ishitani, H.; Biotechnol. Bioeng. (Comb. Chem.) 1998, 61, 23.

196. Patane, M. A.; Scott, A. L.; Broten, T. P.; Chang, R. S. L.; Ransom, R. W.; Disalvo, J.; Forray, C.; Bock, M. G.; J. Med. Chem. 1998, 41, 1205.

197. Kung, P. P.; Casper, M. D.; Cook, K. L.; Wilson-Ligardo, L.; Risen, L. M.; Vickers, T. A.; Ranken, R.; Blyn, L. B.; Wyatt, J. R.; Cook, D. P.; Ecker, D. J.; J. Med. Chem. 1999, 42, 4705.

198. Werbel, L. M.; Elslager, E. F.; Newton, L. S.; J. Heterocycl. Chem. 1987, 24, 345.

199. Wilson, L. J.; Organic Lett. 2001, 3, 585.

200. Dunbar, D. C.; Rimoldi, J. M.; Clark, A. M.; Kelly, M.; Hamann, M. T.; Tetrahedron 2000, 56, 8795.

201. Chan, G. W.; Mong, S.; Hemling, M. E.; Freyer, A. J.; Offen, P. H.; De Brosse, C. W.; Sarau, H. M.; Westley, J. W.; J. Nat. Prod. 1993, 56, 116

202. Saha, A. K.; Liu, L.; Simoneaux, R. L.; Kukla, M. J.; Marichal, P.; Odds, F.; Bioorg. Med. Chem. Lett. 2000, 10, 2175.

203. Govindachari, T. R.; Ravindranath, K. R.; Viswanathan, N.; J. Chem. Soc., Perkin Trans. 1 1974, 1215.

204. Wu, T. S.; Chan, Y. Y.; Leu, Y. L.; Chern, C. Y.; Chen, C. F.; Phytochemistry 1996, 42, 907.

205. Pendrak, I.; Barney, S.; Wittrock, R.; Lambert, D. M.; Kingsbury, W. D.; J. Org. Chem. 1994, 59, 2623.

206. Frutos, O.; Curran, D. P.; J. Comb. Chem. 2000, 2, 639.

207. Medina, J. H.; Paladin, A. C.; Izquierdo, I.; Behav. Brain Res. 1993, 58, 1 .

208. Nefzi, A.; Ong, N. A.; Houghten, R. A.; Tetrahedron Lett. 2001, 42, 5141.

209. Houghten, R. A.; Proc. Natl. Acad. Sci. USA 1998, 81, 3998.

210. Davis, R. A.; Carrol, A. R.; Quinn, R. J.; Aust. J. Chem. 2001, 54, 355.

211. Pelish, H. E.; Westwood, N. J.; Feng, Y.; Kirchhausen, T.; Shair, M. D.; J. Am. Chem. Soc. 2001, 123, 6740.

212. Vesely, J.; Havlícek, L.; Strnad M.; Blow, J. J.; Donella-Deana, A.; Pinna, L.; Letham, D. S.; Kato, J. Y.; Detivaud, L.; Leclerc, S.; Meijer, L.; Eur. J. Biochem. 1994, 224, 771.

213. Norman, T. C.; Gray, N. S.; Koh, J. T.; Schultz, P. G.; J. Am. Chem. Soc. 1996, 118, 7430.

214. VanWagenen, B. C.; Larsen, R.; Cardellina, J. H. II; Randazo, D.; Lidert, Z. C.; Swithenbank, C.; J. Org. Chem. 1993, 58, 335.

215. Pettit, G. R.; Herald, C. L.; Leet, J. E.; Gupta, R.; Schaufelberger, D. E.; Bates, R. B.; Clewlow, P. J.; Doubek, D. L.; Manfredi, K. P.; Rützler, K.; Schmidt, J. M.; Tackett, L. P.; Ward, F. B.; Bruck, M.; Camou, F.; Can. J. Chem. 1990, 68, 1621.

216. Nefzi, A.; Dooley, C.; Ostresch, J. M. Houghten, R. A.; Bioorg. Med. Chem. Lett. 1998, 8, 2273.

217. Green, J.; J. Org. Chem. 1995, 60, 4287.

218. Onoda, T.; Iinuma, H.; Sasaki, Y.; Hamada, M.; Isshiki, K.; Naganawa, H.; Takeuchi, T.; Tatsuta, K.; Umekawa, K.; J. Nat. Prod. 1989, 52, 1252. 
219. Hsu, C. J.; Persons, P. E.; Spada, A. P.; Bednar, R. A.; Levitski, A.; Zilberstein, A.; J. Biol. Chem. 1991, 266, 21105.

220. Nielsen, J.; Lyngsø, L. O.; Tetrahedron Lett. 1996, 37, 8439, and references cited therein.

221. Beck, B.; Hess, S.; Dömling, A.; Bioorg. Med. Chem. Lett. 2000, 10, 1701.

222. Toske, S. G.; Jensen, P. R.; Kauffman, C. A.; Fenical, W. Tetrahedron, 1998, 54, 13450.

223. Eldefrawi, A. T.; Eldefrawi, M. E.; Konno, K.; Mansor, N. A.; Nakanishi, K.; Oltz, E.; Usherwood, P. N. R.; Proc. Natl. Acad. Sci. U.S.A. 1998, 85, 4910.

224. Strømgaard, K.; Brier, T. J.; Anderson, K.; Mellor, I. R.; Saghyan, A.; Tikhonov, D.; Usherwood, P. N. R:; Larsen, P. K.; Jaroszewski, J. W.; J. Med. Chem. 2000, 43, 4526.

225. Kim, Y. J.; Furihata, K.; Yamanaka, S.; Fudo, R.; Seto, H.; J. Antibiot. 1991, 44, 553

226. Andrus, M. B.; Turner, T. M.; Sauna, Z. E.; Ambudkar, S. V.; J. Org. Chem. 2000, 65, 4973.

227. Fecik, R. A.; Frank, K. E.; Gentry, E. J.; Mitscher, L. A.; Shibata, M.; Pure Appl. Chem. 1999, 71, 559.

228. Gerwick, W. H.; Proteau, P. J.; Nagle, D. G.; Hamel, E.; Blokhin, A.; Slate, D.; J. Org. Chem. 1994, 59, 1243.

229. Wipf, P.; Reeves, J. T.; Balachandran, R.; Giuliano, K. A.; Hamel, E.; Day, B. W.; J. Am. Chem. Soc. 2000, 122, 9395.
230. Kulkarni, B. A.; Roth, G. P.; Lobkovsky, E.; Porco Jr., J. A.; J. Comb. Chem. 2002, 4, 56.

231. Brophy, G. C.; Mohandas, J.; Slaytor, M.;Sternhell, S.; Watson, T. R.; Wilson, L. A.; Tetrahedron Lett. 1969, 10, 5159.

232. Lindslay, C. W.; Chan, L. K.; Goess, B. C.; Joseph, R.; Shair, M. D.; J. Am. Chem. Soc. 2000, 122, 422.

233. Xiao, X. -Y.; Li, Rongshi, L.; Zhuang, H.; Ewing, B.; Karunaratne, K.; Lillig, J.; Brown, R.; Nicolaou, K. C.; Biotechnol. Bioeng. 2000, 71, 44.

234. Jung, G.; Combinatorial Chemistry: Synthesis, Analysis, Screening, Wiley-VCH: Weinheim, 1999.

235. Shapiro, M. J.; Gounarides, J. S.; Progr. Nucl. Magn. Reson. Spectr. 1999, 35, 153.

236. Keifer, P. A.; Curr. Opin. Biotechnol. 1999, 10, 34.

237. Swali, V.; Langley, G. J.; Bradley, M.; Curr. Opin. Chem. Biol. 1999, 3, 337.

238. Keifer, P. A.; Comb. Chem. Drug. Discov. 1998, 23, 301.

239. Chin, J.; Fell, J. B.; Jarosinski, M.; Shapiro, M. J.; Wareing, J. R.; J. Org. Chem. 1998, 63, 386.

240. Keifer, P. A.; Drug Discovery Today 1997, 2, 468.

Received: September 24, 2002 Published on the web: July 29, 2003 